\title{
CARACTERIZAÇÃO FÍSICA E FORMULAÇÃO DE SUBSTRATOS PARA O CULTIVO DE ALGUMAS ORNAMENTAIS
}

\section{ELISABETE DOMINGUES SALVADOR}

Engenheira Agrônoma

Orientador: Prof. Dr. Keigo Minami

Tese apresentada à Escola Superior de Agricultura "Luiz de Queiroz", Universidade de São Paulo, para obtenção do titulo de Doutor em Agronomia, Área de Concentração: Produção Vegetal.

PIRACICABA

Estado de São Paulo - Brasil

Outubro - 2000 


\title{
Dados Internacionais de Catalogaçāo na Publicação (CIP) DIVISĀO DE BIBLIOTECA E DOCUMENTAÇÃO - Campus "Luiz de Queiroz"/USP
}

\author{
Salvador, Elisabete Domingues \\ Caracterização fisica e formulação de substratos para o cultivo de algumas ornamentais \\ / Elisabete Domingues Salvador. - - Piracicaba, 2000.
}

$148 \mathrm{p}$.

Tese (doutorado) - Escola Superior de Agricultura Luiz de Queiroz, 2000.

Bibliografia.

1. Análise fisica 2. Floricultura 3. Gloxinia 4. Lisianthus 5. Planta ornamental 6. Substrato 7. Violenta africana I. Título

CDD 635.93381

"Permitida a cópia total ou parcial deste documento, desde que citada a fonte - $\mathrm{O}$ autor" 


\section{AGRADECIMENTOS}

Agradeço a todos que contribuíram para a realização deste trabalho, em especial a:

. Escola Superior de Agricultura "Luiz de Queiroz", Universidade de São Paulo

. Fundação de Amparo a Pesquisa do Estado de São Paulo / FAPESP

.Prof. Dr. Keigo Minami

. Departamento de Produção Vegetal

. Produtores Rene Groot, Etiene Groot, Edson T. Tamada, Reginaldo T. Yamaguti

. Eucatex

. Laboratório de Análises Físicas do Solos do Departamento de Engenharia Rural

. Laboratorista Gilmar Batista Gricolon

. Prof. Dr. Ricardo Ferraz de Oliveira

. Agrônomo Sergio K. Tanioka.

. Marcela dos Santos Müller

. Secretárias Bete, Célia, Sílvia e Ivete

. Funcionárias Dona Elena e Clarice

. Todos os funcionários de campo do Departamento de Produção Vegetal, em especial a Aparecido, Mário, Osvaldo, Atílio.

. Colegas e amigos do curso de Pós-Graduação 


\section{SUMÁRIO}

Página

LISTA DE FIGURAS ….......................................................

LISTA DE TABELAS ............................................................. vii

LISTA DE ANEXOS ............................................................. ix

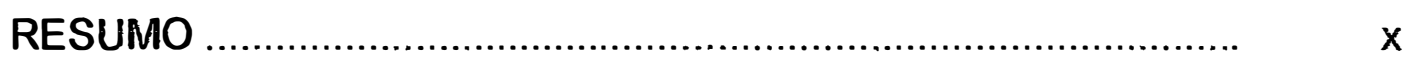

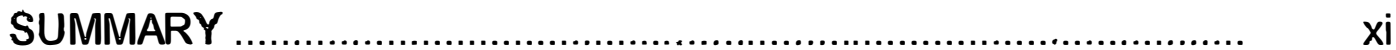

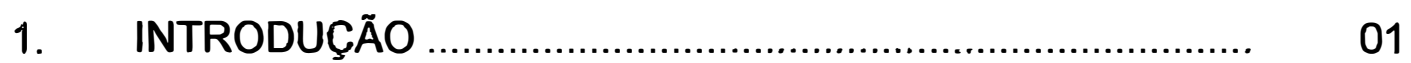

2. REVISÃO DE LITERATURA …..................................... 03

2.1. Características das culturas ............................................... 04

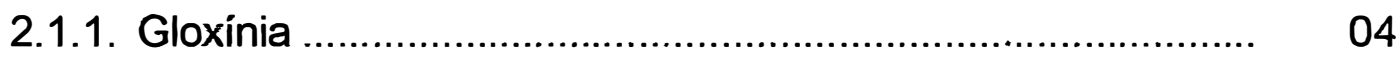

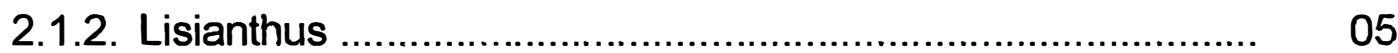

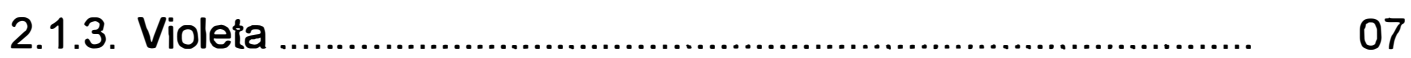

2.2. Características dos substratos .............................................. 08

2.2.1. Características físicas ..................................................... 10

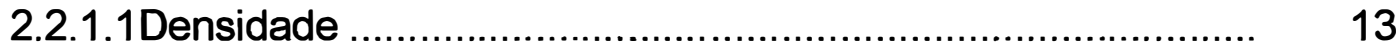

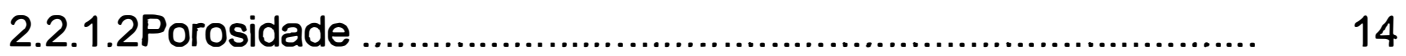

2.2.1.3Espaço de aeração .............................................................. 16

2.2.1.4Água disponivel às plantas ............................................. 18

3. AVALIAÇÃO DE DIFERENTES SUBSTRATOS NO

CULTIVO DE GLOXÍNIA (Sinningia speciosa Lood. Hiern.).. 21

Resumo ............................................................. 22

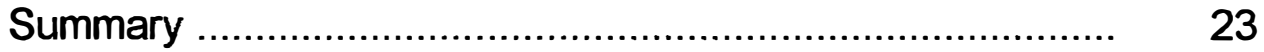

Introdução ..................................................................... 24

Material e Métodos ........................................................... 27

Resultados e Discussão ..................................................... 34

Conclusões ................................................................. 50

Referências Bibliográficas ................................................ 51 
4 AVALIAÇÃO DE DIFERENTES SUBSTRATOS NO

CULTIVO DE LISIANTHUS (Eustoma grandiflorum Shinn). 56

Resumo ................................................................... 5

Summary ......................................................... 58

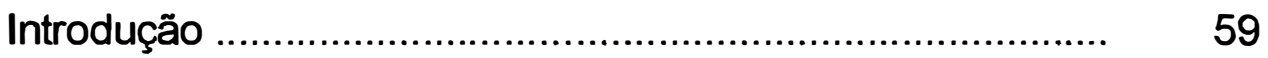

Material e Métodos ........................................................... 62

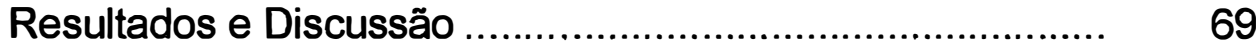

Conclusões ................................................................... 88

Referências Bibliográficas ................................................ 88

5 AVALIAÇÃO DE DIFERENTES SUBSTRATOS NO

CULTIVO DE VIOLETA AFRICANA (Saintpaulia ionantha

Wendl.) .......................................................................... 93

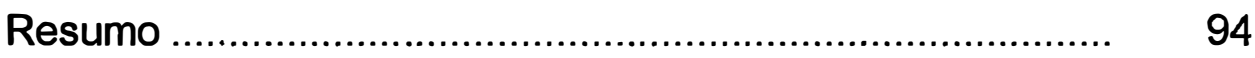

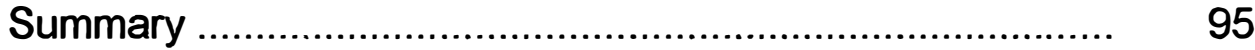

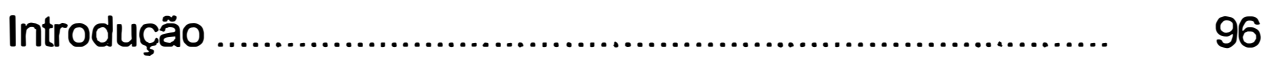

Material e Métodos ........................................................... 99

Resultados e Discussão ................................................... 107

Conclusões ............................................................. 125

Referências Bibliográficas ................................................ 126

6. CONCLUSÕES GERAIS ............................................ 130

REFERÊNCIAS BIBLIOGRÁFICAS ............................... 132 
Página

\section{Avaliação de diferentes substratos no cultivo de gloxínia (Sinningia speciosa Lood. Hiern.).}

1. Cultura da gloxínia no ponto de colheita

2. Qualidade comercial de gloxínias cultivadas em substratos de diferentes densidades

3. Características fitotécnicas avaliadas no cultivo de gloxínia em diferentes densidades do substrato

4. Qualidade comercial de gloxínias produzidas em diferentes substratos

5. Características fitotécnicas avaliadas no cultivo da gloxínia em diferente substratos

Avaliação de diferentes substratos no cultivo de lisianthus (Eustoma grandiflorum Shinn).

1. Cultura do lisianthus no ponto de colheita

2. Qualidade comercial de lisianthus cultivado em substratos de diferentes densidades

3. Características fitotécnicas avaliadas no cultivo de lisianthus em diferentes densidades do substrato

4. Qualidade comercial de lisianthus cultivado em diferentes substratos

5. Características fitotécnicas avaliadas no cultivo do lisianthus em diferente substratos 
Avaliação de diferentes substratos no cultivo de violeta africana (Saintpaulia ionantha Wendl.)

1. Cultura da violeta no ponto de colheita

106

2. Qualidade comercial de violetas cultivadas em substratos de diferentes densidades

3. Características fitotécnicas avaliadas no cultivo de violeta em diferentes densidades do substrato

4. Qualidade comercial de violetas produzidas em diferentes substratos

5. Características fitotécnicas avaliadas no cultivo da violeta em diferente substratos 


\section{Avaliação de diferentes substratos no cultivo de gloxínia}

(Sinningia speciosa Lood. Hiern.).

1. Qualidade comercial de gloxínias cultivadas em substratos de diferentes densidades

2. Resultados obtidos em características fitotécnicas, quando se avaliou diferentes densidades do substrato, no cultivo de gloxínia

3. Análise física dos substratos utilizados no cultivo de gloxínia.

4. Qualidade comercial de gloxínias produzidas em diferentes substratos

5. Resultados obtidos em características fitotécnicas, quando se avaliou o uso de diferente substratos no cultivo da gloxínia

Avaliação de diferentes substratos no cultivo de lisianthus (Eustoma grandiflorum Shinn).

1. Qualidade comercial do lisianthus cultivado em substratos de diferentes densidades

2. Resultados obtidos em características fitotécnicas, quando se avaliou diferentes densidades do substrato, na cultura do lisianthus.

3. Análise física dos substratos utilizados no cultivo de lisianthus

4. Qualidade comercial do lisianthus cultivado em diferentes substratos 
5. Resultados obtidos em características fitotécnicas, quando se avaliou o uso de diferente substratos no cultivo de lisianthus

\section{Avaliação de diferentes substratos no cultivo de violeta africana (Saintpaulia ionantha Wendl.)}

1. Qualidade comercial de violetas cultivadas em substratos de diferentes densidades

2. Resultados obtidos em características fitotécnicas, quando se avaliou diferentes densidades do substrato, no cultivo de violeta

3. Análise física dos substratos utilizados no cultivo de violeta. 116

4. Qualidade comercial de violetas cultivadas em diferentes substratos

5. Resultados obtidos em características fitotécnicas, quando se avaliou o uso de diferente substratos no cultivo de violeta 


\section{LISTA DE ANEXOS}

Página

1. Adubos utilizados no cultivo de gloxínia .................................. 143

2. Formulação MASTER 20-20-20 .......................................... 144

3. Formulação Megafol ........................................................... 145

4. Controle químico feito na cultura do lisianthus......................... 146

5. Critérios de classificação para violetas do S.D.Q. - Veiling Holambra ...................................................................... 147

6. Análise física de misturas de materiais................................... 148 


\section{CARACTERIZAÇÃO FÍSICA E FORMULAÇÃO DE SUBSTRATOS PARA O CULTIVO DE ALGUMAS ORNAMENTAIS}

Resumo: Experimentos com gloxínia (Sinningia speciosa Lood. Hiern.), lisianthus (Eustoma grandiflorum) e violeta (Saintpaulia ionantha) foram conduzidos com o objetivo de formular substratos adequados às culturas. Foram avaliadas as características físicas e misturas de materiais, observando-se que gloxínia se desenvolveu melhor em substratos de densidade $0,55{\mathrm{~g} . \mathrm{cm}^{-3}}^{-3} 77,60 \%$ de porosidade total , $26,93 \%$ de espaço de aeração, $18,75 \%$ de água disponivel e $16,36 \%$ de água facilmente disponivel, sendo o substrato vermiculita : húmus de minhoca : perlita o mais indicado. Lisianthus se desenvolveu melhor em substratos com densidades de $0,75 \mathrm{~g} . \mathrm{cm}^{-3}$ a $0,95 \mathrm{~g} . \mathrm{cm}^{-3}$, porosidade total de 72,60 a $75,10 \%$, espaço de aeração de 12,81 a 19,53\%, água disponivel de 19,79 a $26,03 \%$ e água facilmente disponível de 17,41 a $23,71 \%$, sendo os substratos turfa cultivadora : vermiculita, casca de eucalipto : turfa convencional : areia e testemunha adequados para a cultura. Violeta se desenvolveu melhor em substratos de densidade $0,75 \mathrm{~g}_{\mathrm{cm}} \mathrm{cm}^{-3}$, porosidade total de $75,10 \%$, espaço de aeração de $19,53 \%$, água disponivel de $26,03 \%$ e água facilmente disponível de $23,71 \%$, sendo indicados os substratos turfa convencional : casca de eucalipto : areia, húmus de minhoca : vermiculita : areia, casca de pinus : húmus de minhoca, turfa cultivadora : vermiculita, Eucatex à base de turfa e Vida Verde - Substrato para Violeta.

Palavras-chave: substrato, plantas ornamentais, floricultura, análise física, gloxínia, Sinningia speciosa, lisianthus, Eustoma grandiflorum violeta africana, Saintpaulia ionantha 


\section{PHYSICAL CHARACTERIZATION AND FORMULATION OF SUBSTRATES FOR SOME ORNAMENTAL PLANTS GROWTH.}

Summary: Experiments on gloxinia (Sinningia speciosa Lood. Hiern.), lisianthus (Eustoma grandiflorum) and African violet (Saintpaulia ionantha) cultures were carried out with the objective of formulating suitable substrates to these cultivation. The physical characteristics and mixtures of materials were evaluated, noticing that gloxinia developed well in the following conditions: $0.5 \mathrm{~g} . \mathrm{cm}^{-3}$ density, $77.60 \%$ total porosity, $26.93 \%$ air space, $18.75 \%$ available water and $16.36 \%$ easily available water, and the vermiculite : earthworm humus : perlite substrate was the most suitable for gloxinia cultivation. Lisianthus developed well in the following conditions: 0.75 and $0.95 \mathrm{~g} \mathrm{.cm}^{-3}$ densities, 72.60 to $75.10 \%$ total porosity, 12.81 to $19.53 \%$ air space, 19.79 to $26.03 \%$ available water, 17,41 a $23,71 \%$ easily available water, and the cultivated peat : vermiculite; eucalyptus bark: conventional peat : sand substrates and control, presented the best results. African violet developed well in the following conditions: $0.75 \mathrm{g.cm}$ $3,75.10 \%$ total porosity, $19.53 \%$ air space, $26.03 \%$ available water and $23.71 \%$ easily available water, and the substrates conventional peat : eucalyptus bark : sand, earthworm humus : vermiculite : sand, pine bark : earthworm humus, cultivated peat : vermiculite, commercial substrates ("Eucatex", made from peat, and "Vida Verde - substrate for African violet"), showed to be adequate for African violet cultivation.

Key words: substrate, ornamental plants, floriculture, physical analysis, gloxinia, Sinningia speciosa, lisianthus, Eustoma grandiflorum, african violet, Saintpaulia ionantha 


\section{INTRODUÇÃO}

$\mathrm{Na}$ década de 70 houve grandes mudanças na produção de plantas. $\mathrm{O}$ avanço técnico permitiu um melhor controle dos fatores de produção, como climatização de estufas, utilização de cultivares mais produtivas e substratos adequados a cada cultura, formando a base de cultivos sem solo, facilitando a introdução de sistemas de adubação e irrigação, medição de condutividade e $\mathrm{pH}$, e equipamentos de controle automático (Granqvist, 1981).

Inicialmente o substrato predominante era o solo, que diminuiu com o tempo por apresentar desvantagens, como heterogeneidade, dificuldade em desinfetar, irrigar e adubar, e também devido a um aumento da oferta de substratos industrializados que se adequavam as necessidades das culturas. O cultivo de plantas sem solo permitiu grandes aumentos de produção de biomassa, regularização do hábito de crescimento e florescimento, aumento da qualidade, aumento do pegamento pós-transplante e maior facilidade de organizar e programar a produção (Lemaire, 1995).

A nível internacional, a indústria de substratos vem se tornando cada vez mais forte, devido ao crescente interesse pela produção vegetal em ambientes protegidos. A demanda anual da Comunidade Econômica Européia é de 20 milhões de metros cúbicos de substratos industrializados (Gabriëls \& Verdonck, 1991).

Devido as condições restritas para o desenvolvimento das plantas em recipientes, as características físicas são fatores determinantes na escolha de um correto substrato. Por não se poder generalizar recomendações dadas as 
características físicas de substratos para todas as espécies de plantas e observando-se que os resultados obtidos no exterior não se adequavam as condições do Brasil, o presente trabalho teve como objetivos avaliar as necessidades específicas de três espécies ornamentais, a violeta africana (Saintpaulia ionantha Wendl.), a gloxínia (Sinningia speciosa Lood. Hiern.) e o lisianthus (Eustoma grandiflorum Shinn), com relação a características físicas dos substratos, e elaborar substratos com características adequadas ao crescimento e desenvolvimento de cada cultura. 


\section{REVISÃO DE LITERATURA}

Nos últimos anos houve mudanças rápidas na tecnologia de produção de plantas. Estufas e sistemas automatizados de aquecimento, ventilação, irrigação e adubação foram desenvolvidos para um melhor crescimento das plantas (Verdonck, 1983a). Ocorrendo a mudança do cultivo em solos para o cultivo em recipientes, novos materiais começaram a ser usados como substratos, facilitando a automatização dos demais sistemas (Gabriëls, 1995).

Em mercados altamente desenvolvidos, $85 \%$ das pessoas compram flores pelo menos uma vez por ano, enquanto em mercados pouco desenvolvidos, só $42 \%$ das pessoas compram flores (Behe et al., 1993). Matsuo (1990) observou que as preferências diferem de nação para nação e entre diferentes culturas. Os consumidores consideram a variedade de produtos um atributo mais importante que o preço (Behe et al., 1992). Prince et al. (1990) relatam que, no clima empresarial altamente competitivo e internacional da floricultura, os produtores perceberam a importância de melhorar a qualidade dos seus produtos para permanecerem competitivos.

No Brasil, o interesse pela produção de flores e plantas ornamentais começou a ter destaque no início dos anos 70 , apresentando, como decorrência, uma grande demanda na produção e exigindo estudos e pesquisas envolvendo as várias etapas de produção.

A produção em recipientes está baseada em substratos artificiais (Anisko et al., 1994). Em cultivos sem solo, o maior problema agrotécnico é garantir o crescimento da parte aérea com um volume restrito para o 
desenvolvimento do sistema radicular. O substrato serve para fixar a planta, suprir suas necessidades de ar, água e nutrientes e controlar a microflora (Lemaire, 1995).

\subsection{Características das culturas}

\subsubsection{Gloxínia}

A gloxínia é uma planta envasada muito procurada no mercado varejista. A maioria das espécies existentes são originárias das matas brasileiras, normalmente das zonas tropicais, de muito calor e umidade (Bittencourt et al., 1977). São comuns na Serra do Mar, nos estados do Paraná, São Paulo, Rio de Janeiro e Espírito Santo.

Pertencente à família Gesneriácea, a gloxínia (Sinningia speciosa Lood. Hiern.) é uma planta herbácea, perene, de raiz tuberosa, que possui um ou mais caules com folhas pareadas, ovaladas ou oblongas, e com pubescência. Na inflorescência, suas flores são tubulares, pendentes, de coloração variada e colocadas em longos pedúnculos axilares (Longhi \& Tombolato, 1995).

Comercialmente é propagada por sementes (Sheehan \& Tjia, 1976), podendo ser obtidas na propriedade ou compradas de firmas produtoras de sementes (Longhi \& Tombolato, 1995). Apesar de ter origem no Brasil, todos os trabalhos de melhoramento foram realizados em países europeus, conquistando o interesse dos floricultores de todo o mundo (Bittencourt et al., 1977). Os novos híbridos apresentam flores em forma de um buquê, simples ou dobradas, em cores desde branco puro, lilás, rosa, vermelho até a tonalidade púrpura-escura, podendo ainda ser bicolores, com bordas, pintas ou faixas contrastantes (Longhi \& Tombolato, 1995). 
As condições ideais para seu cultivo são umidade relativa entre 50 e $70 \%$, temperatura de $18^{\circ} \mathrm{C}$ noturnos e $24^{\circ} \mathrm{C}$ diurnos, luminosidade em torno de 25,8 Klux (Longhi \& Tombolato, 1995).

Cresce rapidamente em substratos porosos. Sheehan \& Tjia (1976) relatam que existem vários substratos disponíveis no mercado. A gloxínia precisa de um substrato leve, que satisfaça suas exigências de água e ar e que seja capaz de reter nutrientes. Substratos com capacidade de retenção de água de $80 \%$ são ideais para gloxínia, e abaixo de $50 \%$ tem um efeito negativo no seu crescimento. Os autores, pesquisando quatro substratos para seu cultivo, observaram que os produtos comerciais "Metro Mistura 300" e "Mistura Jiffy" obtiveram os melhores resultados. Plantas cultivadas em turfa : areia : casca (1:1:1) e turfa : areia : perlita (1:1:1) tiveram um menor desenvolvimento e demoraram mais para florescer. Plantas cultivadas em turfa : areia : casca floresceram 3 semanas depois dos outros tratamentos.

As gloxínias entram em floração 5 meses após plantadas por semente e suas flores duram de uma a duas semanas (Longhi \& Tombolato, 1995).

\subsubsection{Lisianthus}

No começo dos anos 80, o aparecimento da espécie Eustoma grandiflorum nos mercados europeu e americano despertou grande interesse em seu uso como flor de corte e planta envasada (Pergola \& Farina, 1989). No Brasil foi introduzida pelos japoneses no final da década de 80 .

Pertence à família Gentianaceae, sendo uma das poucas da família a se adaptar ao clima tropical. É originária das planícies do sul dos Estados Unidos e norte do México. A maioria das novas cultivares comerciais foram obtidas por produtores e pesquisadores japoneses (Starman, 1991 e Griesbach, 1992). Das flores azuis foram obtidos híbridos de flores rosas e brancas (Pergola \& Farina, 1989). Sendo uma característica da floricultura a 
procura contínua de novidades, novos híbridos de lisianthus tem grande aceitação pelos consumidores (Harbaugh \& Woltz, 1991).

Lisianthus é uma importante flor de corte e de vaso (Rubino, 1993), produzindo floração de longa durabilidade (Starman, 1991). Possui flores de textura acetinada, de 5 a $10 \mathrm{~cm}$ de diâmetro, que variam da cor púrpura ao branco (Whipker et al., 1994). Tem uma altura média de $60 \mathrm{~cm}$, com folhas ovais, que saem de caules solitários ou não, com ramificações na parte superior.

Embora seja uma cultura perene, é cultivada pelos produtores como cultura anual. É propagada por sementes (Griesbach, 1992), que são muito pequenas e germinam sob nebulização intermitente. Ohkawa et al. (1991) observaram que sementes de lisianthus são sensiveis à altas temperaturas, desde que começam a absorver água até possuírem dois pares de folhas. Pergola \& Farina (1989) relatam que é necessário desenvolver cultivares resistentes a altas temperaturas para que haja produção durante o ano todo. A maioria das cultivares comerciais tem uma tendência a rosetear quando as mudas são expostas a temperaturas acima de $25^{\circ} \mathrm{C}$. Porém, cultivares diferem na sensibilidade a altas temperaturas (Harbaugh, 1995).

As mudas devem ser transplantadas com dois pares de folhas definitivas. São plantadas três mudas por vaso. As plantas devem ser podadas quando alcançam 3 a $5 \mathrm{~cm}$ de altura (Pergola \& Farina, 1989).

Para que o lisianthus apresente um crescimento uniforme, deve possuir um sistema radicular bem desenvolvido. O substrato deve ter um alto teor de matéria orgânica e um pH em torno de 6,5. Pergola \& Farina (1989) indicam misturar 1, 2 ou 3 partes de solo em 4 partes de turfa e 4 partes de perlita (relações em volume) de acordo com a qualidade do solo disponivel. Os autores também citam que pode-se usar substratos comerciais. 


\subsubsection{Violeta}

A violeta africana (Saintpaulia ionantha Wendl.) é uma espécie originária das montanhas de Usambara, no Leste da África. Foi encontrada em 1892 pelo Barão Walter von Saint Paul (Pasqual et al., 1996), sendo há muito tempo cultivada no Brasil pela delicadeza e colorido de suas flores.

Pertencente a família Gesneriaceae é uma espécie florífera perene, da qual se originaram milhares de híbridos comerciais. $\dot{E}$ uma das mais populares plantas de interior. Nos últimos anos foram obtidas novas variedades com flores mais duradouras que a original (Pasqual et al., 1996). No Brasil os híbridos comercializados são, na maioria, originários do Japão e Estados Unidos (Tombolato et al., 1993)

É uma planta herbácea, de $15 \mathrm{~cm}$ de altura, com folhas ovais, de textura aveludada e cor verde-escura, com flores simples ou dobradas de cores branca, rosa, roxo, azul ou bicolor, que florescem o ano todo e duram de 5 a 7 dias (Bianchini \& Pantano, 1974).

Violetas são propagadas comercialmente através estaquias de folhas com ou sem pecíolo (Sanderson \& McGuire, 1988). Também podem ser propagadas por divisão de touceiras ou por propagação in vitro, que é uma das técnicas amplamente utilizada em espécies ornamentais (Pasqual et al., 1996).

Bianchini \& Pantano (1974) citam que violetas devem ser plantadas em mistura de 1 parte de areia, 1 parte de solo, 1 parte de composto e 1 parte de vermiculita, pó-de-xaxim ou turfa. O substrato deve ser poroso, rico em matéria orgânica e com boa drenagem. 


\subsection{Características dos substratos}

O uso de substratos é uma das prioridades para produtores de mudas e plantas envasadas (Fitzpatrick et al., 1998). É definido como substrato, em Horticultura, um meio físico, natural ou sintético, onde se desenvolvem as raízes das plantas que crescem em um recipiente, com um volume limitado (Ballester-Olmos, 1992).

Na produção de plantas ornamentais é freqüente o uso de recipientes. O tipo de substrato e recipiente são fatores importantes no crescimento das plantas (Castro et al., 1996). Segundo Bunt (1961), o uso de vasos muda as propriedades físicas entre raiz e substrato, de forma que:

1. o pequeno volume do vaso conduz a uma alta concentração de raízes e, como conseqüência, a necessidade de uma alta demanda da taxa de oxigênio e remoção de gás carbônico.

2. a grande quantidade de água, exigida para sustentar as altas taxas de crescimento, deve estar disponivel num volume muito restrito.

3. a pequena profundidade do recipiente impede a drenagem, com risco da água se acumular.

4. a alta freqüência das irrigações torna o substrato sujeito a lixiviação.

O uso de substratos industriais tem crescido muito nos últimos anos (Günther, 1983). Essa mudança ocorreu devido a produção hortícola estar cada vez mais baseada em substratos artificiais (Wilson, 1983). Atualmente são usados diferentes substratos, dependendo da espécie a ser cultivada. Existem substratos já preparados, com diferentes composições, que podem ser encontrados no comércio (Ballester-Olmos, 1992). Infelizmente no Brasil ainda não há uma legislação que regulamente tal comércio (Gonçalves, 1992).

Enquanto não existe um substrato perfeito para todas as plantas ornamentais, diversos autores fazem recomendações gerais (Fitzpatrick et al., 
1998). Um substrato ideal seria um material que possuísse uma distribuição harmoniosa entre as fases sólida, líquida e gasosa, tendo o $\mathrm{pH}$ adaptado à cultura, com um poder tampão razoável e constante. Teoricamente, estas qualidades deveriam ser inalteráveis durante o tempo (Anstett \& Pasquier, 1981).

Dentre as características que se espera de um substrato, pode-se citar propriedades físicas e químicas conhecidas e constantes, baixa densidade, boa capacidade de retenção de água, boa capacidade de aeração, boa drenagem, elevada capacidade de troca de cátions, não alterar propriedades físicas e químicas quando submetidos a esterilização, não se alterar quando armazenado, ser livre de pragas e doenças, bem como propágulos de plantas daninhas, ser um meio preferencialmente estéril, rico em nutrientes, não ser salino, não deve conter substâncias tóxicas, ser inodoro, não deve ser nem muito alcalino, nem muito ácido (ter valores de $\mathrm{pH}$ próximo da neutralidade), deve ser uniforme em toda a extensão, de fácil manuseio, ser facilmente encontrado, adequado ao cultivo de várias espécies, disponível em grandes quantidades e à baixo custo.

Todas essas são condições exigidas em qualquer substrato. É dificil encontrar um material que, sozinho, atenda a todas as exigências, para tanto são feitas misturas de materiais (Unver, 1991; Kampf, 1993 e Strigheta et al., 1997).

Verdonck (1983a) afirma que as características físicas são as mais importantes em um substrato, porque as relações entre água e ar não podem ser mudadas durante o cultivo. Rac (1985) relata que a utilização de mistura de materiais proporciona uma maior aeração e um menor déficit hídrico aos substratos. Para assegurar uma mistura adequada recomenda-se a análise física do substrato para cada cultura, porque não se pode generalizar recomendações físicas para todas as espécies de plantas, pois cada espécie tem suas próprias necessidades (Salvador, 1995). 
Um substrato é formado de três fases, a fase sólida que garante a manutenção mecânica do sistema radicular e sua estabilidade, a fase líquida que garante o suprimento de água e nutrientes, e a fase gasosa que garante o transporte de oxigênio e gás carbônico entre as raízes e a atmosfera (Lemaire, 1995).

É difícil reproduzir um substrato com as mesmas propriedades físicas, químicas e biológicas em diferentes países, onde as matérias-primas são diferentes. Por causa disto, é difícil extrapolar resultados de outros pesquisadores (Deulofeu \& Aguila Vila, 1983). No Brasil há vários materiais com potencial de uso como substratos, entretanto a falta de testes e informações limitam sua exploração (Backes et al., 1991).

Segundo Gonçalves (1995), os substratos podem ser de origem animal (esterco, farinhas de sangue, chifre e cascas), de origem vegetal (xaxim, esfagno, turfa, carvão, fibra de coco e resíduos de beneficiamento, como tortas, bagaços e cascas), de origem mineral (vermiculita, perlita, granito, calcário, areia, cinasita) e de origem sintética (lã de rocha, espuma fenólica e isopor). Muitos materiais diferentes podem ser usados, como por exemplo, lodo de esgoto, composto de lixo domiciliar urbano, argila expandida, serragem e acículas de pínus (Wilson, 1983).

As características físicas do substrato incluem densidade, porosidade, espaço ocupado por ar e água disponivel às plantas. Dentre estas, as relações entre os volumes de água e ar presentes no substrato são especialmente importantes.

\subsubsection{Caracteristicas físicas}

A análise física dos substratos é necessária antes de seu uso, porque depois do plantio a relação sólidos/arlágua não pode ser modificada. Características inadequadas resultam em plantas de baixa qualidade. 
O substrato tem como função dar sustentação às plantas, apoiando o crescimento das raízes e fornecendo água e ar em quantidades adequadas (Singh \& Sainju, 1998). A adequada relação águalar é uma característica importante, devido ao pequeno volume e pequena profundidade dos recipientes, que criam para os substratos propriedades físicas diferentes de um solo (Hartmann et al., 1981).

Inicialmente os substratos tentavam imitar as condições em que as plantas cresciam naturalmente. Atualmente os substratos combinam condições físicas e químicas favoráveis, que permitem automação de programas de adubação e irrigação, padronização de produção, colheitas uniformes e redução de custos (Verdonck et al., 1981).

A qualidade de um substrato é determinada por suas características físicas (Verdonck et al., 1981) e está na habilidade em fornecer água e ar adequadamente para as raízes das plantas e microorganismos do solo. Por se julgar importante as características físicas, a curva de tensão é de significado fundamental, pois caracteriza a relação arlágua (Bix, 1973). Para um ótimo crescimento das plantas, um substrato tem que ter ar e água facilmente disponível. Na maioria dos casos a água é suficiente, mas o conteúdo de ar é a propriedade determinante (Verdonck et al., 1983a).

Dependendo das características das matérias-primas, pode-se fazer substratos com as quantias desejadas de ar e água (Verdonck et al., 1983a). Alguns autores estudaram métodos para calcular substratos adequados (Rac, 1985; Niedziela \& Nelson, 1992). Jenkins \& Jarrell (1989) pesquisaram sistema para predizer propriedades de substratos através de seus componentes, já Burés et al. (1995) usaram simulação por computador "Monte Carlo".

O controle rígido de componentes e substratos comerciais deve ser evidente. Substratos são comercializados internacionalmente e, a maioria dos países, tem diferentes métodos de análise e interpretação (Günther, 1983). 
Laboratórios ao longo do mundo desenvolveram seus próprios métodos para analisar e caracterizar substratos, de forma que comparação entre os resultados é problemática e confusa (Gabriëls, 1995 e Verdonck et al., 1995).

Análises físicas feitas em laboratório são mais precisas do que as feitas visualmente. As análise físicas devem seguir uma metodologia unificada, oferecendo vantagens como os resultados poderem ser analisados e comparados à especificações padrão (Boertje, 1983).

$A$ análise dos substratos tem que ser rápida e, feita de tal forma, que possa ser repetida. Autores lamentam a insuficiência de precisão em expressar resultados analíticos, de forma que muitos dados citados em bibliografias não podem ser explorados (Anstett \& Pasquier, 1981). A necessidade para se obter dados comparáveis e padronizados conduziram várias pesquisas por todo o mundo, tentando comparar os resultados entre métodos diferentes e entre laboratórios. Por causa da variabilidade dos resultados, o grupo de substratos em Horticultura do ISHS busca uma metodologia de referência com o objetivo de unificar os resultados (Terés et al., 1995).

A caracterização de um substrato começa na distribuição da relação arlágua. Como em solos, é feita pela curva de tensão de água (De Boodt \& Verdonck, 1972). As tensões usadas para substratos (10, 50 e $100 \mathrm{~cm})$ são mais baixas do que as usadas em solos, porque em recipientes as plantas são cultivadas em condições de umidade muito mais altas (Verdonck, 1983b).

Da curva de tensão de água se obtém dados como (De Boodt \& Verdonck, 1972 e Verdonck, 1983b):

. Porosidade - corresponde a umidade volumétrica das amostras quando submetidas a uma tensão de $0 \mathrm{~cm}$.

. Espaço de aeração - é a porcentagem de ar, em volume, após a drenagem do excesso de água do substrato. Corresponde a diferença entre os pontos de tensão 0 e $10 \mathrm{~cm}$. 
Água disponível - é a diferença entre o volume de água à $10 \mathrm{~cm}$ de tensão e o volume de água à $100 \mathrm{~cm}$ de tensão.

Água facilmente disponível - é a quantidade de água retida entre 10 e $50 \mathrm{~cm}$ de tensão.

Dentro da Sociedade Internacional para Ciência Hortícola (ISHS) estão sendo feitos esforços para desenvolver métodos de referência para a determinação de propriedades físicas e químicas de substratos e seus componentes (Gabriëls, 1995).

Caracterização física dos substratos dá informações sobre a distribuição de sólidos, água e ar, que podem ser usadas para estabelecer o manejo da irrigação (Terés et al.; 1995). Propriedades físicas mudam durante o cultivo, devido ao crescimento do sistema radicular da planta, degradação da estrutura, reestruturação de partículas e processos de mineralização (Burés et al., 1991).

\subsubsection{Densidade}

Densidade é a massa do material seco por unidade de volume, sendo, atualmente, expressa em gramas por centímetro cúbico. Deve ser suficiente para dar sustentação às plantas, não sendo muito alta, porque o peso dos vasos é um parâmetro importante na manipulação e comercialização das plantas. Se considera o intervalo de 0,1 a $0,8 \mathrm{~g}_{\mathrm{cm}} \mathrm{cm}^{-3}$, tendo como ideal de 0,3 a $0,4 \mathrm{~g}_{\mathrm{cm}} \mathrm{cm}^{-3}$, para a maioria das plantas em vaso (Ballester-Olmos, 1992).

Vários métodos para se determinar densidade dos substratos foram desenvolvidos (De Boodt et al., 1973; Pokorny \& Henny, 1984; Verdonck \& Gabriëls, 1988). O que se observou foi que os resultados das análises de laboratório não eram condizentes com as condições de campo, porque esses métodos não avaliam o encolhimento inesperado ao se misturar diferentes partículas, de diferentes formas e tamanhos (Burés et al., 1991). 
A densidade que o substrato apresenta dá uma idéia prévia de características como porosidade, água disponível e espaço de aeração. Valores extremos de densidade são considerados inadequados (Bellé, 1990).

Um aumento na densidade reduz a porosidade e muda a relação arlágua do substrato (Beardsell et al., 1979 e Bunt, 1983). Densidade e porosidade são inversamente relacionados. Quando a densidade aumenta, diminui a porosidade. Alta densidade e baixa porosidade restringem 0 crescimento das raízes (Singh \& Sainju, 1998).

Kämpf (1992) relata que, apesar da heterogeneidade de informações, busca-se uma baixa densidade, com valores em torno de $0,5 \mathrm{~g}_{\mathrm{cm}}^{-3}$ para o

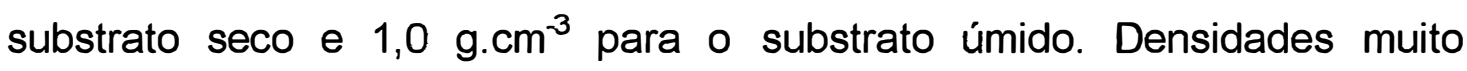
elevadas (maiores que $1,0 \mathrm{~g} \mathrm{~cm}^{-3}$ ), indicam baixa porosidade e baixos teores de água facilmente disponível. Já substratos que apresentam baixas densidades fornecem pouca estabilidade às plantas.

\subsubsection{Porosidade}

O aspecto físico mais importante num substrato é a presença de poros que proporcionem aeração adequada e sejam capazes de guardar e fornecer água para as plantas. Se a porosidade não for a ideal, muitos dos poros estarão cheios de água, diminuindo o espaço de aeração, tendo como efeito um mal desenvolvimento das plantas (Verdonck et al., 1983b).

A porosidade é o volume total do substrato não ocupado por minerais ou partículas orgânicas (Lemaire, 1995). Uma parte deste volume corresponde aos poros que proporcionam aeração para as raízes e são de tamanho maior. O resto da porosidade é de tamanho pequeno e determina uma intensa retenção de água (Ballester-Olmos, 1992).

A porosidade não mantém um valor constante durante todo o cultivo, devido a fenômenos como compactação, evolução biológica de materiais 
orgânicos e segregação de partículas finas pela irrigação, que se acumulam no fundo do vaso (Lemaire, 1995).

Segundo Verdonck et al. (1981), a porosidade total pode ser determinada pela curva de retenção de água, e corresponde ao teor de umidade a zero de pressão, ou seja, quando se encontra no ponto de saturação.

O valor de porosidade ideal indicado por Riviere (1980) é de $75 \%$, e por De Boodt \& Verdonck (1972), Bix (1973), Goh \& Haynes (1977), Boertje (1983), Verdonck (1983a), Rac (1985) e Verdonck \& Gabriels (1988) o valor indicado com ideal é $85 \%$ de porosidade. Verdonck (1983a) ressalta que o substrato deve apresentar uma relação de 1:1 entre volume de água e ar.

Porosidade é inversamente proporcional a densidade (Bunt, 1983). A porosidade pode ser relacionado com a densidade, mas seus componentes separadamente, espaço de aeração e capacidade de retenção de água, não podem. Isto porque a relação entre macro e microporos varia consideravelmente de substrato para substrato (Beardsell et al., 1979).

Burés et al. (1995) caracterizando a distribuição do tamanho de poros, por meio de simulação por computador "Monte Carlo", observaram que a mudança no tamanho das partículas em sistemas de esferas uniformes não afeta a porosidade, mas afeta o tamanho dos poros, sendo o tamanho dos poros proporcional ao diâmetro das partículas. Também observaram que a porosidade relativa não dependia do tamanho das partículas, mas sim da proporção de vazios. Quando partículas de diferentes tamanhos foram misturadas, a porosidade diminuiu porque as partículas pequenas preencheram os espaços vazios entre as partículas grandes. Os autores concluíram que a porosidade dependia do tamanhos das partículas misturadas e não do tamanho individual.

Bunt, em 1983, já havia observado que não existia nenhuma interação entre tamanho de partícula e porosidade. Diferente substratos tem diferentes 
teores de ar e água por causa do tamanho de suas partículas e de suas características específicas (forma e estrutura interna). Não se consegue, na prática, fazer um substrato com características de ar e água específicas, levando-se em conta somente o tamanho das partículas. Para se ter precisão deve-se começar avaliando as propriedades internas dos seus componentes (Burés et al., 1995). Misturas de turfa com materiais finos (perlita, vermiculita, areia, argila) apresentaram menor espaço de aeração do que os materiais separados. Já materiais grossos aumentaram o espaço de aeração das misturas.

A estimativa da porosidade é uma condição prévia essencial para se avaliar o espaço ocupado por ar e a capacidade do substrato em reter e liberar água às plantas (Waller \& Harrison, 1991).

\subsubsection{Espaço de aeração}

Boa aeração é uma das características físicas importantes para o crescimento de plantas em recipientes (Beardsell et al., 1979). Não somente a água é necessária para as plantas, mas também o ar é importante para o crescimento radicular (Verdonck et al., 1981). Poros que não estão

preenchidos de água estão cheios de ar. O crescimento das raízes é restringido por uma aeração deficiente (Singh \& Sainju, 1998).

A difusão é o processo físico mais importante para o fornecimento de oxigênio para a zona radicular (Gislerød, 1982). As raízes requerem oxigênio para manter sua atividade metabólica e seu crescimento. Um déficit temporário, reduz o crescimento das raízes e condições de encharcamento prolongado podem provocar sua morte. Também é necessário aos microorganismos e, plantas cultivadas em substratos orgânicos, requerem duas vezes mais oxigênio que plantas cultivadas em solos minerais (Ballester-Olmos, 1992). 
O crescimento do sistema radicular em vasos causa uma compactação do substrato e, por conseguinte, a obstrução de uma parte da porosidade (Ballester-Olmos, 1992). Fatores como variedade, condições ambientais e freqüência de irrigação, determinam a resposta das plantas ao espaço de aeração (Bunt, 1983).

Partículas pequenas diminuem o espaço de aeração das misturas. Vermiculita fina e argila fina não reduzem a aeração tanto quanto a areia. Em substratos à base de cascas, partículas maiores que $0,5 \mathrm{~mm}$ tem pequeno efeito na aeração e na água facilmente disponível, enquanto que, em partículas de 0,1 a 0,25 mm, causam maiores efeitos (Bunt, 1983).

Se o fornecimento de oxigênio para a raiz fica limitado, o crescimento das plantas será reduzido (Gislerød, 1982). As paredes e fundo do vaso restringem a drenagem de água. Esta é a razão por que substratos precisam ter melhor aeração que solos no campo (Beardsell et al., 1979).

Segundo Gislerød (1982), o teor de ar ideal, para formação de raízes de plantas cultivadas em recipientes, é de aproximadamente $20 \%$ e, em alguns casos, 45\%. Para De Boodt \& Verdonck (1972) e Bix (1973), o ideal é que seja próximo de 10 a $20 \%$. Ballester-Olmos (1992) cita que, para a maioria das espécie oscila entre os 10 e $30 \%$. Bunt (1983) observou que plantas necessitam de 10 a $13 \%$ de ar em vasos de $10 \times 10 \mathrm{~cm}$.

A aeração é a percentagem do volume de poros ocupados pelo ar em um meio, após ter sido saturado com água e deixado drenar (Bunt, 1973; Bugbee \& Frink, 1986; Ballester-Olmos, 1992). É representa pela diferença obtida entre os pontos 0 e $10 \mathrm{~cm}$ de sucção na curva de retenção de água (De Boodt \& Verdonck, 1972 e Prasad, 1979). 


\subsubsection{4 Água disponivel às plantas}

A água e o ar são necessários para o crescimento das raízes. Uma boa distribuição do espaço poroso é muito importante para um substrato ideal (Verdonck et al., 1981). Se um substrato tem porosıdade de ar suficiente, sua próxima propriedade mais importante é sua capacidade em reter água (Beardsell et al., 1979). A água deve estar disponivel de forma que as plantas gastem o mínimo possivel de energia na sua absorção e, ao mesmo tempo, permita uma aeração adequada próximo às raízes. As duas características são contrárias, ou os poros estão ocupados por ar ou por água (De Boodt \& Verdonck, 1972).

A água é retida em poros, e o tamanho dos poros determinam em que tensão essa água é retida (Burés et al., 1995). Existe água que é acessivel à planta e água fortemente retida pelo substrato, que não pode ser utilizada pela planta, pois a sucção aplicada pelas raízes é menor que a força com que a água é retida pelas partículas do substrato. Em um substrato o que interessa é a água disponivel às plantas, e não a capacidade total de retenção de água. Um substrato pode ter baixos teores de água disponivel por três motivos, ou porque a porosidade total é baixa, os poros são grandes e a água é perdida por gravidade, ou porque os poros são muito pequenos e a planta é incapaz de absorver uma parte importante da água, ou uma combinação das situações anteriores (Ballester-Olmos, 1992). Diferentes substratos tem diferentes quantias de água disponivel. Esta propriedade é muito importante para a adequação do programa de irrigação (Verdonck et al., 1981).

Métodos precisos para medir o teor de umidade são extremamente desejados pelos pesquisadores (Anisko et al., 1994). A distribuição de água pode ser determinada pela curva de retenção de água. Da curva avaliam-se a maioria das propriedades físicas importantes (Verdonck et al., 1981). 
Segundo Bunt (1983), a água em um substrato pode ser classificada como água facilmente disponível, água disponivel e água não disponível às plantas.

O termo "água facilmente disponivel" foi proposto por De Boodt \& Verdonck (1972) para definir a diferença de água obtida entre 10 e $50 \mathrm{~cm}$ de tensão. Em um bom substrato isto representa $75-90 \%$ da água disponivel.

A água disponivel é a diferença entre a quantidade de água do substrato depois de saturado e drenado, e corresponde a água retida entre 10 e $100 \mathrm{~cm}$ de tensão. O valor ideal de água disponivel em um substrato oscila entre os 20 e $30 \%$. Altos valores causam asfixia das raizes, enquanto que baixas valores significam a necessidade de irrigações muito freqüentes (Ballester-Olmos, 1992).

A água disponivel para as plantas em substratos é bem maior do que na maioria dos solos in situ (Beardsell et al., 1979). Plantas cultivadas em substratos sem solo requererem irrigação mais freqüente do que substratos à base de solo. A maior freqüência é devida a sua menor capacidade de retenção de água (Boyle et al., 1991).

A areia promove excelente aeração, mas pode apresentar déficit de água para as plantas próximo à superfície. A argila tem pouca aeração, mas fornece um alto teor de água. As desvantagens desses dois extremos podem ser parcialmente resolvidos fazendo-se misturas de materiais que forneçam adequado tamanho de partículas, espaço poroso e uma boa retenção de água (Hartmann et al., 1981).

A água disponivel para plantas cultivadas em recipientes é limitada pelo tamanho do recipiente (Hummel, 1990). Devido a pequena profundidade do vaso, no fundo do pote cria-se uma camada de água que não pode ser drenada livremente, mesmo que o pote possua furos livres para a drenagem. A água contida no substrato decresce do fundo para a superfície do vaso. Desta forma, após uma irrigação, o fundo do vaso pode estar saturado e sua 
superfície permanecer relativamente seca, dependendo do espaço poroso da mistura (Hartmann et al., 1981).

Em substratos adequados a água penetra pelo vaso com relativa facilidade, permitindo uma pequena lixiviação, reduzindo, dessa forma, o risco de acúmulo de sais prejudiciais às plantas (Hartmann et al., 1981). A qualidade da água de irrigação influi no substrato (Gabriels, 1978).

Quando chegam ao ponto de comercialização, geralmente, as plantas têm altura 1 a 3 vezes maior do que o tamanho do vaso, uma relação muito alta entre o volume ocupado pelo sistema radicular e a parte aérea. 0 substrato pode secar muito depressa, se o teor de água não for constantemente monitorado e reposto. Durante $o$ transporte e a comercialização aconselha-se o uso de antitranspirantes, que reduzem a perda de umidade pelas plantas (Hummel, 1990). 
3 AVALIAÇÃO DE DIFERENTES SUBSTRATOS NO CULTIVO DE GLOXÍNIA (Sinningia speciosa Lood. Hiern.) 


\section{AVALIAÇÃO DE DIFERENTES SUBSTRATOS NO CULTIVO DE GLOXINIA (Sinningia speciosa Lood. Hiern.)}

Resumo: Foram montados dois experimentos com a cultura da gloxínia (Sinningia speciosa Lood. Hiern.), com o objetivo de se formular substratos adequados ao seu cultivo. $O$ primeiro experimento foi conduzido na área experimental do Departamento de Produção Vegetal da Escola Superior de Agricultura "Luiz de Queiroz"/USP, no município de Piracicaba, estado de São Paulo. Foram avaliadas as características físicas adequadas ao seu cultivo, observando-se que o tratamento de densidade $0,55 \mathrm{~g} . \mathrm{cm}^{-3}, 77,60 \%$ de porosidade total, $26,93 \%$ de espaço de aeração, $18,75 \%$ de água disponivel e $16,36 \%$ de água facilmente disponivel, apresentou-se superior aos demais, dando os melhores resultados nos parâmetros avaliados. O tratamento com densidade $0,75 \mathrm{g.cm}^{-3}, 75,10 \%$ de porosidade total, $19,53 \%$ de espaço de aeração, $19,79 \%$ de água disponivel e $17,41 \%$ de água facilmente disponivel, também mostrou bons resultados. $O$ segundo experimento foi conduzido na propriedade de Reginaldo T. Yamaguti, produtor de plantas omamentais no município de Itapeti, São Paulo. Analisou-se diferentes misturas de materiais, que possuíam as características físicas adequadas à cultura, e observou-se que o substrato vermiculita : húmus de minhoca : perlita foi o mais indicado no cultivo de gloxínia.

Palavras-chave: Sinningia speciosa, gloxínia, substrato, análise física 


\section{EVALUATION OF DIFFERENT SUBSTRATES ON GLOXINIA (Sinningia speciosa Lood. Hiern.) GROWTH}

Summary: Two experiments on gloxinia (Sinningia speciosa Lood. Hiern.) culture were carried out with the objective of formulating suitable substrates to its cultivation. The first was carried out in experimental area on the "Departamento de Produção Vegetal - Escola Superior de Agricultura "Luiz de Queiroz" /USP", in Piracicaba, Sao Paulo. The suitable physical characteristics for gloxinia culture were evaluated, noticing that the treatment presenting $0.5 \mathrm{~g} \mathrm{~cm}^{-3}$ density, $77.60 \%$ total porosity, $26.93 \%$ air space, $18.75 \%$ available water and $16.36 \%$ easily available water, was found to be superior in relation to the other treatments, giving the best results for the evaluated characteristics. The treatment presenting $0.75 \mathrm{~g} \mathrm{~cm}^{-3}$ density, $75.10 \%$ total porosity, $19.53 \%$ air space, $19.79 \%$ available water and $17.41 \%$ easily available water, also showed good results. The second experiment was carried out on Reginaldo T. Yamaguti's property, ornamental plant grower, in Itapeti, Sao Paulo. Different mixtures of materials, which had physical characteristics suitable for the culture, were analyzed and the vermiculite : earthworm humus : perlite substrate was the most suitable for gloxinia cultivation.

Key words: Sinningia speciosa, gloxinia, substrate, physical analysis 


\section{INTRODUÇÃO}

A floricultura abrange o cultivo de plantas ornamentais, apresentando alta evolução agrícola por ser altamente competitiva, exigindo tecnologias avançadas, profundo conhecimento técnico e sistema eficiente de comercialização.

O atual estágio de desenvolvimento da floricultura foi atingido devido ao uso de tecnologias como condução de culturas em ambientes protegidos, uso de mudas de alta qualidade, de fitorreguladores, de sistemas de irrigação e adubação, manejo fitossanitário e utilização de substratos adequados (Verdonck, 1983). Novos materiais começaram a ser usados na formulação de substratos, facilitando a automatização dos demais sistemas (Gabriëls, 1995). O cultivo da gloxínia atualmente é feito em estufas, com sistemas automatizados de controle geral de luminosidade, umidade, temperatura e fertirrigação (Longhi \& Tombolato, 1995).

As gloxínias são plantas herbáceas, cultivadas em vasos pela beleza de suas flores. A maioria das espécies são originárias das matas brasileiras (Bittencourt et al., 1977), florescendo espontaneamente na Serra do Mar, sendo comuns nos estados do Paraná, São Paulo, Rio de Janeiro e Espírito Santo. A cultura conquistou o interesse de consumidores do mundo todo, sendo cultivada há séculos (Bittencourt et al., 1977). Atualmente é uma flor envasada muito encontrada no mercado varejista (Sheehan \& Tjia, 1976).

A gloxínia cresce rapidamente em substratos porosos. Segundo Longhi \& Tombolato (1995), a gloxínia necessita de substratos orgânicos, leves e com boa capacidade de reter água e fertilizantes. Sheehan \& Tjia (1976) relatam que substratos com capacidade de retenção de água de $80 \%$ são ideais para gloxínia, e abaixo de $50 \%$ tem um efeito negativo no seu crescimento. 
O uso de substratos industriais cresceu devido a produção de plantas envasadas estar baseada em substratos artificiais (Günther, 1983; Wilson, 1983; Anisko et al., 1994), sendo usados diferentes substratos, dependendo da espécie a ser cultivada (Salvador, 1995). O cultivo em substratos adequados é de fundamental importância por influir na qualidade e nos custos de produção (Grolli, 1991). Substrato tem como função dar sustentação as plantas, fornecendo água e ar em quantidades adequadas (Singh \& Sainju, 1998).

É definido como substrato um meio físico, natural ou sintético, onde se desenvolvem as raízes das plantas que crescem em um recipiente, com um volume limitado (Ballester-Olmos, 1992). Sua qualidade é determinada por suas características físicas, porque as relações entre água e ar não podem ser mudadas durante o cultivo (Verdonck, 1983). As características físicas incluem densidade, porosidade, espaço ocupado por ar e água disponível às plantas, sendo, a relação arlágua extremamente importante.

A densidade é a massa seca por unidade de volume, expressa em gramas por centímetro cúbico. Se considera o intervalo de 0,1 a $0,8 \mathrm{~g} . \mathrm{cm}^{-3}$. Um substrato deve sustentar às plantas sem ter densidade muito alta, porque o peso dos vasos é um parâmetro para manejo e comercialização dos mesmos (Ballester-Olmos, 1992). Densidades muito elevadas (maiores que $1,0 \mathrm{~g} \mathrm{~cm}^{-3}$ ), indicam baixa porosidade e baixos teores de água facilmente disponivel. Baixas densidades fornecem pouca estabilidade às plantas (Kämpf, 1992).

Segundo Verdonck et al. (1983b), o aspecto físico mais importante num substrato é a presença de poros que proporcionem aeração adequada e sejam capazes de guardar e fornecer água para as plantas. Se a porosidade não for a ideal, muitos dos poros estarão cheios de água, diminuindo o espaço de aeração, tendo como efeito um mal desenvolvimento das plantas. 
A porosidade é o volume do substrato não ocupado por sólidos (Lemaire, 1995), sendo inversamente proporcional a densidade (Bunt, 1983). A estimativa da porosidade é uma condição prévia essencial para avaliar o espaço ocupado por ar e a capacidade de retenção de água (Waller \& Harrison, 1991).

A água e o ar são necessários para o crescimento das raízes. A água deve estar disponivel de forma que as plantas gastem o mínimo possivel de energia na sua absorção e, ao mesmo tempo, permita uma aeração adequada próximo às raízes. Poros que não estão preenchidos de água estão cheios de ar. $O$ crescimento das raízes é restringido por uma aeração deficiente (Singh \& Sainju, 1998). Se o fornecimento de oxigênio para a raiz fica limitado, o crescimento das plantas será reduzido. $O$ teor de ar ideal para formação de raízes é aproximadamente $20 \%$ e em alguns casos $45 \%$ (Gislerød, 1982). Para a maioria das espécie oscila entre os 10 e $30 \%$ (Ballester-Olmos, 1992).

A água disponivel para plantas cultivadas em recipientes é limitada pelo tamanho do recipiente (Hummel, 1990). Devido a pequena profundidade do vaso, no fundo cria-se uma camada de água que não pode ser drenada livremente, mesmo que o pote possua furos livres para a drenagem. A água contida no substrato decresce do fundo para a superfície do vaso. Desta forma, após uma irrigação, o fundo do vaso pode estar saturado e sua superfície permanecer relativamente seca, dependendo da porosidade da mistura (Hartmann et al., 1981).

Dependendo das características das matérias-primas pode-se fazer substratos com as quantia desejada ar e água (Verdonck et al., 1983a). O controle rígido de componentes e substratos comerciais deve ser evidente (Günther, 1983).

É difícil reproduzir um substrato com as mesmas propriedades físicas, químicas e biológicas, em diferentes países onde as matérias-primas são 
diferentes. Por causa disto, é difícil de extrapolar os resultados de outros pesquisadores (Deulofeu \& Aguila Vila, 1983). No Brasil há vários materiais com potencial de uso como substratos, entretanto a falta de testes e informações limitam sua exploração (Backes \& Kämpf, 1991).

Diversos pesquisadores, no mundo todo, tem procurado estabelecer as propriedades ideais de um substrato. Observando-se que os resultados obtidos no exterior não se adequavam as condições do Brasil, o presente trabalho teve como objetivo avaliar as necessidades específicas da gloxínia (Sinningia speciosa Lood. Hiern.), com relação a características físicas dos substratos, e elaborar substratos adequados à cultura.

\section{MATERIAL E MÉTODOS}

O estudo com a cultura da gloxínia foi dividido em três fases distintas. Na primeira fase montou-se um experimento, em casa de vegetação, onde se avaliou características físicas adequadas ao seu cultivo. Numa segunda fase foram elaborados 136 diferentes substratos e suas características físicas foram determinadas. Numa terceira fase montou-se um novo experimento onde, dos 136 substratos analisados, foram selecionados quatro substratos, que apresentavam características físicas adequadas à cultura, sendo estes comparados ao substrato usado pelo produtor.

\section{Primeira fase - Primeiro experimento}

O experimento foi montado na área experimental do Departamento de Produção Vegetal da Escola Superior de Agricultura "Luiz de Queiroz", ESALQIUSP, situada no município de Piracicaba, estado de São Paulo. 
O experimento foi montado no dia 05 de agosto de 1998. O cultivo foi feito em casa de vegetação climatizada, coberta por plástico leitoso, com sistemas de irrigação, fertilização, medição de condutividade elétrica e pH.

$\mathrm{O}$ delineamento experimental adotado foi o inteiramente casualizado com cinco tratamentos, cinco repetições e sete plantas por parcela, perfazendo um total de cento e setenta e cinco plantas.

Os tratamentos constaram de misturas de casca de arroz carbonizada e areia, as quais foram lavadas e secas em estufa por 72 horas a $60^{\circ} \mathrm{C}$, até peso constante. A areia foi previamente peneirada em peneira $n^{0} 10$ da ABNT. Os tratamentos se diferenciaram na proporção dos componentes, de forma que se obtivesse substratos com densidades 0,$15 ; 0,35 ; 0,55 ; 0,75$ e $0,95 \mathrm{~g} \cdot \mathrm{cm}^{-3}$.

Foram utilizadas mudas adquiridas de um produtor comercial, acondicionadas em bandejas plásticas. Possuiam 62 dias e dois pares de folhas definitivas. As mudas foram plantadas em vaso 14 , com volume de $750 \mathrm{~cm}^{3}$, já contendo os substratos em estudo.

A primeira irrigação foi feita imediatamente após o plantio e repetida diariamente.

As adubações foram feitas em dias alternados, desde 0 início do experimento, via fertirrigação. A cada 60 litros de água eram adicionados:

. N-P-K - $80 \mathrm{~mL}$ da fórmula 06-06-08 (Anexo A)

. $15 \mathrm{~mL}$ de cálcio $6 \%$ (Produto comercial 'Basfoliar')

. N-P-K - $10 \mathrm{~g}$ da fórmula 20-05-20 (Anexo A)

$.10 \mathrm{~g}$ de sulfato de magnésio.

A água de fertirrigação possuía condutividade elétrica de $1,5 \mathrm{mS} . \mathrm{cm}^{-1}$.

Semanalmente foram feitas três adubações foliares com $1,0 \mathrm{~g} \cdot \mathrm{L}^{-1} \mathrm{da}$ fórmula 20-05-20, 2,0 mL. $\mathrm{L}^{-1}$ de cálcio, $1,0 \mathrm{~g} . \mathrm{L}^{-1}$ de sulfato de magnésio e $0,3 \mathrm{~mL} \cdot \mathrm{L}^{-1}$ de Agral.

O experimento foi conduzido até o dia 15 de novembro de 1998, 
quando as plantas chegaram no ponto de comercialização. Ao final do experimento foram avaliados os parâmetros qualidade comercial das plantas produzidas, características fitotécnicas e características físicas dos substratos.

A qualidade comercial de uma planta é uma característica importante a ser avaliada, pois indica seu preço no mercado consumidor. Os vasos de gloxínia foram classifica em:

. Plantas especiais - plantas que possuem 4 ou mais flores, com muitos botões.

. Plantas comuns - plantas com 4 flores e poucos botões.

. Plantas fracas - plantas que possuem menos de 4 flores.

As características fitotécnicas avaliadas na cultura da violeta foram:

. número de flores

. número de botões.

. número de folhas

. área foliar

. peso da matéria fresca da parte aérea.

- peso da matéria fresca do sistema radicular.

- peso da matéria seca da parte aérea.

. peso da matéria seca do sistema radicular.

volume do sistema radicular.

As características físicas dos substratos avaliadas foram :

. porosidade total.

. espaço de aeração.

. água disponivel.

. água facilmente disponível. 


\section{Segunda fase - Análises laboratoriais}

A segunda fase dos estudos com a cultura da gloxínia constou de duas etapas, a primeira foi a elaboração de difereńtes substratos e a segunda a análise de suas características físicas. As duas etapas foram conduzidas nas instalações da Escola Superior de Agricultura "Luiz de Queiroz"/USP, situada no município de Piracicaba.

$\mathrm{Na}$ área experimental do Departamento de Produção Vegetal foram elaborados diferentes substratos, utilizando como componentes:

. areia

. casca de arroz carbonizada

. casca de pínus

. húmus de minhoca

. perlita

. turfa convencional

. turfa cultivadora

. vermiculita

torta de filtro

. casca de eucalipto

Os substratos constaram de misturas de dois a três materiais, em diferentes proporções. Foram elaborados, no total, 136 diferentes substratos, sendo que, quatro destes apresentaram características físicas adequadas à cultura (Anexo F).

A curva de tensão de cada substrato foi determinada seguindo-se o método citado por De Boodt \& Verdonck (1972). As análises foram feitas no Laboratório de Análises Físicas de Solos do Departamento de Engenharia Rural.

Da curva de tensão de água se obteve dados como:

. porosidade - corresponde a umidade volumétrica do substrato a $0 \mathrm{~cm}$ de tensão. 
. espaço de aeração - corresponde a diferença entre os pontos 0 e $10 \mathrm{~cm}$ de tensão.

. água disponível - é a diferença entre 10 e $100 \mathrm{~cm}$ de tensão.

. água facilmente disponível - é a quantidade de água retida entre 10 e $50 \mathrm{~cm}$ de tensão.

\section{Terceira fase - Segundo experimento}

O experimento com a cultura da gloxínia foi conduzido na propriedade de Reginaldo T. Yamaguti, produtor de plantas ornamentais no município de Itapeti, estado de São Paulo. O cultivo foi feito em casa de vegetação climatizada, com sistemas de aquecimento, ventilação, controle de luminosidade, irrigação, fertilização, medição de condutividade elétrica e pH. Seguiu-se o manejo usualmente dado pelo produtor para a cultura.

$O$ delineamento experimental adotado foi o delineamento inteiramente casualizado com cinco tratamentos, cinco plantas por parcela e seis repetições.

Para se definir os tratamentos foram utilizados dados obtidos em um experimento anterior, onde se avaliou as características físicas adequadas ao cultivo de gloxínia, observando-se que estas se desenvolvem bem em condições de baixa água disponivel, desde que o espaço ocupado por ar e a porosidade sejam adequados.

A partir dos resultados nas características fitotécnicas (Tabela 2), qualidade comercial (Tabela 1) e análise física dos substratos (Tabela 3), foram definidas misturas de materiais que atendessem as exigências da cultura. Buscou-se substratos que apresentassem as seguintes características físicas:

. porosidade total: $77 \%( \pm 2 \%)$

. espaço ocupado por ar: $26 \%( \pm 2 \%)$

. água disponivel: $18 \%( \pm 2 \%)$ 
água facilmente disponível: $16 \%( \pm 2 \%)$

Foram encontrados quatro substratos, que apresentavam características físicas adequadas a cultura, e que foram comparados a uma testemunha. Os tratamentos constaram de:

. Casca de pínus : húmus de minhoca : perlita $(1: 1: 0,2)$

. Vermiculita : húmus de minhoca : perlita $(1: 2: 0,5)$

. Turfa convencional : casca de eucalipto (1:1)

. Turfa cultivadora : casca de arroz carbonizada (1:2)

. Testemunha

Como testemunha foi utilizado o substrato usado comumente pelo produtor, e constava de uma mistura à base de solo mineral e pó-de-xaxim.

Foram utilizadas mudas fornecidas pelo produtor, que estavam acondicionadas em bandejas plásticas, apresentando, em média, dois pares de folhas definitivas. As mudas foram plantadas em vaso $n^{0} 14$, com volume de $750 \mathrm{~cm}^{3}$, já contendo os substratos em estudo.

O experimento foi montado no dia 14 de setembro de 1999, sendo o plantio idêntico ao feito pelo produtor. Utilizou-se uma muda por vaso, estando esta centralizada no vaso.

A primeira irrigação foi feita no dia seguinte ao plantio, sendo repetida quando necessário.

O experimento foi conduzido até o dia 07 de janeiro de 2000, quando as plantas chegaram no ponto de comercialização (Figura 1). Ao final do experimento foram avaliados os parâmetros qualidade comercial e características fitotécnicas das plantas produzidas, sendo idênticos ao experimento anterior. 

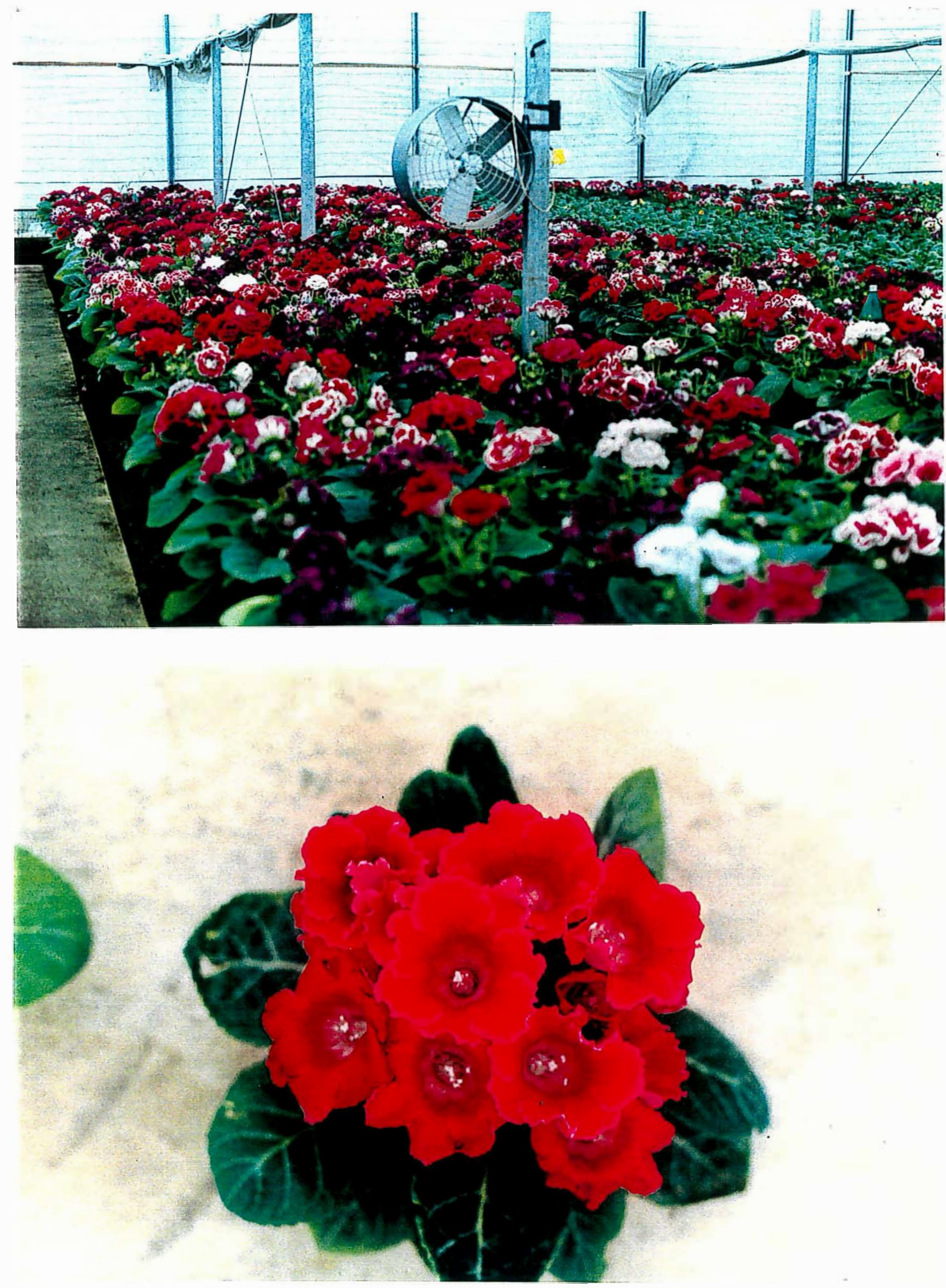

Figura 1. Cultura da gloxínia no ponto de colheita. 


\section{RESULTADOS E DISCUSSÃO}

\section{Primeiro experimento}

Quando se avaliou diferentes densidades de substrato no cultivo de gloxínia, observou-se que o tratamento $0,55 \mathrm{~g} \cdot \mathrm{cm}^{-3}$ apresentou-se superior aos demais, dando os melhores resultados nos parâmetros avaliados. Tal desempenho está relacionado ao substrato possuir as características ideais para o cultivo da gloxínia.

A densidade deve ser suficiente para dar sustentação às plantas, não sendo muito alta, porque o peso dos vasos é um parâmetro para a manipulação e comercialização das plantas (Ballester-Olmos, 1992). Kämpf (1992) relata que busca-se uma baixa densidade de volume, com valores em torno de $0,5 \mathrm{~g}_{\mathrm{cm}} \mathrm{cm}^{-3}$.

No parâmetro qualidade comercial das plantas produzidas (Tabela 1),

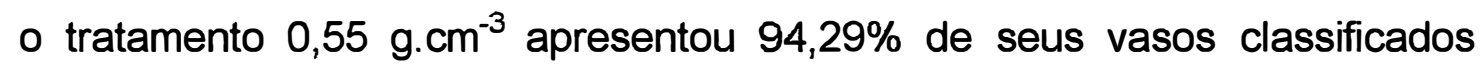
como especiais e $5,71 \%$ classificados como comuns. Foi o tratamento que apresentou plantas de melhor qualidade, alcançando os melhores preços para comercialização. 
Tabela 1: Qualidade comercial de gloxínias cultivadas em substratos de diferentes densidades. ${ }^{x}$

\begin{tabular}{cccc}
\hline Tratamento & $\begin{array}{c}\text { Plantas } \\
\text { Especiais }\end{array}$ & $\begin{array}{c}\text { Plantas } \\
\text { Comuns }\end{array}$ & $\begin{array}{r}\text { Plantas } \\
\text { Fracas }\end{array}$ \\
\hline $0,15 \mathrm{~g} \cdot \mathrm{cm}^{-3}$ & $54,29 \%$ & $20,00 \%$ & $25,71 \%$ \\
$0,35 \mathrm{~g} \cdot \mathrm{cm}^{-3}$ & $60,00 \%$ & $17,14 \%$ & $22,86 \%$ \\
$0,55 \mathrm{~g} \cdot \mathrm{cm}^{-3}$ & $94,29 \%$ & $5,71 \%$ & $0,0 \%$ \\
$0,75 \mathrm{~g} \cdot \mathrm{cm}^{-3}$ & $88,57 \%$ & $2,86 \%$ & $8,57 \%$ \\
$0,95 \mathrm{~g} \cdot \mathrm{cm}^{-3}$ & $80,00 \%$ & $11,43 \%$ & $8,57 \%$ \\
\hline
\end{tabular}

${ }^{x}$ Classificação das plantas quanto a qualidade comercial:

Plantas especiais - plantas que possuem 4 ou mais flores, com muitos botões.

Plantas comuns - plantas com 4 flores e poucos botões.

Plantas fracas - plantas que possuem menos de 4 flores. 

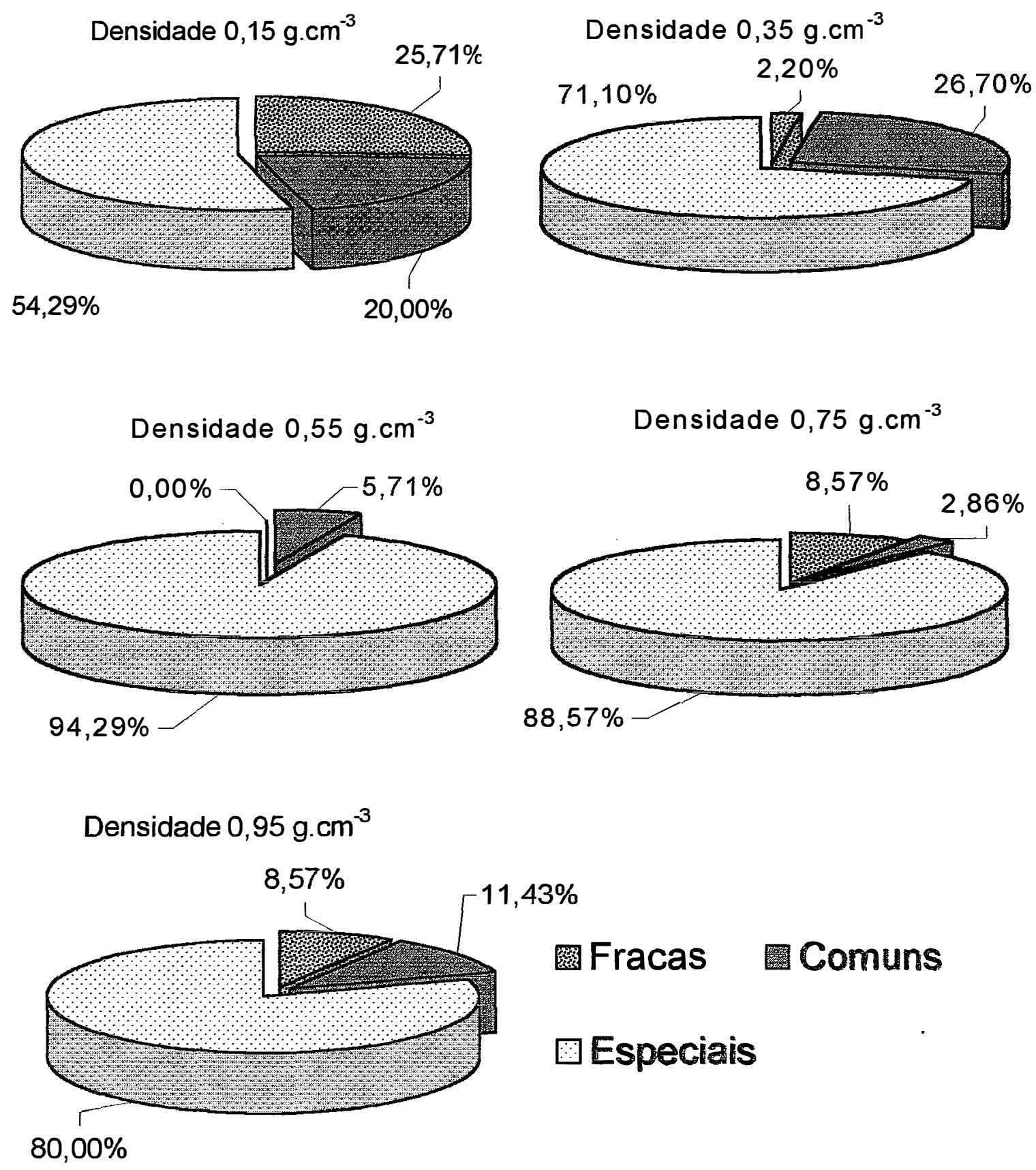

Figura 2: Qualidade comercial de gloxínias cultivadas em substratos de diferentes densidades. 
No parâmetro características fitotécnicas (Tabela 2) observou-se que o tratamento apresentou, em média, 4,93 flores e 14,07 botões por vaso. As flores apresentaram coloração intensa, sem manchas ou deformações, estando centralizadas no vaso e acima das folhas. As folhas eram grandes (área foliar de $657,04 \mathrm{~cm}^{2}$ por planta), em grande número (20,02 folhas), estando bem distribuídas e abaixo das flores. A parte aérea possuía peso fresco de $72,21 \mathrm{~g}$ e peso seco $12,27 \mathrm{~g}$.

Tabela 2: Resultados obtidos em características fitotécnicas, quando se avaliou diferentes densidades do substrato, no cultivo de gloxínia. ${ }^{\times}$

\begin{tabular}{cccccc}
\hline Tratamento $^{y}$ & $\begin{array}{c}0,15 \\
\left(\mathrm{~g} \cdot \mathrm{cm}^{-3}\right)\end{array}$ & $\begin{array}{c}0,35 \\
\left(\mathrm{~g} \cdot \mathrm{cm}^{-3}\right)\end{array}$ & $\begin{array}{c}0,55 \\
\left(\mathrm{~g} \cdot \mathrm{cm}^{-3}\right)\end{array}$ & $\begin{array}{c}0,75 \\
\left(\mathrm{~g} \cdot \mathrm{cm}^{-3}\right)\end{array}$ & $\begin{array}{c}0,95 \\
\left(\mathrm{~g} \cdot \mathrm{cm}^{-3}\right)\end{array}$ \\
\hline $\mathrm{NB}$ & $3,33 \mathrm{~b}$ & $6,47 \mathrm{~b}$ & $14,07 \mathrm{a}$ & $11,13 \mathrm{ab}$ & $4,47 \mathrm{~b}$ \\
$\mathrm{NFL}$ & $3,01 \mathrm{ab}$ & $3,47 \mathrm{ab}$ & $4,93 \mathrm{a}$ & $4,0 \mathrm{ab}$ & $3,94 \mathrm{ab}$ \\
$\mathrm{NFO}$ & $10,8 \mathrm{~b}$ & $14,0 \mathrm{~b}$ & $20,07 \mathrm{a}$ & $20,4 \mathrm{a}$ & $22,54 \mathrm{a}$ \\
AF $\left(\mathrm{cm}^{2}\right)$ & $156,99 \mathrm{c}$ & $329,99 \mathrm{bc}$ & $657,04 \mathrm{a}$ & $520,91 \mathrm{ab}$ & $402,21 \mathrm{ab}$ \\
PFPA (g) & $14,9 \mathrm{c}$ & $38,19 \mathrm{~b}$ & $72,21 \mathrm{a}$ & $58,09 \mathrm{~b}$ & $42,79 \mathrm{~b}$ \\
PSPA (g) & $7,75 \mathrm{~b}$ & $8,82 \mathrm{~b}$ & $12,27 \mathrm{a}$ & $10,02 \mathrm{ab}$ & $9,78 \mathrm{ab}$ \\
PFSR (g) & $4,35 \mathrm{~b}$ & $7,85 \mathrm{ab}$ & $11,91 \mathrm{a}$ & $8,03 \mathrm{ab}$ & $8,03 \mathrm{ab}$ \\
$\operatorname{PSSR}(\mathrm{g})$ & $1,44 \mathrm{~b}$ & $1,61 \mathrm{a}$ & $1,89 \mathrm{a}$ & $1,75 \mathrm{a}$ & $1,67 \mathrm{a}$ \\
$\operatorname{VSR}(\mathrm{mL})$ & $4,5 \mathrm{~b}$ & $10,27 \mathrm{a}$ & $10,53 \mathrm{a}$ & $12,93 \mathrm{a}$ & $9,6 \mathrm{a}$ \\
\hline
\end{tabular}

* Teste de Tukey para as médias de densidade de substrato. Médias horizontais seguidas por letras distintas diferem, entre si, ao nível de 5,00\% de significância.

${ }^{\mathrm{Y}}$ Número de botões (NB), número de flores (NFL), número de folhas (NFO), área foliar (AF), peso da matéria fresca da parte aérea (PFPA), peso da matéria seca da parte aérea (PSPA), peso da matéria fresca do sistema radicular (PFSR), peso da matéria seca do sistema radicular (PSRS), volume do sistema radicular (VSR). 

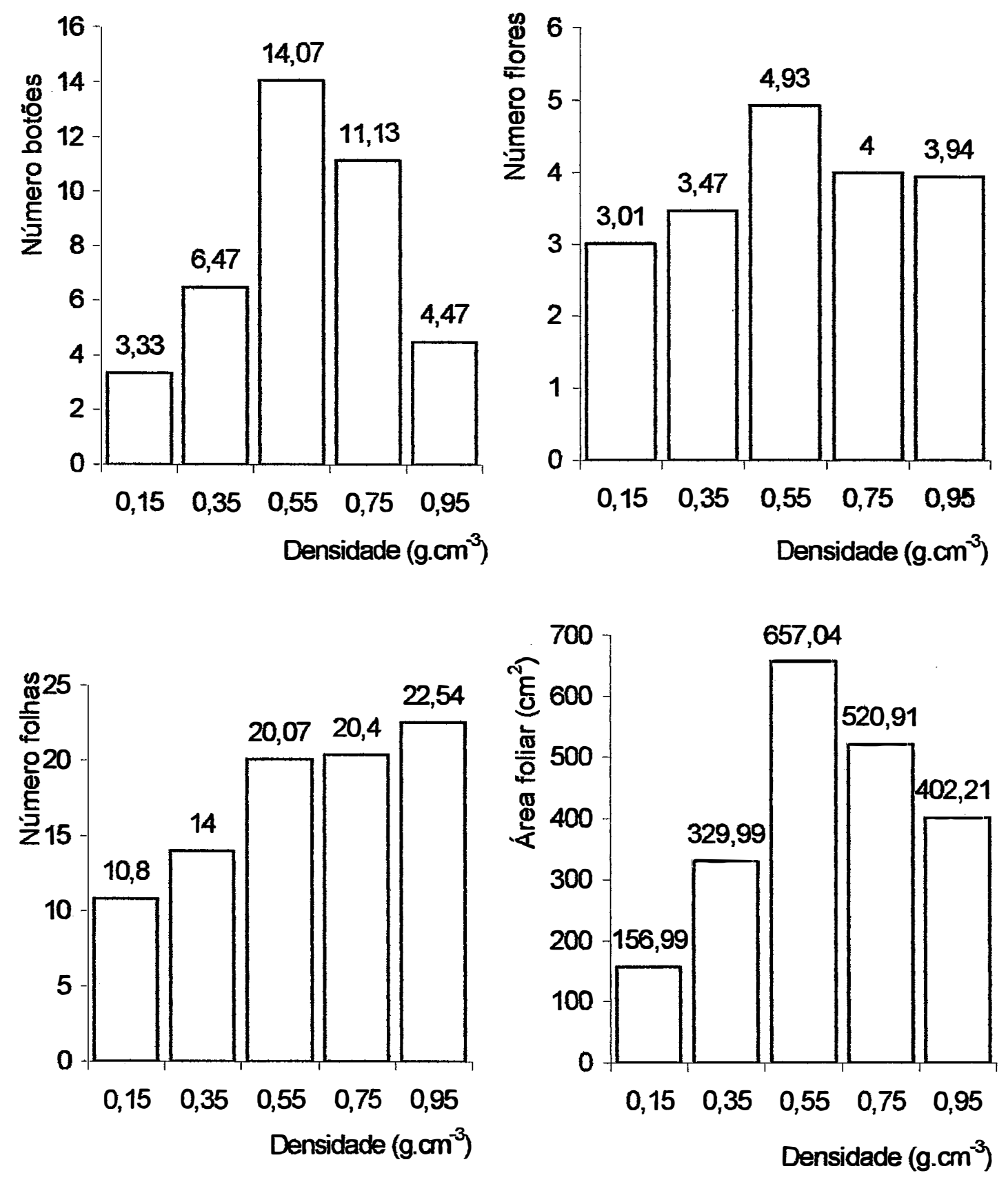

Figura 3: Características fitotécnicas avaliadas no cultivo de gloxínia em diferentes densidades do substrato. 

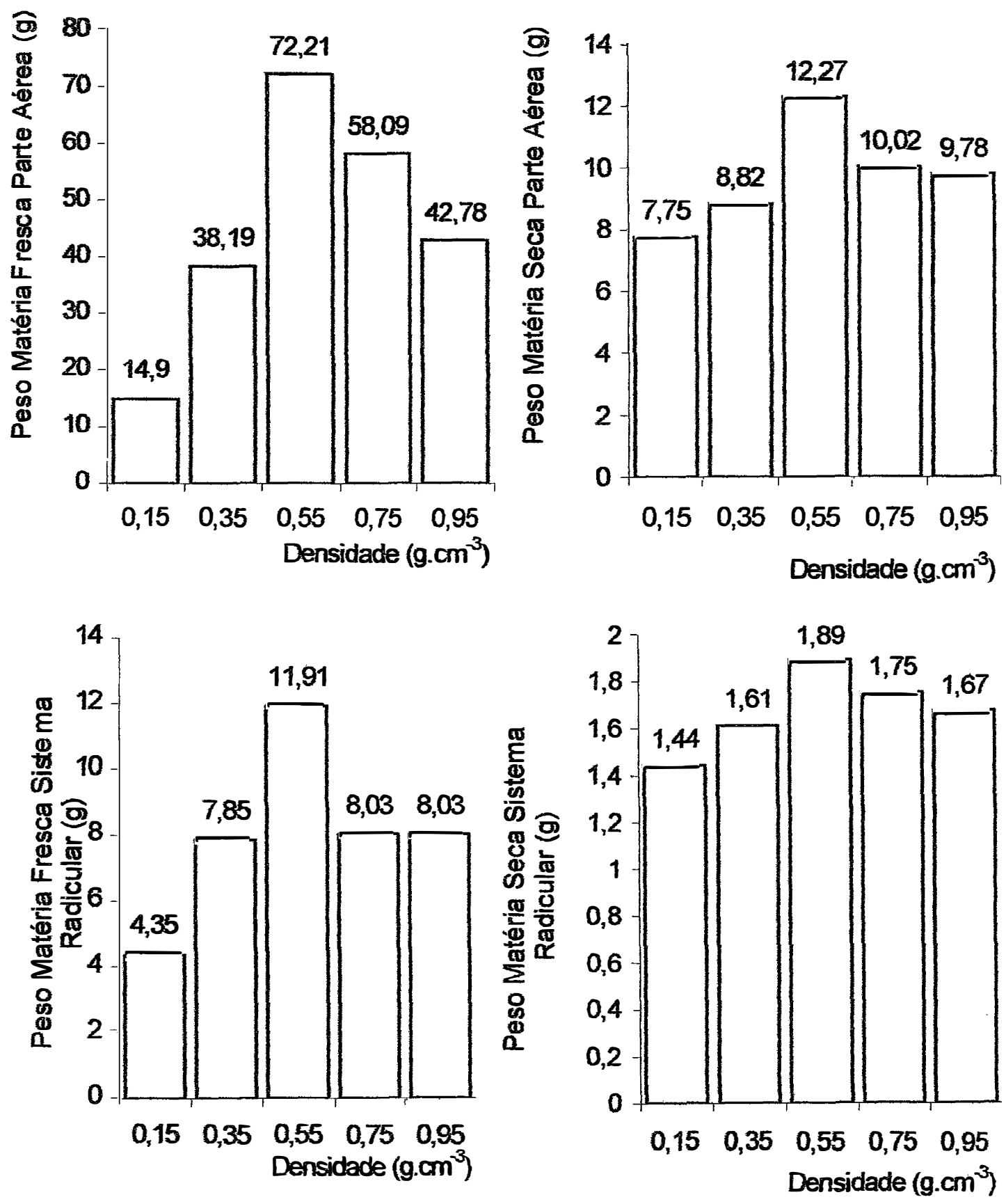

Figura 3: Características fitotécnicas avaliadas no cultivo de gloxínia em diferentes densidades do substrato (continuação). 


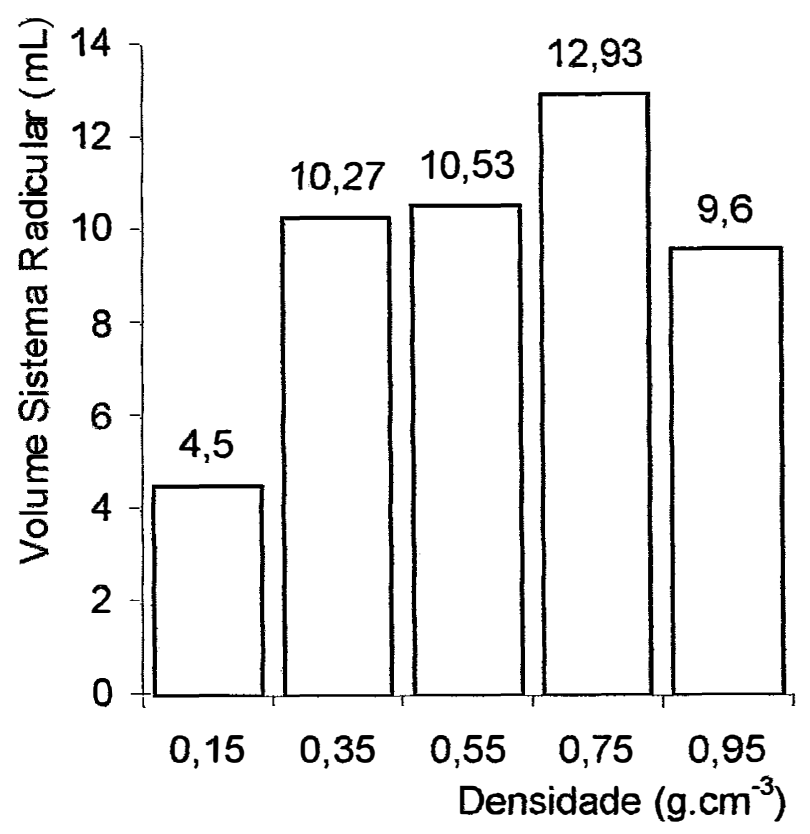

Figura 3: Características fitotécnicas avaliadas no cultivo de gloxínia em diferentes densidades do substrato (continuação).

Quando se avaliou o sistema radicular das plantas produzidas, pode-se observar que este tratamento apresentou os melhores resultados. Em média, o peso fresco do sistema radicular foi de $11,91 \mathrm{~g}$, o peso seco de $1,89 \mathrm{~g}$ e o volume de $10,53 \mathrm{~mL}$. O melhor desenvolvimento do sistema radicular permitiu uma maior absorção de água e nutrientes e, como conseqüência, um maior desenvolvimento da parte aérea. Um bom desenvolvimento do sistema radicular está relacionado ao substrato possuir as características físicas mais adequadas ao desenvolvimento da cultura.

Com relação as características físicas (Tabela 3) o substrato apresentou porosidade total e espaço ocupado por ar de acordo com as recomendações dadas pelos autores consultados (De Boodt \& Verdonck, 1972; Goh \& Haynes, 1977; Riviere, 1980; Boertje, 1983; Rac, 1985; 
Verdonck \& Gabriëls, 1988), enquanto que a água disponível às plantas mostrou níveis abaixo dos indicados pelos autores.

Possui porosidade total de $77,6 \%$ ( $/ \mathrm{v})$, estando bem próxima a porosidade recomendada por Riviere (1980) para substratos, que é de $75 \%$, mas abaixo da recomendada por De Boodt \& Verdonck (1972), Goh \& Haynes (1977), Boertje (1983), Rac (1985) e Verdonck \& Gabriëls (1988), que citam que um substrato ideal deve possuir $85 \%$ de volume em poros.

Tabela 3: Análise física dos substratos utilizados no cultivo de gloxínia.

\begin{tabular}{lcccc}
\hline Tratamento & $\begin{array}{c}\text { Porosidade } \\
\text { total } \\
(\%)\end{array}$ & $\begin{array}{c}\text { Espaço de } \\
\text { aeração } \\
(\%)\end{array}$ & $\begin{array}{c}\text { Água } \\
\text { facilmente } \\
\text { disponível } \\
(\%)\end{array}$ & $\begin{array}{c}\text { Água } \\
\text { disponível } \\
(\%)\end{array}$ \\
\hline $0,15 \mathrm{~g} \cdot \mathrm{cm}^{-3}$ & 87,49 & 57,78 & 8,90 & 11,11 \\
$0,35 \mathrm{~g} \cdot \mathrm{cm}^{-3}$ & 83,34 & 40,56 & 10,38 & 13,13 \\
$0,55 \mathrm{~g} \cdot \mathrm{cm}^{-3}$ & 77,60 & 26,93 & 16,36 & 18,75 \\
$0,75 \mathrm{~g} \cdot \mathrm{cm}^{-3}$ & 75,10 & 19,53 & 17,41 & 19,79 \\
$0,95 \mathrm{~g} \cdot \mathrm{cm}^{-3}$ & 72,60 & 12,81 & 23,71 & 26,03 \\
\hline
\end{tabular}

O substrato possui $26,93 \%$ de espaço ocupado por ar, estando de acordo com as recomendações dadas pelos autores anteriormente mencionados, que citam que um substrato deve possuir de 20 a $30 \%$ de seu volume ocupado por ar. Gislerød (1982) observou que o teor de ar ideal, para formação de raízes de plantas cultivadas em recipientes, é de aproximadamente $20 \%$ e, em alguns casos, 45\%. Para De Boodt \& 
Verdonck (1972) e Bix (1973), o ideal é que seja próximo de 10 a $20 \%$. Ballester-Olmos (1992) cita que, para a maioria das espécie oscila entre 10 e $30 \%$.

Os teores de água disponível (18,75\%) e água facilmente disponivel (16,36\%), estão bem abaixo dos recomendados por Rac (1985), que cita que um substrato deve ter, no mínimo, $26 \%$ de seu volume ocupado por água, sendo $20 \%$ do volume em água facilmente disponível às plantas.

0 tratamento $0,75 \mathrm{~g} . \mathrm{cm}^{-3}$ também mostrou bons resultados nas características fitotécnicas, não apresentando diferenças estatísticas em algumas características avaliadas. Apresentou porosidade total $(75,10 \%)$ e espaço de aeração $(19,53 \%)$ adequados, e baixos teores de água disponivel $(19,79 \%)$ e água facilmente disponível $(17,41 \%)$.

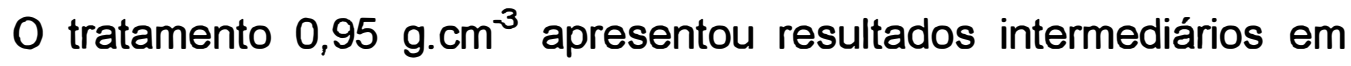
algumas características, baixo número de botões por planta $(4,47)$, baixo peso fresco da parte aérea $(42,79 \mathrm{~g})$, baixa porosidade total $(72,60 \%)$ e espaço de aeração (12,81\%), e adequadas água disponível $(26,03 \%)$ e água facilmente disponível $(23,71 \%)$.

Os tratamentos $0,15 \mathrm{~g} \cdot \mathrm{cm}^{-3}$ e $0,35 \mathrm{~g} \cdot \mathrm{cm}^{-3}$ apresentaram os piores resultados nas características fitotécnicas avaliadas. Com relação à suas características físicas apresentaram, porosidade total adequada, espaço de aeração muito elevado, estando acima de $30 \%$, e baixos teores de água disponível e água facilmente disponível.

Segundo a literatura consultada a densidade do substrato nos dá uma idéia de características físicas como porosidade total, água disponível e espaço de aeração (Boelter, 1969). Valores extremos de densidade são considerados inadequados (Bellé, 1990), sendo consideradas como ideais densidade em torno de $0,50{\mathrm{~g} . \mathrm{cm}^{3}}^{-3}$ (Kämpf, 1992). Densidades muito altas, acima de $1,0 \mathrm{~g} \mathrm{~cm}^{-3}$, indicam baixa porosidade, pois a densidade é inversamente proporcional a porosidade (Beardsell et al., 1979). 
Ao final do experimento, pode-se observar que:

1. a cultura da gloxínia se desenvolveu muito bem em densidade de $0,55 \mathrm{~g} \cdot \mathrm{cm}^{-3}$, apresentando porosidade e espaço de aeração de acordo com as recomendações dadas pelos autores consultados.

2. o excesso ou a falta de poros ocupados por ar foi um fator limitante no crescimento e desenvolvimento da cultura.

3. quando se avaliou características ligadas à capacidade do substrato em liberar água para as plantas, pode-se observar que a gloxínia se desenvolveu melhor em condições de água disponivel, e água facilmente disponivel às plantas abaixo das recomendadas, demonstrando que a cultura não se desenvolve bem em substratos com excesso de água.

4. não se pode generalizar recomendações dadas as características físicas dos substratos para todas as espécies de plantas, pois cada espécie tem suas próprias necessidades. 


\section{Segundo experimento}

Quando se avaliou o desempenho de cinco diferentes substratos no cultivo de gloxínia, pode-se observar que o substrato vermiculita : húmus de minhoca : perlita apresentou-se superior aos demais.

Quando se avaliou o parâmetro qualidade comercial das plantas produzidas (Tabela 4), observou-se que $98 \%$ das plantas cultivadas neste substrato apresentaram alto valor comercial, sendo $71 \%$ tipo especial e $27 \%$ tipo comum. Só $2 \%$ das plantas cultivadas apresentaram baixo valor comercial.

Tabela 4: Qualidade comercial de gloxínias produzidas em diferentes substratos. ${ }^{x}$

Tratamento $^{y}$ Plantas especiais Plantas comuns Plantas fracas

\begin{tabular}{llll}
\hline CP & $0 \%$ & $32 \%$ & $68 \%$ \\
VE & $71 \%$ & $27 \%$ & $2 \%$ \\
HU & $21 \%$ & $21 \%$ & $58 \%$ \\
TU & $16 \%$ & $32 \%$ & $52 \%$ \\
TE & $27 \%$ & $43 \%$ & $30 \%$ \\
\hline
\end{tabular}

${ }^{x}$ Classificação das plantas quanto a qualidade comercial:

. Plantas especiais - plantas que possuem 4 ou mais flores, com muitos botões.

Plantas comuns - plantas com 4 flores e poucos botões.

Plantas fracas - plantas que possuem menos de 4 flores.

${ }^{\text {y }}$ Casca pínus : húmus de minhoca : perlita (CP), Vermiculita : húmus de minhoca : perlita (VE), Turfa convencional : casca de eucalipto (HU), Turfa cultivadora : casca de arroz carbonizada (TU), Testemunha (TE). 

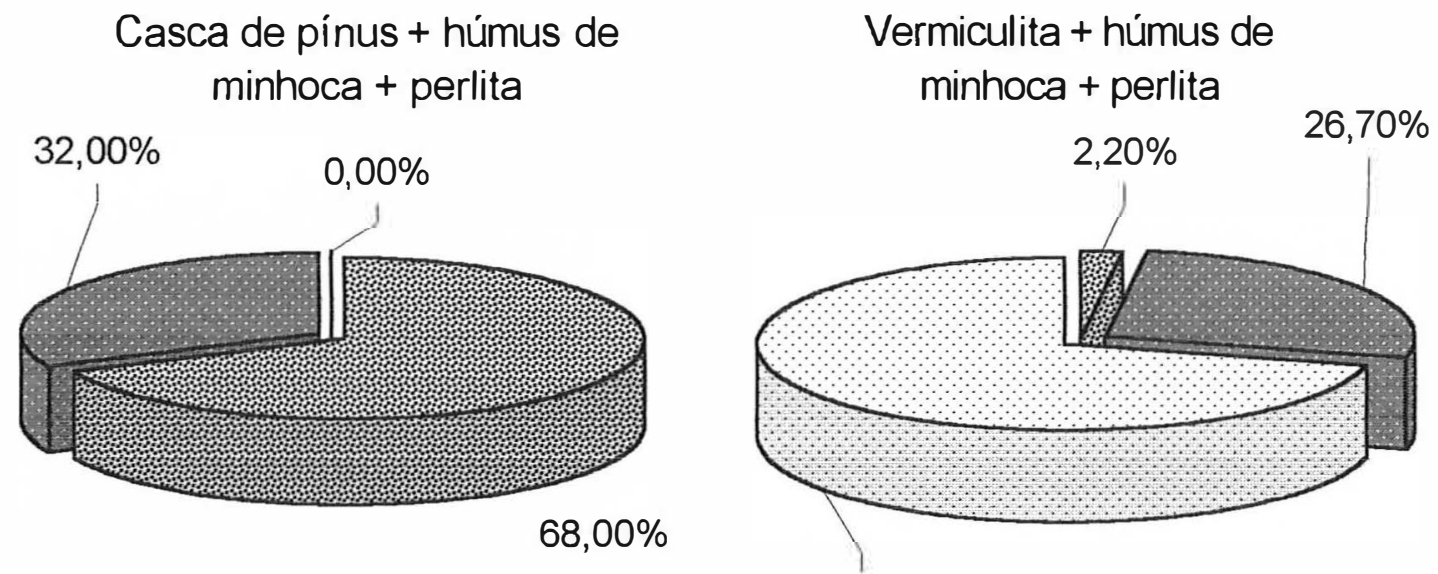

$71,10 \%$
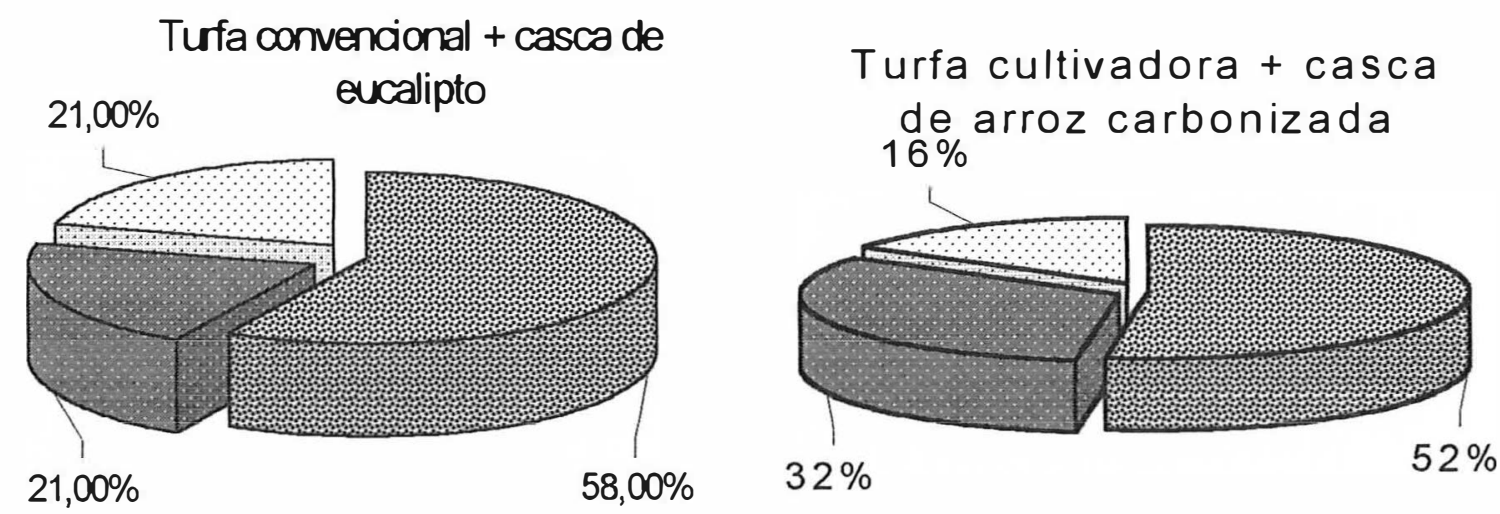

Testemunha
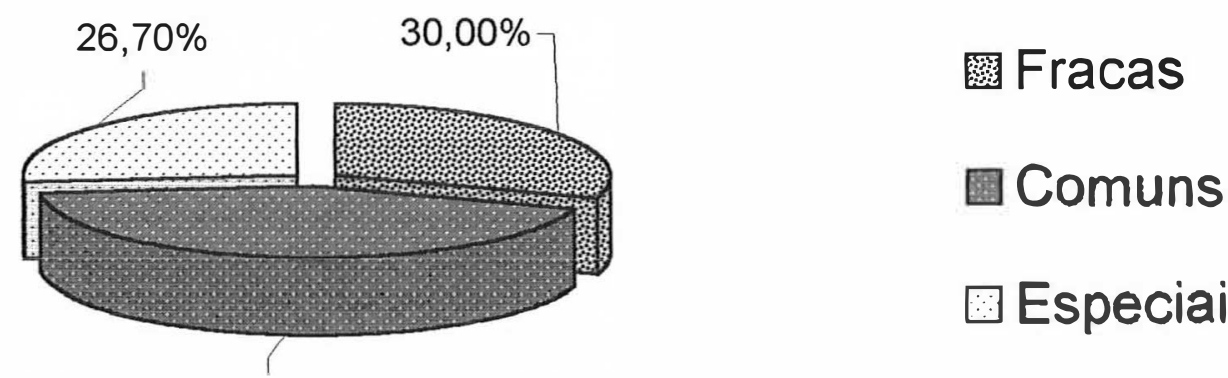

Especiais

$43,30 \%$

Figura 4: Qualidade comercial de gloxínias produzidas em diferentes substratos. 
No parâmetro características fitotécnicas (Tabela 5) plantas cultivadas em vermiculita : húmus de minhoca : perlita apresentaram os melhores resultados na maioria das características avaliadas.

Tabela 5: Resultados obtidos em características fitotécnicas, quando se avaliou $o$ uso de diferente substratos no cultivo da gloxínia. ${ }^{x}$

\begin{tabular}{lccccc}
\hline Tratamento $^{y}$ & $\mathrm{CP}^{z}$ & VE & HU & TU & TE \\
\hline NB & $4,83 \mathrm{~b}$ & $11,00 \mathrm{ab}$ & $10,33 \mathrm{ab}$ & $14,33 \mathrm{a}$ & $7,33 \mathrm{ab}$ \\
$\mathrm{NFL}$ & $2,33 \mathrm{~b}$ & $5,83 \mathrm{a}$ & $1,83 \mathrm{~b}$ & $2,33 \mathrm{~b}$ & $2,83 \mathrm{~b}$ \\
NFO & $11,50 \mathrm{a}$ & $17,17 \mathrm{a}$ & $13,50 \mathrm{ab}$ & $14,67 \mathrm{ab}$ & $10,33 \mathrm{~b}$ \\
$\mathrm{AF}\left(\mathrm{cm}^{2}\right)$ & $714,33 \mathrm{a}$ & $1209,50 \mathrm{a}$ & $980,83 \mathrm{a}$ & $1153,33 \mathrm{a}$ & $893,67 \mathrm{a}$ \\
$\mathrm{PFPA}(\mathrm{g})$ & $82,50 \mathrm{~b}$ & $158,00 \mathrm{a}$ & $128,17 \mathrm{ab}$ & $145,33 \mathrm{ab}$ & $122,83 \mathrm{ab}$ \\
PSPA $(\mathrm{g})$ & $9,67 \mathrm{a}$ & $13,83 \mathrm{a}$ & $12,83 \mathrm{a}$ & $10,83 \mathrm{a}$ & $11,83 \mathrm{a}$ \\
PFSR $(\mathrm{g})$ & 28,94 & $30,56 \mathrm{a}$ & $27,61 \mathrm{a}$ & $23,00 \mathrm{~b}$ & $21,78 \mathrm{~b}$ \\
PSSR $(\mathrm{g})$ & 5,33 & $4,22 \mathrm{a}$ & $3,42 \mathrm{ab}$ & $2,94 \mathrm{~b}$ & $2,47 \mathrm{~b}$ \\
$\operatorname{VSR}(\mathrm{mL})$ & $27,13 \mathrm{a}$ & $30,10 \mathrm{a}$ & $28,14 \mathrm{a}$ & $23,52 \mathrm{~b}$ & $22,58 \mathrm{~b}$ \\
\hline
\end{tabular}

* Teste de Tukey para as médias de densidade de substrato. Médias horizontais seguidas por letras distintas diferem, entre si, ao nível de $5,00 \%$ de significância.

${ }^{Y}$ Número de botões (NB), número de flores (NFL), número de folhas (NFO), área foliar (AF), peso da matéria fresca da parte aérea (PFPA), peso da matéria seca da parte aérea (PSPA), peso da matéria fresca do sistema radicular (PFSR), peso da matéria seca do sistema radicular (PSRS), volume do sistema radicular (VSR).

${ }^{\mathrm{z}}$ Casca de pínus : húmus de minhoca : perlita (CP), Vermiculita : húmus de minhoca : perlita (VE), Turfa convencional : casca de eucalipto (HU) Turfa cultivadora : casca de arroz carbonizada (TU), Testemunha (TE). 

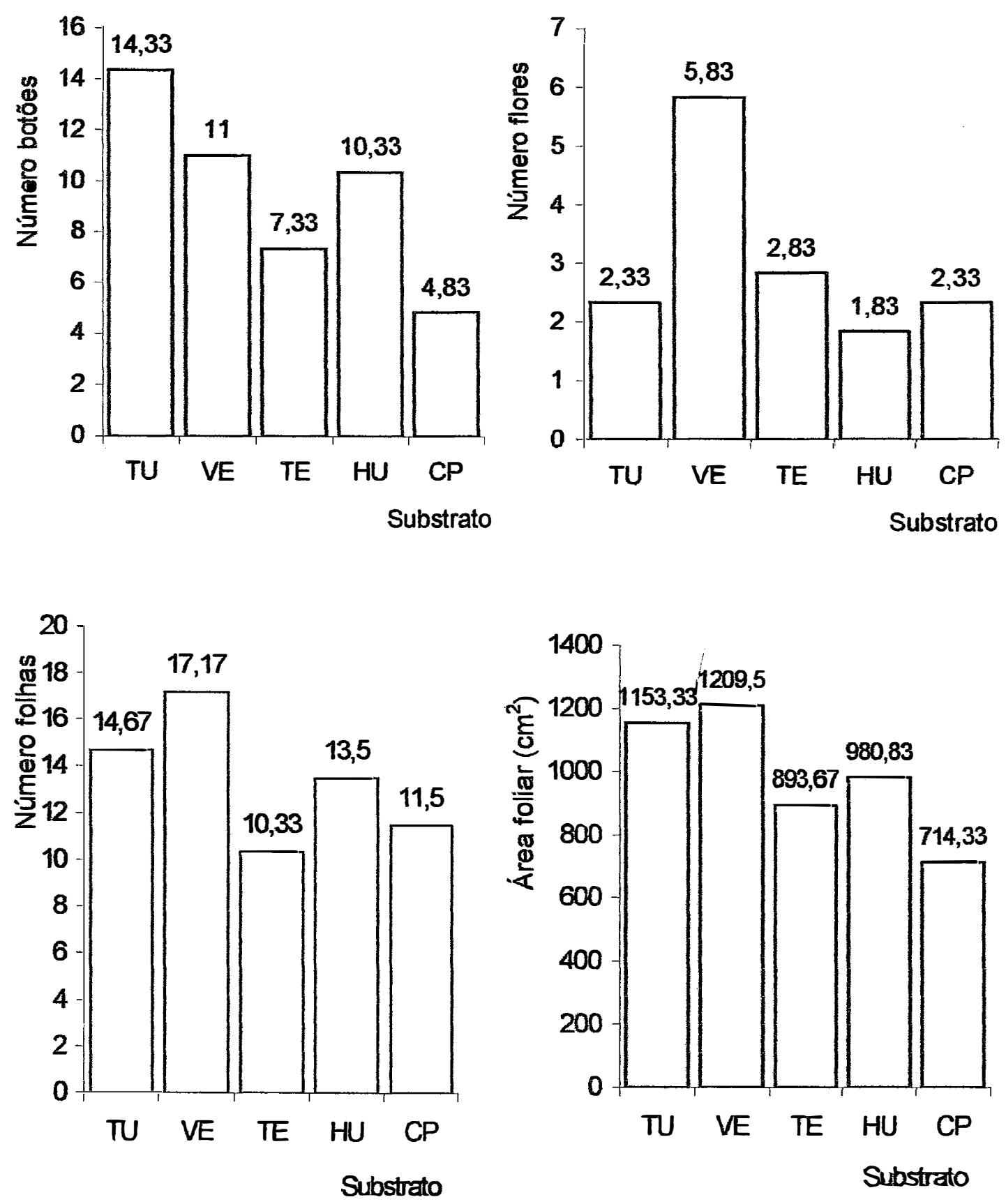

Figura 5: Características fitotécnicas avaliadas no cultivo da gloxínia em diferente substratos.

* CP - casca pínus : húmus de minhoca : perlita, VE - vermiculita : húmus de minhoca : perlita, HU - turfa convencional : casca de eucalipto, TU - turfa cultivadora : casca de arroz carbonizada, TE - testemunha. 

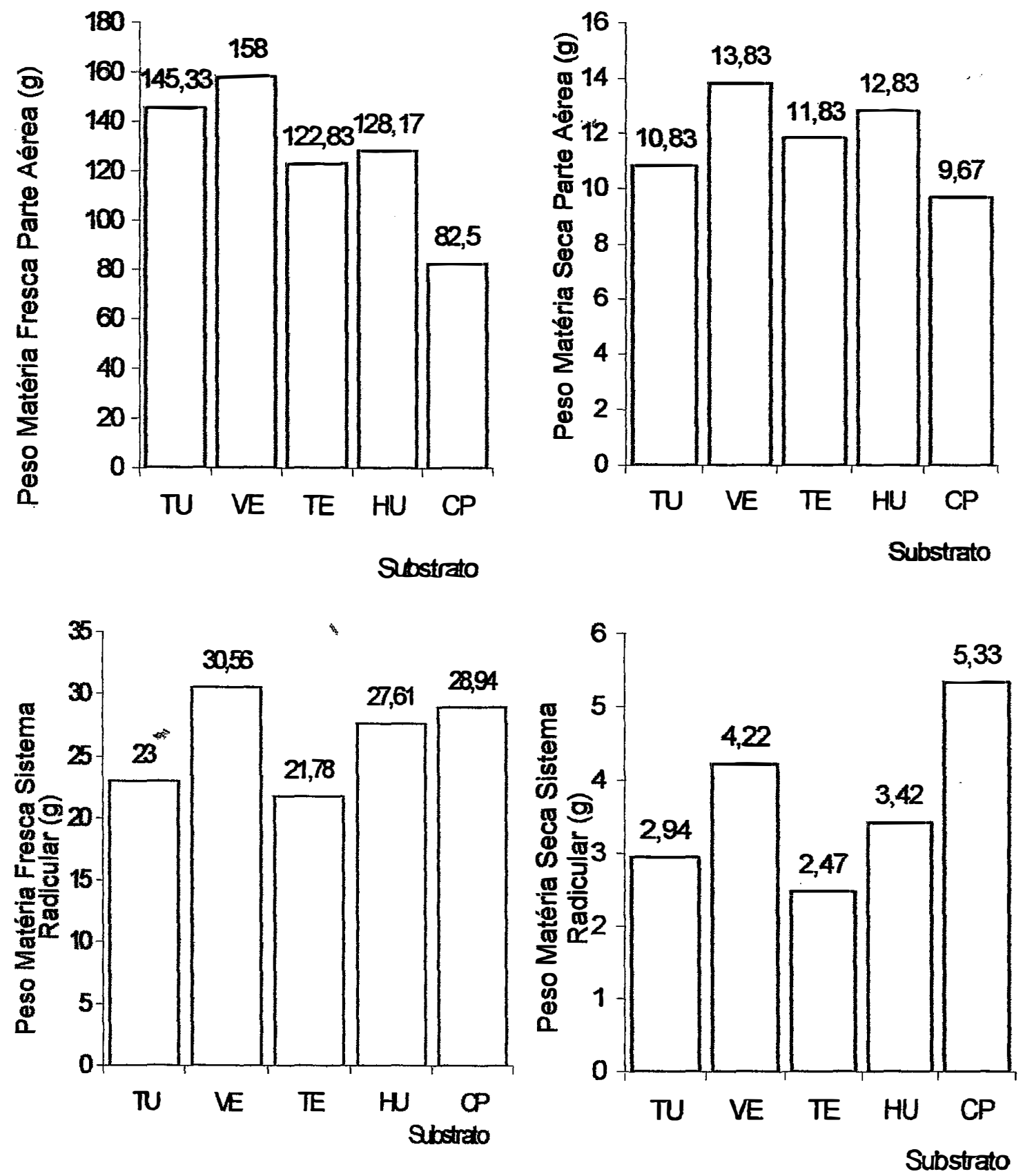

Figura 5: Características fitotécnicas avaliadas no cultivo da gloxínia em diferente substratos (continuação).

* CP - casca pínus : húmus de minhoca : perlita, VE - vermiculita : húmus de minhoca : perlita, HU - turfa convencional : casca de eucalipto, TU - turfa cultivadora : casca de arroz carbonizada, TE - testemunha. 


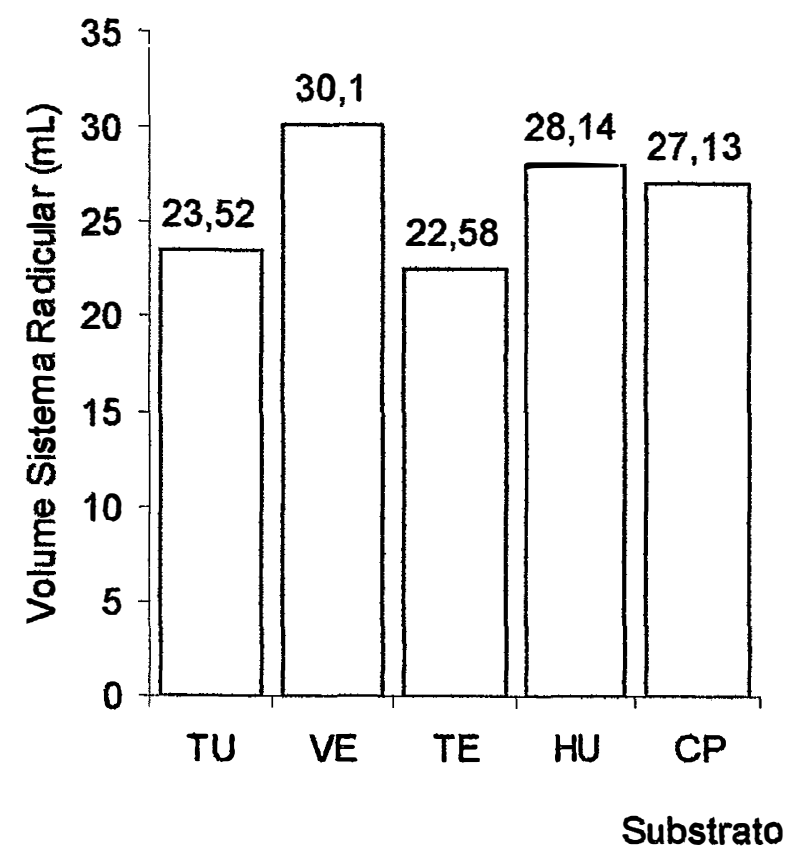

Figura 5: Características fitotécnicas avaliadas no cultivo da gloxínia em diferente substratos (continuação).

* CP - casca pínus : húmus de minhoca : perlita, VE - vermiculita : húmus de minhoca : perlita, HU - turfa convencional : casca de eucalipto, TU - turfa cultivadora : casca de arroz carbonizada, TE - testemunha.

Plantas cultivadas neste substrato possuiam, em média, 11 botōes e 5,83 flores, de coloração intensa, sem manchas ou deformações, centralizadas no vaso e acima das folhas. As folhas eram grandes, possuindo uma área foliar de $1209,5 \mathrm{~cm}^{2}$ e em grande número, 17,17 folhas, de coloração intensa, sem manchas ou deformações, estando bem distribuídas e abaixo das flores, dando uma formação equilibrada e uniforme aos vasos. A parte aérea possuía peso fresco de $158 \mathrm{~g}$ e peso seco $13,83 \mathrm{~g}$. Quando se avaliou o sistema radicular, pode-se observar que o peso fresco do sistema 
radicular foi de $30,56 \mathrm{~g}$, o peso seco de $4,22 \mathrm{~g}$ e o volume de $30,10 \mathrm{~mL}$ (Tabela 5).

Os substratos turfa convencional : casca de eucalipto, turfa cultivadora : casca de arroz carbonizada, testemunha e casca de pínus : húmus de minhoca : perlita apresentaram resultados inferiores.

No parâmetro qualidade comercial (Tabela 4) estes tratamentos não apresentaram bons resultados. A testemunha apresentou $26,7 \%$ das plantas classificadas como especiais e $30 \%$ fracas, a turfa cultivadora : casca de arroz carbonizada apresentou $15,6 \%$ de plantas especiais e $52,2 \%$ fracas, a turfa convencional : casca de eucalipto apresentou $21 \%$ de plantas especiais e $58 \%$ fracas e a casca de pínus : húmus de minhoca : perlita apresentou $32 \%$ de plantas comuns e $68 \%$ fracas.

No parâmetro características fitotécnicas (Tabela 5) nenhum desses tratamentos alcançou a média de 4 flores por planta. A testemunha apresentou 2,83 flores, a turfa cultivadora : casca de arroz carbonizada, 2,33 flores, a casca de pínus : húmus de minhoca : perlita, 2,33 flores e a turfa convencional : casca de eucalipto apresentou 1,83 flores.

$O$ experimento poderia ter apresentado resultados diferentes se 0 produtor tivesse manejado a cultura de outra forma. Na cultura da gloxínia, quando se cortam as duas primeiras flores, a planta é induzida a produzir um número maior de flores, que se abrem ao mesmo tempo. Como se optou por conduzir o experimento nas condições do produtor, as primeiras flores não foram eliminadas.

\section{CONCLUSÕES}

Um substrato adequado ao cultivo de gloxínia (Sinningia speciosa) deve apresentar características físicas densidade de $0,55 \mathrm{g.cm}^{-3}$, porosidade 
total de $77,60 \%$ de, espaço ocupado por ar de $26,93 \%$, água disponivel de $18,75 \%$ e água facilmente disponível de $16,36 \%$.

Gloxínia se desenvolve bem em condições de baixa quantidade de água disponível, desde que o espaço ocupado por ar e a porosidade total sejam adequados. $\mathrm{O}$ excesso de água ou o excesso ou falta ar são fatores limitantes para a cultura.

Quando se avaliou o desempenho de cinco diferentes substratos no cultivo de gloxínia, pode-se observar que o substrato vermiculita : húmus de minhoca : perlita apresentou os melhores resultados, sendo o mais indicado para a cultura.

\section{REFERÊNCIAS BIBLIOGRÁFICAS}

ANISKO, T.; NESMITH, D. S.; LINDSTROM, O.M. Time-domain reflectometry for measuring water content of organic growing media in containers. HortScience, v.29, n.12, p.1511-1513, 1994.

BACKES, M.A.; KÄMPF, A.N. Substrato a base de composto de lixo urbano para a produção de plantas ornamentais. Pesquisa agropecuária brasileira, v.26, n.5, p.753-758, maio 1991.

BALLESTER-OLMOS, J.F. Substratos para el cultivo de plantas ornamentales. Valencia: Instituto Valenciano de Investigaciones Agrarias, 1992. 44p. (Hojas Divulgadoras, 11).

BEARDSELL, D.V.; NICHOLS, D.G.; JONES, D.L. Physical properties of nursery potting-mixtures. Scientia Horticulturae, v.11, p.1-8, 1979. 
BELLÉ, S. Uso da turfa "Lagoa dos Patos" (Viamão/RS) como substrato hortícola. Porto Alegre, 1990. 143p. (Dissertação de Mestrado) Universidade Federal do Rio Grande do Sul.

BITTENCOURT, J.F.N.; FERNANDES, P.D.; DE MATTOS, J.R. Efeitos da aplicação de fertilizantes comerciais, via foliar, em gloxínia (Sinningia speciosa, Hiern). Anais da Escola Superior de Agricultura "Luiz de Queiroz", v.34, p.121-126, 1977.

BIX, R.A. Some thoughts on the physical properties of substrates with special reference to aeration. Acta Horticulturae, n.31, p.149-160, 1973.

BOELTER, D.H. Physical properties of peats as related to degree of decomposition. Soil Science Society of America Proceedings, v.33, p.606-609, 1969.

BOERTJE, G.A. Physical laboratory analyses of potting composts. Acta Horticulturae, n.150, p.47-50, 1983.

BUNT, A.C. Physical properties of mixtures of peats and mineral of different particle size and bulk density for potting substrates. Acta Horticulturae, n.150, p.143-153, 1983.

De BOODT, M.; VERDONCK, O. The physical properties of the substrates in floriculture. Acta Horticulturae, n.26, p.37-44, 1972.

DEULOFEU, C.; AGUILA VILA, J. Fine bark as substrate for primula and petunia. Acta Horticulturae, n.150, p.283-288, 1983. 
GABRIELS, R. Standardization of growing media analysis and evaluation. Acta Horticulturae, n.401, p.555-557, 1995.

GISLERØD, H.R. Physical conditions of propagation media and their influence on the rooting of cuttings. Plant and Soil, n.69, p.445-456, 1982.

GOH, K.M.; HAYNES, R.J. Evaluation of potting media for comercial nursery production of container grow plants: 1- Physical and chemical characteristics of soil and soiless media and their constituents. New Zealand Journal of Agricultural Research, v.20, p.363-370, 1977.

GROLLI, P.R. Composto de lixo domiciliar como condicionador de substratos para plantas arbóreas. Porto Alegre, 1991. 125p. (Dissertação de Mestrado) - Universidade Federal do Rio Grande do Sul.

GÜNTHER, J. Analytics of substrates and problems by transmitting the results into horticultural practice. Acta Horticulturae, n.150, p.33-40, 1983.

HARTMANN, H.T.; FLOCKER, W.J.; KOFRANEK, A.M. Plant Science growth, development, and utilization of cultivated plants. New York: Prentice-hall, Inc, 1981. 637p.

HUMMEL, R.L. Water relations of container-grown woody and herbaceous plants following antitranspirant sprays. HortScience, v.25, n.7, p.772$775,1990$. 
KÄMPF, A.N. Substratos para floricultura. In: SIMPÓSIO BRASILEIRO DE FLORICULTURA E PLANTAS ORNAMENTAIS, Maringá, 1992. Manual de Floricultura. Maringá: SBFPO, 1992. p.36-43.

LEMAIRE, F. Physical, chemical and biolological properties of growing medium. Acta Horticulturae, n.396, p.273-284, 1995.

LONGHI, A.A.; TOMBOLATO, A.F.C. Gloxínia. Comunicado Técnico - CATI. n.123, junho, 1995. $6 p$.

RAC, D. P. Disponibité en eau des substrats horticoles. Revue Suisse de Viticulture Arboriculture Horticultural. v.17, n.3, p.177-178, Mai/Juin 1985.

RIVIERE, L. M. Importance des caractéristiques physiques dans le choix des substrats pour les cultures hors sol. Revue Horticole. v.209, p.2327, Sep 1980.

SALVADOR, E.D. Efeito de diferentes substratos no crescimento e desenvolvimento de samambaia matogrossense (Polypodium aureum). Lavras, 1995. 67p. (Dissertação de Mestrado) - Universidade Federal de Lavras.

SHEEHAN, T. J. ; TJIA, B. The effects of growing media on growth and flowering of gloxinia. Proceedings of Florida State Horticulturae Society, n.89, p.319-320, 1976.

SINGH, B.P.; SAINJU, U.M. Soil physical and morphological properties and root growth. HortScience, v.33, n.6, p.966-971, 1998. 
VERDONCK, 0 . Reviewing and evaluation of new materials used as substrates. Acta Horticulturae, n.150, p.467-473, 1983.

VERDONCK, O.; VLEESCHAUWER, D.; PENNINCK, R. Barckcompost a new accepted growing medium for plants. Acta Horticulturae, n.133, p.221-227, 1983a.

VERDONCK, 0.; PENNINCK, R.; De BOODT, M. The physical properties of differet horticultural substrates. Acta Horticulturae, n.150, p.155-160, 1983b.

VERDONCK, O.; GABRIËLS, R. Summary and discussion session 'standardization of analytical methods'. Acta Horticulturae, n.221, p.443444, 1988.

WALLER, P.L.; HARRISON A.M. Estimation of pore space and the calculation of air volume in horticultural substrates. Acta Horticulturae, n.294, p.29-39, 1991.

WILSON, G.C.S. The physico-chemical and physical properties of horticultural substrates. Acta Horticulturae, n.150, p.19-32, 1983. 
4 AVALIAÇÃO DE DIFERENTES SUBSTRATOS NO CULTIVO DE LISIANTHUS (Eustoma grandiflorum Shinn). 


\section{AVALIAÇÃO DE DIFERENTES SUBSTRATOS NO CULTIVO DE LISIANTHUS (Eustoma grandiflorum Shinn).}

Resumo: Dois experimentos com a cultura do lisianthus (Eustoma grandiflorum) foram conduzidos na propriedade do produtor Edson Tsuyoshi Tamada, no município de Arujá, São Paulo. No primeiro experimento foram avaliadas as características físicas adequadas ao seu cultivo e observou-se que os tratamentos com densidades $0,75{\mathrm{~g} . \mathrm{cm}^{-3}}^{-3} 0,95 \mathrm{~g}^{\mathrm{cm}} \mathrm{cm}^{-3}$ apresentaram os melhores resultados nos parâmetros avaliados. $O$ lisianthus se desenvolveu bem em porosidade de 72,60 a $75,10 \%$, espaço de aeração de 12,81 a $19,53 \%$, água disponivel de 19,79 a $26,03 \%$ e água facilmente disponivel de 17,41 a $23,71 \%$. Num segundo experimento analisou-se diferentes misturas de materiais, que possuiam as características físicas adequadas à cultura, e observou-se que os substratos turfa cultivadora : vermiculita, casca de eucalipto : turfa convencional : areia e testemunha, apresentaram os melhores resultados, com alta qualidade comercial das plantas produzidas. Já o substrato casca de pínus : húmus de minhoca apresentou-se inadequado ao cultivo de lisianthus.

Palavras-chave: lisianthus, Eustoma grandiflorum, substrato, análise física 


\section{EVALUATION OF DIFFERENT SUBSTRATES ON LISIANTHUS (Eustoma grandiflorum Shinn) GROWTH}

Summary: Two experiments on the lisianthus culture (Eustoma grandiflorum) were conducted in Edson Tsuyoshi Tamada's property, an ornamental plant grower's, in Arujá, Sao Paulo. In the first experiment the physical characteristics suitable for the cultivation of this plant were evaluated and it was observed that treatments presenting 0.75 and $0.95 \mathrm{~g} \mathrm{.} \mathrm{cm}^{-3}$ densities showed the best results for the evaluated parameters. Lisianthus developed well in the following conditions: 72.60 to $75.10 \%$ porosity, 12.81 to $19.53 \%$ air space, 19.79 to $26.03 \%$ available water, 17.41 to $23.71 \%$ easily available water. Different mixtures of materials, which had physical characteristics suitable for the culture, were analyzed in a second experiment and the cultivated peat : vermiculite; eucalyptus bark : conventional peat : sand substrates and control, presented the best results, showing good plant commercial quality. Yet, the pine bark : earthworm humus substrate showed to be inadequate to lisianthus cultivation.

Key words: lisianthus, Eustoma grandiflorum, substrate, physical analysis 


\section{INTRODUÇÃO}

Uma característica da floricultura é a procura contínua de novas espécies (Harbaugh \& Woltz, 1991). No começo dos anos 80, o aparecimento do lisianthus nos mercados europeu e americano despertou grande interesse dos consumidores (Pergola \& Farina, 1989). Originário dos Estados Unidos foi introduzido no Brasil por empresas japonesas produtoras de sementes, no final da década.

Eustoma grandifforum é uma importante flor de corte e de vaso (Rubino, 1993), produzindo flores de longa durabilidade (Starman, 1991). Embora sendo uma cultura perene, é cultivada pelos produtores como cultura anual (Griesbach, 1992) e suas flores variam da cor púrpura ao branco (Whipker et al., 1994).

Para os agricultores é difícil encontrar informações técnicas adequadas (Pergola \& Farina, 1989). Como a maioria das novas culturas, os produtores tem informações limitadas sobre o cultivo de lisianthus (Harbaugh \& Woltz, 1991). Segundo Pergola \& Farina (1989), para um crescimento uniforme, o lisianthus deve apresentar um sistema radicular bem desenvolvido. $O$ substrato deve ter um alto teor de matéria orgânica e um pH em torno de 6,5.

Na produção de plantas ornamentais o tipo de substrato e recipiente são fatores importantes no crescimento das plantas (Castro et al., 1996). É definido como substrato um meio físico, natural ou sintético, onde se desenvolvem as raízes das plantas que crescem em um recipiente, com um volume limitado (Ballester-Olmos, 1992).

O uso de vasos muda as propriedades físicas entre raiz e substrato, de forma que o pequeno volume do vaso conduz a uma alta concentração de raízes. Como conseqüências deste fato, observa-se que: a. há uma necessidade de alta demanda de oxigênio e remoção de gás carbônico; $b$. uma grande quantidade de água, exigida para sustentar as altas taxas de 
crescimento, deve estar disponivel num volume muito restrito; c. a pequena profundidade do recipiente impede a drenagem, com risco de água se acumular; d. a alta freqüência das irrigações torna o substrato sujeito a lixiviação (Bunt, 1961).

O uso de substratos industriais tem crescido muito nos últimos anos (Günther, 1983). Essa mudança ocorreu devido a produção de mudas e plantas envasadas estar cada vez mais baseada em substratos artificiais (Wilson, 1983). Atualmente são usados diferentes substratos, dependendo da espécie a ser cultivada. Existem substratos já preparados, com diferentes composições, que podem ser encontrados no comércio (Ballester-Olmos, 1992). Infelizmente no Brasil ainda não há uma legislação que regulamente tal comércio (Gonçalves, 1992).

O substrato tem como função dar sustentação às plantas, apoiando o crescimento das raízes, e fornecendo água e ar em quantidades adequadas (Singh \& Sainju, 1998). A adequada relação águalar é uma característica importante, devido ao pequeno volume e profundidade dos recipientes, que criam para os substratos propriedades físicas diferentes de um solo (Hartmann et al., 1981).

Atualmente os substratos combinam condições físicas e químicas favoráveis, que permitem automação de programas de adubação e irrigação, padronização de produção, colheitas uniformes e redução de custos (Verdonck et al., 1981).

Análises físicas feitas em laboratório são mais precisas do que as feitas visualmente. As análise físicas devem seguir uma metodologia unificada, oferecendo vantagens como os resultados poderem ser analisados e comparados à especificações padrão (Boertje, 1983).

A caracterização de um substrato começa na distribuição da relação arlágua. Como em solos, é feita pela curva de tensão de água (De Boodt \& Verdonck, 1972). As tensões usadas para substratos $(10,50$ e $100 \mathrm{~cm})$ são 
mais baixas do que as usadas em solos, porque em recipientes as plantas são cultivadas em condições de umidade muito mais altas (Verdonck, 1983).

Da curva de tensão de água se obtém dados como (De Boodt \& Verdonck, 1972):

. porosidade total - corresponde a umidade volumétrica das amostras quando submetidas a uma tensão de $0 \mathrm{~cm}$.

. espaço de aeração - é a porcentagem de ar, em volume, após a drenagem do excesso de água do substrato. Corresponde a diferença entre os pontos de tensão 0 e $10 \mathrm{~cm}$.

. água disponível - é a diferença entre o volume de água a $10 \mathrm{~cm}$ de tensão e o volume de água à $100 \mathrm{~cm}$ de tensão.

. água facilmente disponível - é a quantidade de água retida entre 10 e $50 \mathrm{~cm}$ de tensão.

Caracterização física dos substratos dá informações sobre a distribuição de sólidos, água e ar, que pode ser usada para estabelecer o manejo da irrigação (Terés et al., 1995). Propriedades físicas mudam durante o cultivo, devido à planta, degradação da estrutura, reestruturação de partículas e processos de mineralização (Burés et al., 1991). Devido as condições restritas para o desenvolvimento das plantas em recipientes, as características físicas são fatores determinantes na escolha de um correto substrato.

Diversos pesquisadores, no mundo todo, tem procurado estabelecer as propriedades ideais de um substrato. Observando-se que os resultados obtidos no exterior não se adequavam as condições do Brasil, o presente trabalho teve como objetivo avaliar as necessidades específicas do lisianthus (Eustoma grandiflorum Shinn), com relação a características físicas dos substratos, e elaborar substratos adequados à cultura. 


\section{MATERIAL E MÉTODOS}

O estudo com a cultura do lisianthus foi dividido em três fases distintas. Na primeira fase montou-se um experimento, em casa de vegetação, onde se avaliou características físicas adequadas ao seu cultivo. Numa segunda fase foram elaborados 136 diferentes substratos e suas características físicas foram determinadas. Numa terceira fase montou-se um novo experimento onde, dos 136 substratos analisados, foram selecionados três substratos, que apresentavam características físicas adequadas à cultura, sendo estes comparados ao substrato usado pelo produtor.

\section{Primeira fase - Primeiro experimento}

O experimento com a cultura do lisianthus foi conduzido na propriedade do $\mathrm{Eng}^{\circ}{ }^{\circ}$ Agrônomo Edson Tsuyoshi Tamada, produtor de plantas ornamentais no município de Arujá, estado de São Paulo.

No dia 21 de novembro de 1997 sementes da variedade 'Eco', comercializadas no Brasil pela empresa Sakata, foram semeadas em bandejas plásticas de 288 células, contendo o substrato comercial 'Terra do Paraiso Light', comumente utilizado pelo produtor. Após a semeadura, as bandejas foram colocadas em germinador, com temperatura, luminosidade e umidade controladas. Tal procedimento se faz necessário para que haja uma alta taxa de germinação das sementes. Ohkawa et al. (1991) observaram que sementes de lisianthus são sensíveis à altas temperaturas, desde que começam a absorver água até possuírem dois pares de folhas. A temperatura diurna foi mantida em torno de $20^{\circ} \mathrm{C}$ e a noturna $8^{\circ}$ abaixo da diurna. A umidade relativa do ar foi mantida acima de $80 \%$.

Após a germinação das sementes, as mudas foram adubadas com $50 \mathrm{~g}$ de 'Master 20-20-20' (Anexo B) em 200 litros de água. 
No dia 29 de dezembro, quando as mudas apresentavam tamanho adequado para serem transplantadas para os vasos, ou seja, dois pares de folhas definitivas, o primeiro experimento com a cultura do lisianthus foi montado.

A partir deste momento o cultivo foi feito em casa de vegetação climatizada, com sistemas de aquecimento, ventilação, controle de luminosidade, irrigação, fertilização, medição de condutividade elétrica e pH. Seguiu-se o manejo usualmente dado pelo produtor para a cultura.

$O$ delineamento experimental adotado foi o inteiramente casualizado com cinco tratamentos, vinte plantas por parcela e cinco repetições, perfazendo um total de cem plantas por tratamento, e quinhentas plantas no total.

Os tratamentos constaram de misturas de casca de arroz carbonizada e areia, as quais foram lavadas e secas em estufa por 72 horas a $60^{\circ} \mathrm{C}$, até peso constante. A areia foi previamente peneirada em peneira $\mathrm{n}^{\circ} 10$ da ABNT. Os tratamentos se diferenciaram na proporção dos componentes, de tal forma que se obtivessem substratos com densidades 0,$15 ; 0,35 ; 0,55 ; 0,75$ e $0,95 \mathrm{~g} \cdot \mathrm{cm}^{-3}$.

Foram plantadas três mudas por vaso, sendo idêntico ao plantio feito pelo produtor. Utilizou-se vasos plásticos $\mathrm{n}^{0} \mathbf{0}$, com capacidade de $750 \mathrm{~cm}^{3}$, já contendo os substratos em estudo.

A primeira irrigação foi feita imediatamente após o plantio. A água do município de Arujá possui pH 7,0, sendo muito alcalino para o cultivo de lisianthus. Desta forma se faz necessário a correção do $\mathrm{pH}$ da água de irrigação com ácido fosfórico até o pH adequado, que para a cultura é de 4,5.

Após o plantio das mudas fez-se uma adubação rica em fósforo disponivel, com adubo de formulação (N-P-K) 10-52-10, colocando-se 0,1\% do volume do vaso. 
Durante a fase vegetativa foram feitas adubações a cada dez dias alternando-se as fórmulas $20-20-20(0,2 \%)$ e 5-5-6 (0,2\%) + 0-12-12 (0,1\%) Quando começaram a surgir os primeiros botões florais, diminuiu-se 0 fornecimento de adubos nitrogenados e as adubações começaram a ser feitas semanalmente, alternado-se as formulações $15-15-30(0,1 \%)$ e 5-5-6 $(0,1 \%)+0-12-12(0,2 \%)$.

As adubações foliares, até o aparecimento do primeiro botão floral, foram feitas semanalmente com adubo $20-20-20(0,1 \%)$ mais $3,0 \mathrm{~mL} \cdot \mathrm{L}^{-1}$ do produto comercial 'CAB 2'.

'CAB 2' possui, em sua formulação, $8 \%$ de cálcio e $2 \%$ de boro. Por ser o lisianthus uma cultura extremamente exigente em cálcio, convém salientar que todas as pulverizações realizadas na cultura (com adubos, inseticidas e fungicidas) até o aparecimento do primeiro botão floral, foram acompanhadas pelo produto.

Após o aparecimento do primeiro botão floral, as adubações foram feitas com 15-15-30 $(0,1 \%)$ mais 3,0 mL. $\mathrm{L}^{-1}$ do produto comercial 'CALBIT B'.

'CALBIT B' é um produto quelatizado, mais facilmente absorvido pelas plantas, e que possui em sua formulação $9,5 \%$ de cálcio e 1,6\% de boro. Todas as pulverizações realizadas, desde o aparecimento do primeiro botão floral até a colheita, foram acompanhadas pelo produto.

Em 15 de janeiro de 1998 fez-se a primeira poda, quando as plantas apresentavam aproximadamente $8,0 \mathrm{~cm}$. A poda foi feita acima do segundo nó, mantendo-se a planta com 3,0 a 5,0cm de altura. Em 07 de fevereiro fezse a segunda poda, quando as plantas apresentavam aproximadamente $15,0 \mathrm{~cm}$ de altura.

Foram realizadas pulverizações com regulador de crescimento de ação sistêmica, de uso exclusivo para plantas ornamentais, com o nome comercial de 'B-Nine 850 PS', pó solúvel, tendo em sua composição química $850 \mathrm{~g} \cdot \mathrm{Kg}^{-1}$ 
de ácido $\mathrm{N}$-dimetilaminosuccinamico (Daminizide) e $150 \mathrm{~g} \cdot \mathrm{Kg}^{-1}$ de ingredientes inertes.

A cada litro de água adicionou-se $5,0 \mathrm{~g}$ de $\mathrm{B}-\mathrm{Nine}$ mais $3,0 \mathrm{~mL}$ de Megafol (Anexo $\mathrm{C}$ ), um produto comercial à base de aminoácidos, que auxilia na absorção do regulador de crescimento.

As pulverizações foram feitas após a segunda poda (17 de fevereiro), antes do aparecimento do primeiro botão floral (25 de fevereiro) e depois do aparecimento do primeiro botão floral (03 de março).

No dia 21 de janeiro observou-se o aparecimento de lagartas e ácaros na cultura. $O$ controle de ácaros fez-se necessário logo o aparecimento dos primeiros botões florais.

O lisianthus sofre ataques de lagartas, trips, ácaros, principalmente o ácaro branco, e doenças como botritis, fusariose, antracnose, sendo o controle químico preventivo necessário à cultura (Anexo D).

O experimento foi conduzido até o dia 19 de março de 1998, quando as plantas chegaram no ponto de comercialização. Ao final do experimento foram avaliados os parâmetros qualidade comercial das plantas produzidas, características fitotécnicas e características físicas dos substratos.

A qualidade comercial de uma planta é uma característica importante a ser avaliada, pois indica seu preço no mercado consumidor. O produtor classifica suas plantas como:

. Plantas especiais - Os vasos apresentam 3 plantas sadias, com 2 ou mais flores por planta, grande número de botões e altura uniforme (2,5 vezes a altura do vaso). Vasos classificados como "especiais" alcançam maiores preços de venda.

. Plantas comuns - Os vasos apresentam 1 planta morta ou 3 plantas de altura desuniforme, com poucas flores e um número médio de botões.

. Plantas de segunda - Os vasos apresentam somente 1 planta, com poucas flores e poucos botões. 
As características fitotécnicas avaliadas na cultura do lisianthus foram: . número de botões.

. porcentagem de vasos floridos.

. número de flores.

. altura das plantas.

. peso da matéria fresca da parte aérea.

. peso da matéria fresca do sistema radicular.

- peso da matéria seca da parte aérea.

. peso da matéria seca do sistema radicular.

. volume do sistema radicular.

As características físicas dos substratos avaliadas foram :

. porosidade total.

. espaço de aeração.

. água disponível.

. água facilmente disponível.

\section{Segunda fase - Análises laboratoriais}

A segunda fase dos estudos com a cultura do lisianthus constou de duas etapas, a primeira foi a elaboração de diferentes substratos e a segunda, a análise de suas características físicas. As duas etapas foram conduzidas nas instalações da Escola Superior de Agricultura "Luiz de Queiroz" ESALQ/USP, situada no município de Piracicaba, estado de São Paulo.

$\mathrm{Na}$ área experimental do Departamento de Produção Vegetal foram elaborados diferentes substratos, utilizando-se como componentes: . areia

. casca de arroz carbonizada . casca de pínus 
. húmus de minhoca

. perlita

. turfa convencional

. turfa cultivadora

. vermiculita

. torta de filtro

. casca de eucalipto

Os substratos constaram de misturas de dois a três materiais, em diferentes proporções. Ao total foram elaborados 136 substratos, dos quais três apresentaram as características adequadas ao cultivo do lisianthus (Anexo F).

A curva de tensão de cada substrato foi determinada, seguindo-se o método citado por De Boodt \& Verdonck (1972). As análises foram feitas no Laboratório de Análises Físicas de Solos do Departamento de Engenharia Rural.

Da curva de tensão de água se obteve os seguintes dados:

- porosidade total - corresponde a umidade volumétrica do substrato a $0 \mathrm{~cm}$ de tensão.

. espaço de aeração - corresponde a diferença entre os pontos 0 e $10 \mathrm{~cm}$ de tensão.

. água disponível - é a diferença entre 10 e $100 \mathrm{~cm}$ de tensão.

. água facilmente disponível - é a quantidade de água retida entre 10 e $50 \mathrm{~cm}$ de tensão.

\section{Terceira fase - Segundo experimento}

O segundo experimento foi conduzido na propriedade do $\mathrm{Eng}^{\circ}$ Agrônomo Edson Tsuyoshi Tamada, produtor de plantas ornamentais no município de Arujá, eEstado de São Paulo. O cultivo foi feito em casa de 
vegetação climatizada, com sistemas de aquecimento, ventilação, controle de luminosidade, irrigação, fertilização, medição de condutividade elétrica e pH.

$O$ delineamento experimental adotado foi o inteiramente casualizado com quatro tratamentos, seis plantas por parcela e cinco repetições.

Para se definir os tratamentos foram utilizados dados obtidos em um experimento anterior, onde se avaliou as características físicas adequadas ao cultivo do lisianthus.

A partir dos resultados obtidos nas características fitotécnicas (Tabela 2), qualidade comercial (Tabela 1) e análise física dos substratos (Tabela 3), foram definidas misturas de materiais que atendessem as exigências da cultura. Buscou-se substratos que apresentassem as seguintes características físicas:

. porosidade total de 72,60 a $75,10 \%$,

. espaço ocupado por ar de 12,81 a 19,53\%,

. água disponível de 19,79 a $26,03 \%$

. água facilmente disponível de 17,41 a 23,71\%.

Foram encontrados três substratos, que apresentavam características físicas adequadas a cultura, e que foram comparados a uma testemunha. Os tratamentos constaram de:

. Turfa cultivadora : vermiculita (2:1)

. Casca de pínus : húmus de minhoca (1:3)

. Casca de eucalipto : turfa convencional : areia $(1: 3: 0,5)$

. Testemunha

Como testemunha foi usado o substrato comercial comumente utilizado pelo produtor 'Terra do Paraíso Light'.

Foram utilizadas mudas da variedade 'Mariachi', comercializadas pelo produtor de mudas Flávio Yamaguchi, situado no município de Atibaia/SP. As mudas foram comercializadas em bandejas plásticas de 288 células, apresentando dois pares de folhas definitivas. 
O experimento foi montado no dia 28 de julho de 1999. O manejo dado à cultura foi idêntico ao primeiro experimento.

Em 22 de agosto de 1999 fez-se a primeira poda e, em 30 de setembro, a segunda.

Foram realizadas pulverizações com B-Nine e Megafol após a segunda poda (30 de setembro), antes do aparecimento do primeiro botão floral (18 de outubro) e depois do aparecimento do primeiro botão floral (10 de novembro).

O experimento foi conduzido até o dia 07 de dezembro de 1999, quando as plantas chegaram ao ponto de comercialização (Figura 1). Ao final do experimento foram avaliados os parâmetros qualidade comercial e características fitotécnicas das plantas produzidas.

\section{RESULTADOS E DISCUSSÃO}

\section{Primeiro experimento}

Quando se avaliou o desempenho de diferentes densidades de substrato no cultivo de lisianthus, pode-se observar que as densidades 0,75 e

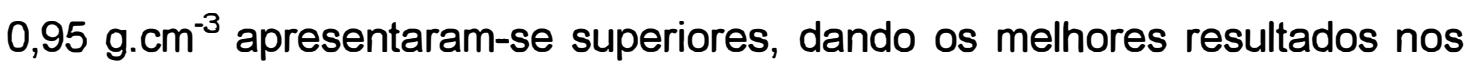
parâmetros avaliados. 

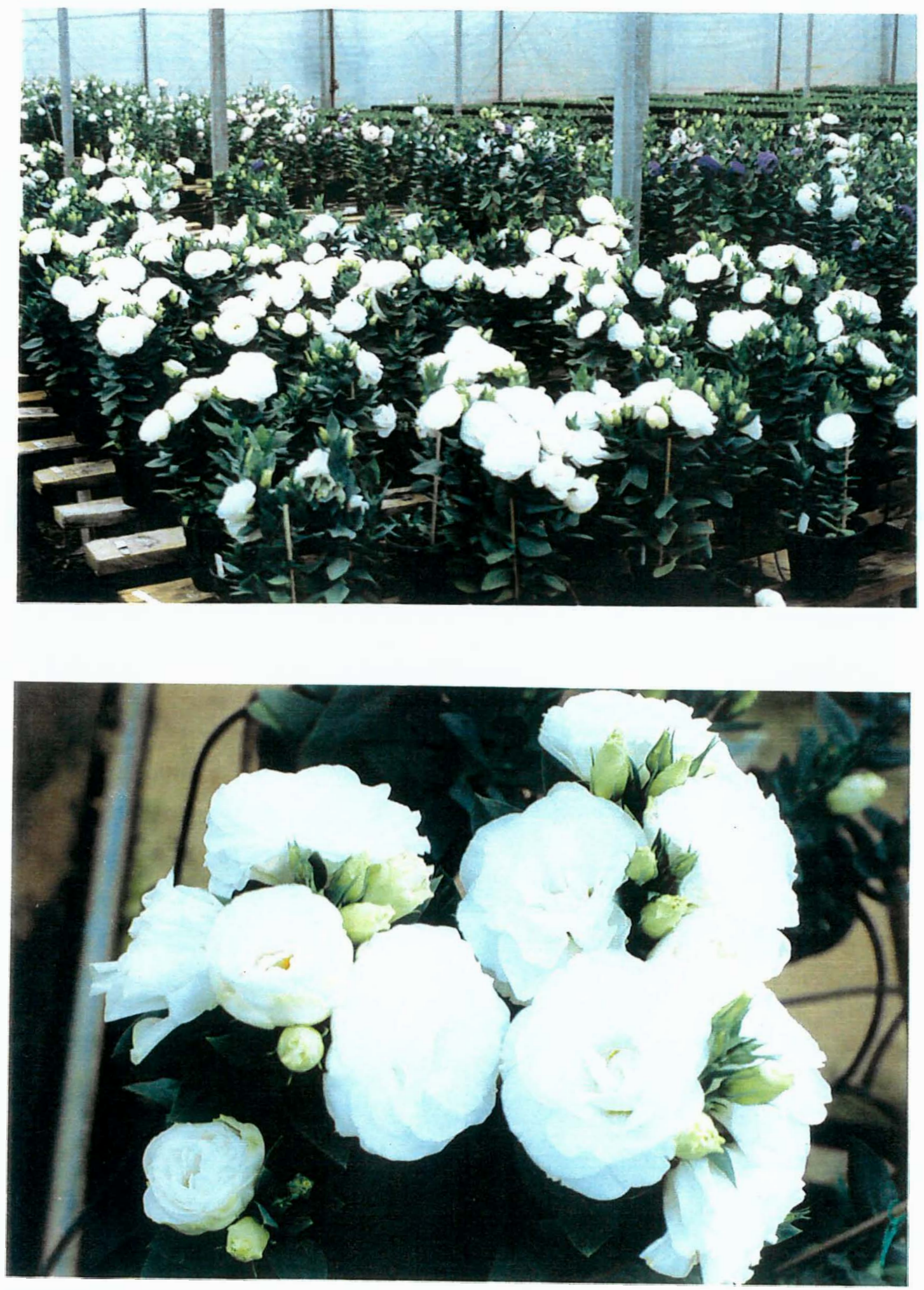

Figura 1. Cultura do lisianthus no ponto de colheita. 
No parâmetro qualidade comercial das plantas produzidas (Tabela 1), o tratamento $0,75{\mathrm{~g} . \mathrm{cm}^{-3}}^{-3}$ apresentou $80 \%$ de seus vasos classificados como plantas tipo 'especial' e $20 \%$ classificados como plantas 'comuns'. Os vasos apresentaram alta qualidade e um aspecto visual bem uniforme, com grande número de flores abertas. De todos os tratamentos analisados, será o que alcançará os melhores preços para comercialização, por apresentar plantas de melhor qualidade.

Tabela 1: Qualidade comercial do lisianthus cultivado em substratos de diferentes densidades. ${ }^{X}$

\begin{tabular}{lccc}
\hline Tratamento & $\begin{array}{c}\text { Plantas de } \\
\text { segunda }\end{array}$ & $\begin{array}{c}\text { Plantas } \\
\text { comuns }\end{array}$ & $\begin{array}{c}\text { Plantas } \\
\text { especiais }\end{array}$ \\
\hline $0,15 \mathrm{~g} \cdot \mathrm{cm}^{-3}$ & $20 \%$ & $60 \%$ & $20 \%$ \\
$0,35 \mathrm{~g} \cdot \mathrm{cm}^{-3}$ & $20 \%$ & $30 \%$ & $50 \%$ \\
$0,55{\mathrm{~g} \cdot \mathrm{cm}^{-3}}^{-3}$ & $0 \%$ & $80 \%$ & $20 \%$ \\
$0,75 \mathrm{~g} \cdot \mathrm{cm}^{-3}$ & $0 \%$ & $20 \%$ & $80 \%$ \\
\hline
\end{tabular}

${ }^{\mathrm{x}}$ Classificação das plantas quanto a qualidade comercial:

Plantas especiais - os vasos apresentam 3 plantas sadias, com 2 ou mais flores por planta, grande número de botões e altura uniforme.

Plantas comuns - os vasos apresentam 1 planta morta ou 3 plantas de altura desuniforme, com poucas flores e um número médio de botões.

Plantas de segunda - os vasos apresentam somente 1 planta, com poucas flores e poucos botões. 

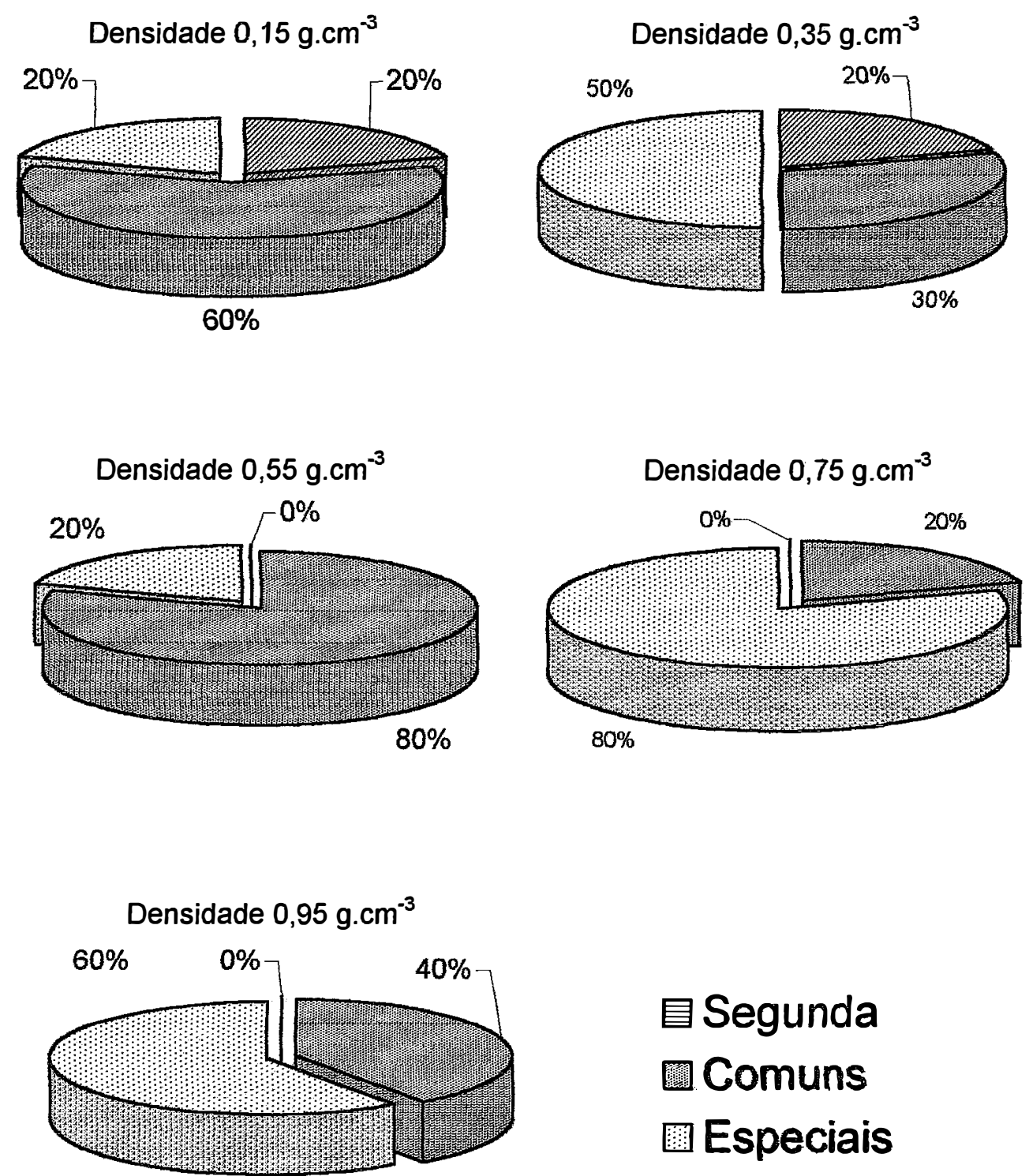

Figura 2: Qualidade comercial de lisianthus cultivado em substratos de diferentes densidades. 
Quando se avaliou o parâmetro características fitotécnicas (Tabela 2), observou-se que $99,67 \%$ de seus vasos estavam floridos, com um grande número de flores e botões por vaso. O produtor classifica vasos com 6 flores abertas como especiais e o tratamento $0,75 \mathrm{~g} \cdot \mathrm{cm}^{-3}$ possuía, em média, 8,64 flores e 38,25 botões.

Tabela 2: Resultados obtidos em características fitotécnicas, quando se avaliou diferentes densidades do substrato, na cultura do lisianthus. $x$

\begin{tabular}{|c|c|c|c|c|c|}
\hline Tratamento $^{\nabla}$ & $\begin{array}{c}0,15 \\
\text { g.cm }\end{array}$ & $\begin{array}{c}0,35 \\
\mathrm{~g} \cdot \mathrm{cm}^{-3}\end{array}$ & $\begin{array}{c}0,55 \\
\text { g. } \mathrm{cm}^{-3}\end{array}$ & $\begin{array}{c}0,75 \\
\mathrm{~g} \cdot \mathrm{cm}^{-3}\end{array}$ & $\begin{array}{c}0,95 \\
\text { g.cm-3 }\end{array}$ \\
\hline NB & $30,78 a b$ & $26,37 \mathrm{~b}$ & $17,28 \mathrm{c}$ & $38,25 a$ & $37,74 \mathrm{a}$ \\
\hline$\%$ VF & $27,83 \mathrm{c}$ & $44,67 b$ & $55,00 \mathrm{~b}$ & 99,67 a & $90,60 a$ \\
\hline NFV & $1,29 b$ & $2,82 a b$ & $3,57 a b$ & 8,64 a & $7,68 \mathrm{a}$ \\
\hline $\mathrm{AP}(\mathrm{cm})$ & $23,00 \mathrm{a}$ & 22,96 a & 23,07 a & $25,53 a$ & $25,01 \mathrm{a}$ \\
\hline $\operatorname{PFPA}(g)$ & 62,57 a & 65,67 a & 57,31 a & 74,16 a & $73,91 a$ \\
\hline $\operatorname{PSPA}(\mathrm{g})$ & $8,43 a$ & $9,25 a$ & $7,82 \mathrm{a}$ & $10,21 a$ & $10,05 a$ \\
\hline PFSR (g) & $33,77 a b$ & $29,33 a b$ & 23,08 b & $37,91 a b$ & $39,56 \mathrm{a}$ \\
\hline PSSR (g) & $7,34 \mathrm{~b}$ & $7,41 \mathrm{~b}$ & $7,27 \mathrm{~b}$ & $7,72 a b$ & $8,49 a$ \\
\hline VSR (mL) & 35,56 a & 28,37 a & $20,53 a$ & $36,21 a$ & $37,88 \mathrm{a}$ \\
\hline
\end{tabular}

Obs: Em cada vaso foram cultivadas 3 plantas. Os dados acima são médias obtidas de vasos.

x Teste de Tukey para as médias de densidade de substrato. Médias horizontais seguidas por letras distintas diferem, entre si, ao nível de 5,00\% de significância.

${ }^{Y}$ Número de botões (NB), porcentagem de vasos floridos (\%VF), número de flores por vaso (NFV), altura das plantas (AP), peso da matéria fresca da parte aérea (PFPA), peso da matéria seca da parte aérea (PSPA), peso da matéria fresca do sistema radicular (PFSR), peso da matéria seca do sistema radicular (PSRS), volume do sistema radicular (VSR). 

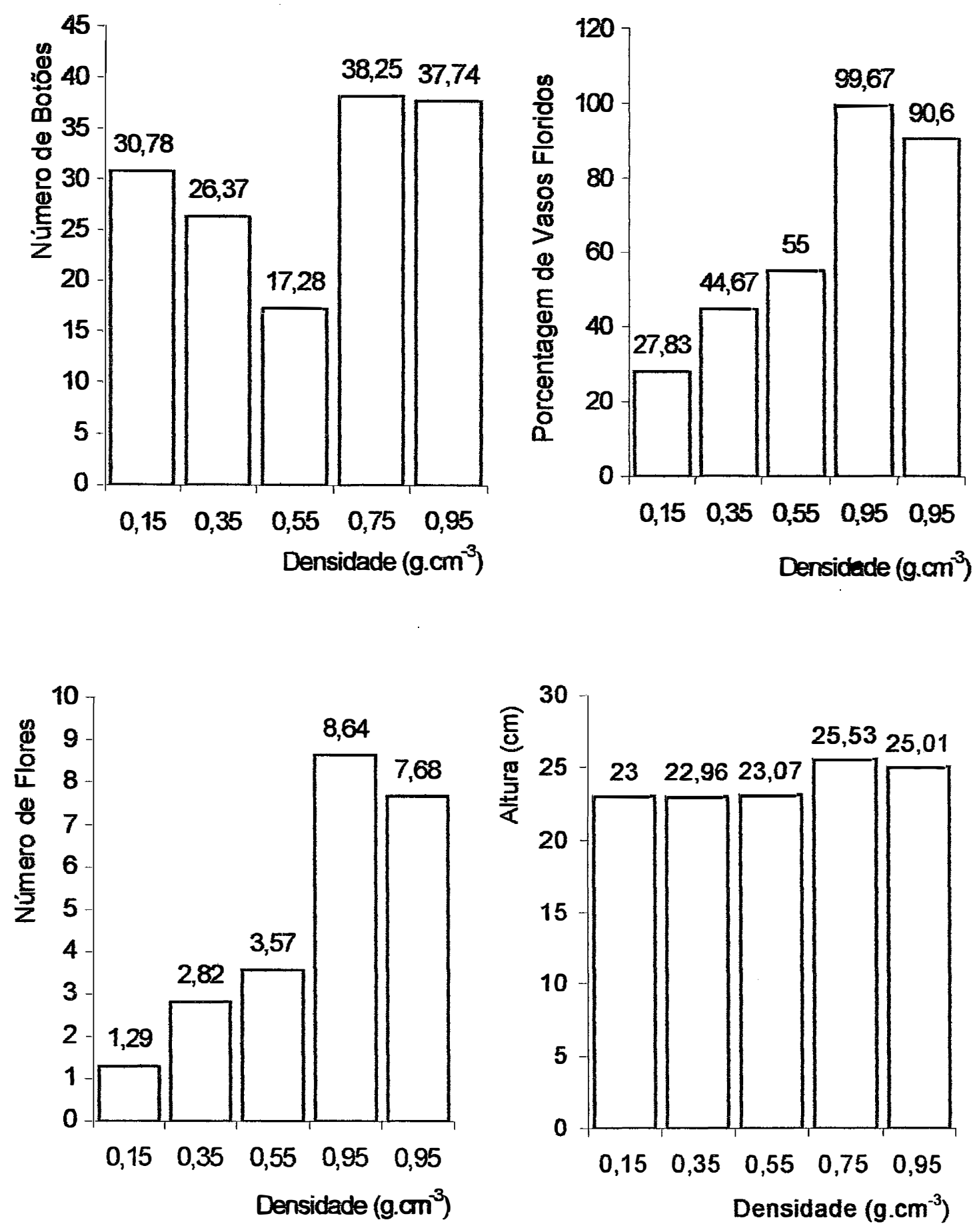

Figura 3: Características fitotécnicas avaliadas no cultivo de lisianthus em diferentes densidades do substrato. 

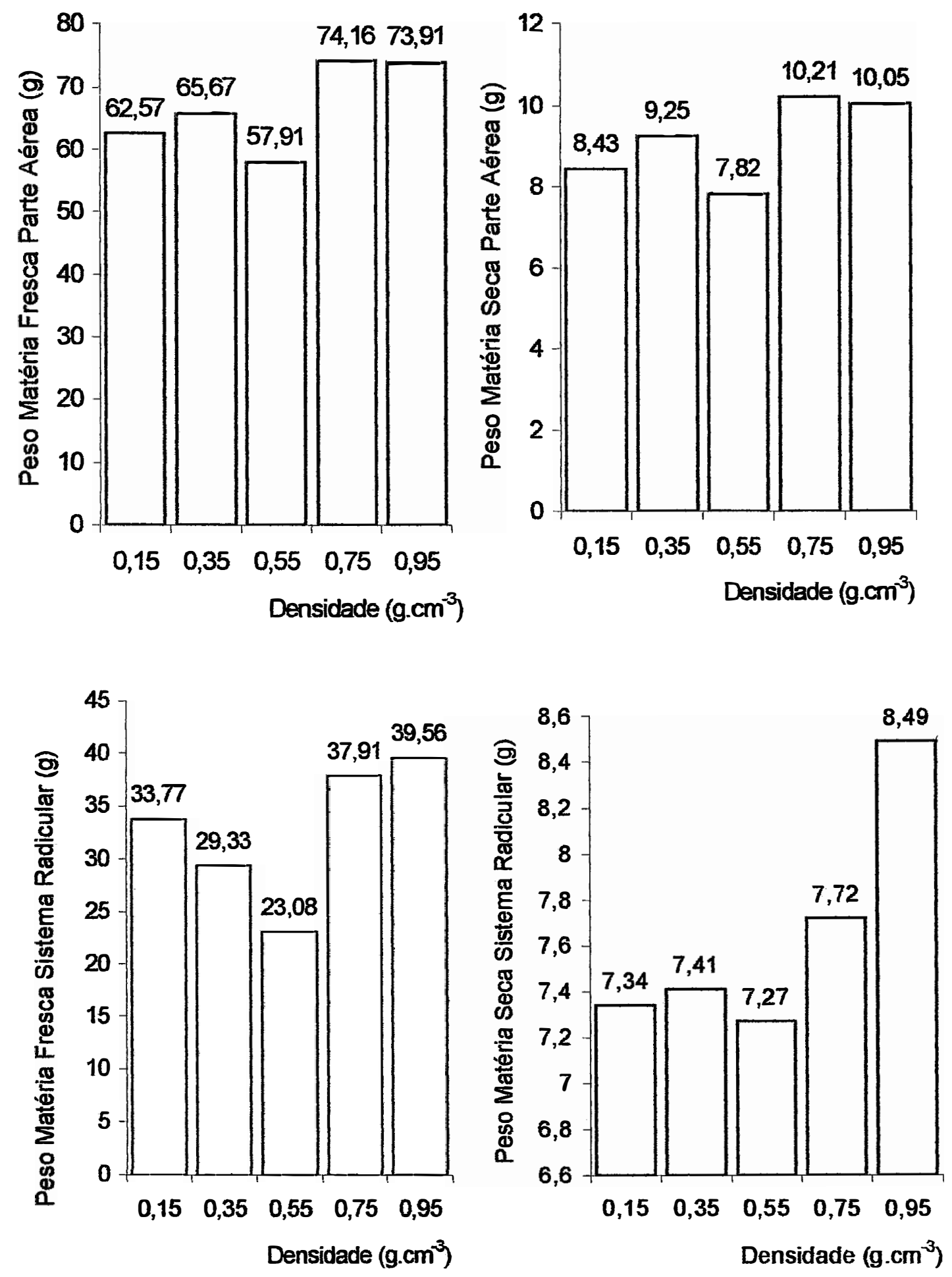

Figura 3: Características fitotécnicas avaliadas no cultivo de lisianthus em diferentes densidades do substrato (continuação). 


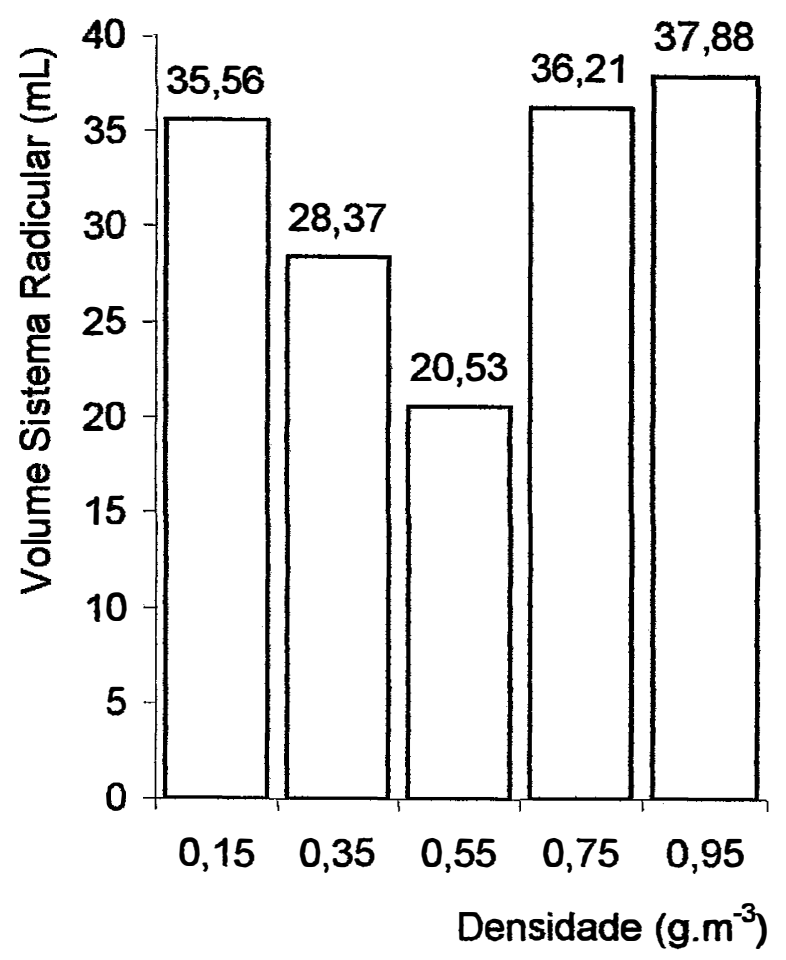

Figura 3: Características fitotécnicas avaliadas no cultivo de lisianthus em diferentes densidades do substrato (continuação).

As flores estavam sadias, sem manchas ou deformações. Os vasos apresentaram-se uniformes, com altura média de $25,53 \mathrm{~cm}$. A parte aérea apresentou peso fresco de 74,16 g e peso seco 10,21 g. O sistema radicular apresentou, em média, peso fresco de $37,91 \mathrm{~g}$, peso seco de $7,72 \mathrm{~g} \mathrm{e} 0$ volume de $36,21 \mathrm{~mL}$.

Com relação as características físicas avaliadas (Tabela 3), o substrato apresentou porosidade e espaço de aeração adequados, e teores de água disponível e água facilmente disponivel um pouco abaixo dos recomendados. 
Tabela 3: Análise física dos substratos utilizados no cultivo de lisianthus.

\begin{tabular}{lcccc}
\hline Tratamento & $\begin{array}{c}\text { Porosidade } \\
\text { total } \\
(\%)\end{array}$ & $\begin{array}{c}\text { Espaço de } \\
\text { aeração } \\
(\%)\end{array}$ & $\begin{array}{c}\text { Água } \\
\text { facilmente } \\
\text { disponivel } \\
(\%)\end{array}$ & $\begin{array}{c}\text { Água } \\
\text { disponivel } \\
(\%)\end{array}$ \\
\hline $0,15 \mathrm{~g} \cdot \mathrm{cm}^{-3}$ & 87,49 & 57,78 & 8,90 & 11,11 \\
$0,35 \mathrm{~g} \cdot \mathrm{cm}^{-3}$ & 83,34 & 40,56 & 10,38 & 13,13 \\
$0,55 \mathrm{~g} \cdot \mathrm{cm}^{-3}$ & 77,60 & 26,93 & 16,36 & 18,75 \\
$0,75 \mathrm{~g} \cdot \mathrm{cm}^{-3}$ & 75,10 & 19,53 & 17,41 & 19,79 \\
$0,95 \mathrm{~g} \cdot \mathrm{cm}^{-3}$ & 72,60 & 12,81 & 23,71 & 26,03 \\
\hline
\end{tabular}

Possui porosidade total de $75,10 \%(\mathrm{v} / \mathrm{v})$, estando de acordo com a porosidade recomendada por Riviere (1980) para substratos, que é de $75 \%$, e próxima a porosidade recomendada por De Boodt \& Verdonck (1972), Goh \& Haynes (1977), Boertje (1983), Rac (1985) e Verdonck \& Gabriëls (1988), que é de $85 \%$ em volume de poros. Verdonck (1983) relata que o aspecto físico mais importante num substrato é a presença de poros que proporcionem aeração adequada, e que sejam capazes de guardar e fornecer água para as plantas. Se a porosidade não for a ideal, muitos dos poros estarão cheios de água, diminuindo o espaço de aeração, tendo como efeito um mal desenvolvimento das plantas

O substrato possuía 19,53\% de espaço ocupado por ar, estando bem próximo ao recomendado por De Boodt \& Verdonck (1972), Goh \& Haynes (1977), Boertje (1983), Rac (1985) e Verdonck \& Gabriëls (1988), que citam que um substrato deve possuir de 20 a $30 \%$ de seu volume ocupado por ar. Boa aeração é uma das características físicas importantes para o 
crescimento de plantas em recipientes (Beardsell et al., 1979). O crescimento das raízes é restringido por uma aeração deficiente (Singh \& Sainju, 1998).

Também apresentou água disponivel de 19,79\% e água facilmente disponivel de $17,41 \%$, estando um pouco abaixo das recomendações de Rac (1985), que cita que um substrato deve ter, no mínimo, $26 \%$ de seu volume ocupado por água, sendo $20 \%$ em água facilmente disponível às plantas.

O tratamento 0,95 g. $\mathrm{cm}^{-3}$ apresentou $60 \%$ de seus vasos com qualidade comercial especial e $40 \%$ dos vasos com qualidade comercial comum (Tabela 1), com plantas uniformes e um grande número de flores abertas.

No parâmetro características fitotécnicas (Tabela 2), este substrato apresentou $90,60 \%$ dos seus vasos floridos, com média de 7,68 flores e 37,74 botões. As flores estavam sadias, sem manchas ou deformações. Os vasos apresentaram-se uniformes, com média de 25,01 cm de altura, 73,91 g de peso fresco da parte aérea e $10,05 \mathrm{~g}$ de peso seco. 0 sistema radicular apresentou-se bem desenvolvido, com um volume de $37,88 \mathrm{~mL}$, peso fresco de $39,56 \mathrm{~g}$ e peso seco de $8,49 \mathrm{~g}$.

Com relação as características físicas avaliadas (Tabela 3), o substrato de densidade $0,95 \mathrm{~g} . \mathrm{cm}^{-3}$ apresentou porosidade total de $72,60 \%$, estando um pouco abaixo dos $75 \%$ recomendados por Riviere (1980). Possuía $12,81 \%$ de espaço de aeração, estando abaixo dos $20 \%$ recomendados por De Boodt \& Verdonck (1972), Goh \& Haynes (1977), Boertje (1983), Rac (1985) e Verdonck \& Gabriëls (1988). Água disponível de $26,05 \%$ e água facilmente disponivel de $23,71 \%$, estão de acordo com Rac (1985), que cita que um substrato deve ter, no mínimo, $26 \%$ de volume ocupado por água, sendo $20 \%$ em água facilmente disponível.

Os tratamentos $0,15,0,35$ e 0,55 g.cm ${ }^{-3}$ apresentaram resultados inferiores nos parâmetros avaliados. 
No parâmetro qualidade comercial das plantas produzidas, os tratamentos 0,15 e $0,35 \mathrm{g.cm}^{-3}$ apresentaram $20 \%$ de seus vasos classificados como plantas de segunda, alcançando os menores preços no mercado varejista, por apresentarem plantas de baixa qualidade. Os tratamentos $0,15{\mathrm{~g} . \mathrm{cm}^{-3}}^{-}$e $0,55 \mathrm{~g} . \mathrm{cm}^{-3}$ apresentaram somente $20 \%$ de seus vasos com qualidade comercial especial, e o tratamento $0,35 \mathrm{~g} \cdot \mathrm{cm}^{-3}$ apresentou $50 \%$ dos vasos com plantas de qualidade especial (Tabela 1 ).

Quando se avaliou o parâmetro características fitotécnicas (Tabela 2), observou-se uma baixa porcentagem de vasos floridos, com baixo número de flores por vaso. Os substratos $0,15,0,35$ e 0,55 g.cm cm $^{-3}$ apresentaram, respectivamente, $27,83 \%, 44,67 \%$ e $55,00 \%$ dos seus vasos floridos e 1,29 , 2,82 e 3,57 flores por vaso. As plantas, dentro do mesmo vaso, apresentaram altura uniforme.

Com relação as características físicas (Tabela 3), os três tratamentos apresentam porosidade total adequada, espaço de aeração elevado, baixos teores de água disponivel e água facilmente disponível.

Ao final do experimento observou-se que:

1. substratos com densidades 0,75 e $0,95 \mathrm{~g} \mathrm{~cm}^{-3}$ apresentaram os melhores resultados nos parâmetros qualidade comercial e características fitotécnicas das plantas produzidas.

2. a cultura do lisianthus se desenvolveu melhor em substratos com porosidade de 72,60 a $75,10 \%$.

3. o lisianthus se desenvolveu melhor em substratos que apresentaram espaço ocupado por ar de 12,81 a 19,53\%.

4. o teor de água do substrato é um fator limitante para o cultivo de lisianthus. Quando se avaliou características ligadas à capacidade do substrato em liberar água para as plantas, pode-se observar que o lisianthus se desenvolveu melhor em condições de água disponivel de 19,79 a $26,03 \%$ e água facilmente disponível de 17,41 a $23,71 \%$. 
5. o bom desenvolvimento do sistema radicular está relacionado ao substrato possuir as características físicas ideais ao desenvolvimento do lisianthus, permitindo uma boa absorção de água e nutrientes e, por conseqüência, um bom desenvolvimento da parte aérea.

6. não se pode generalizar recomendações dadas as características físicas dos substratos para todas as espécies de plantas, pois cada espécie tem suas próprias necessidades.

\section{Segundo experimento}

Quando se avaliou o desempenho de substratos com características físicas adequadas ao cultivo do lisianthus, pode-se observar que, dos quatro substratos analisados, três apresentaram-se adequados ao seu cultivo.

Turfa cultivadora : vermiculita, casca de eucalipto : turfa convencional : areia e a testemunha apresentaram bons resultados nas características fitotécnicas avaliadas, com alta qualidade comercial das plantas produzidas. Já o substrato casca de pínus : húmus de minhoca apresentou-se inadequado ao cultivo de lisianthus.

No parâmetro qualidade comercial das plantas produzidas, os tratamentos turfa cultivadora : vermiculita e testemunha apresentaram $100 \%$ de seus vasos classificados como plantas de alta qualidade, sendo $90 \%$ das plantas classificadas como especiais e $10 \%$ classificadas como plantas comuns (Tabela 4). Plantas produzidas nestes substratos alcançaram os melhores preços para venda, pois vasos classificados como especiais alcançam maiores preços para comercialização. 
Tabela 4: Qualidade comercial do lisianthus cultivado em diferentes substratos. ${ }^{\mathrm{X}}$

\begin{tabular}{lccc}
\hline Tratamento & $\begin{array}{c}\text { Plantas de } \\
\text { segunda }\end{array}$ & $\begin{array}{c}\text { Plantas } \\
\text { comuns }\end{array}$ & $\begin{array}{c}\text { Plantas } \\
\text { especiais }\end{array}$ \\
\hline Turfa cultivadora : vermiculita & $0 \%$ & $10 \%$ & $90 \%$ \\
Casca pínus : Húmus minhoca & $90 \%$ & $10 \%$ & $0 \%$ \\
$\begin{array}{l}\text { Casca eucalipto : turfa } \\
\text { convencional : areia }\end{array}$ & $0 \%$ & $20 \%$ & $80 \%$ \\
Testemunha & $0 \%$ & $10 \%$ & $90 \%$ \\
\hline
\end{tabular}

${ }^{x}$ Classificação das plantas quanto a qualidade comercial:

Plantas especiais - os vasos apresentam 3 plantas sadias, com 2 ou mais flores por planta, grande número de botões e altura uniforme.

Plantas comuns - os vasos apresentam 1 planta morta ou 3 plantas de altura desuniforme, com poucas flores e um número médio de botões.

Plantas de segunda - os vasos apresentam somente 1 planta, com poucas flores e poucos botões. 
Turfa cultivadora + vermiculita

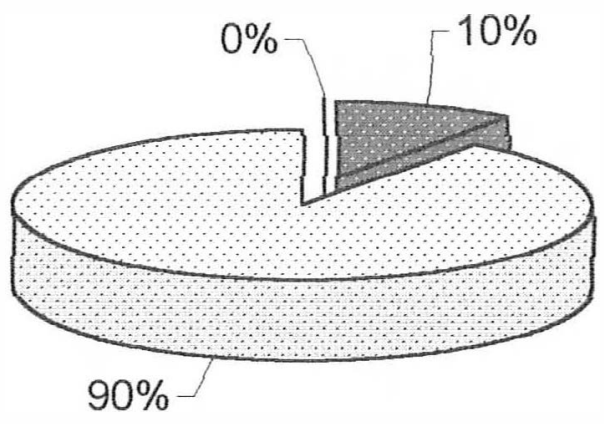

Casca eucalipto + turfa convencional + areia

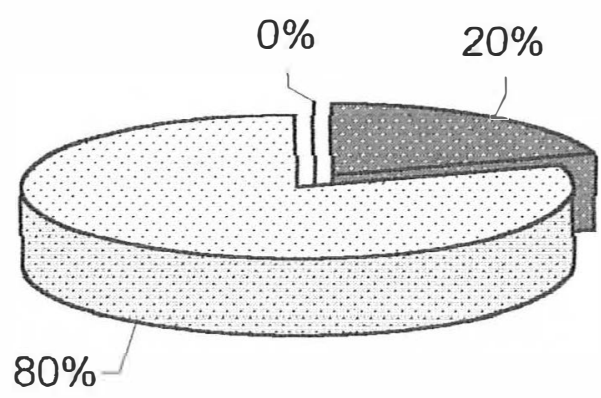

Casca pínus + húmus de minhoca

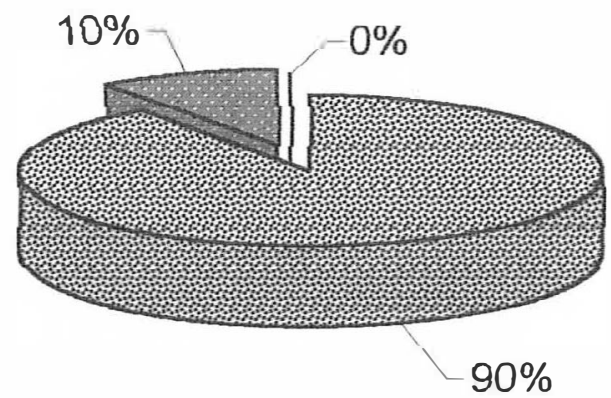

Turfa cultivadora + vermiculita

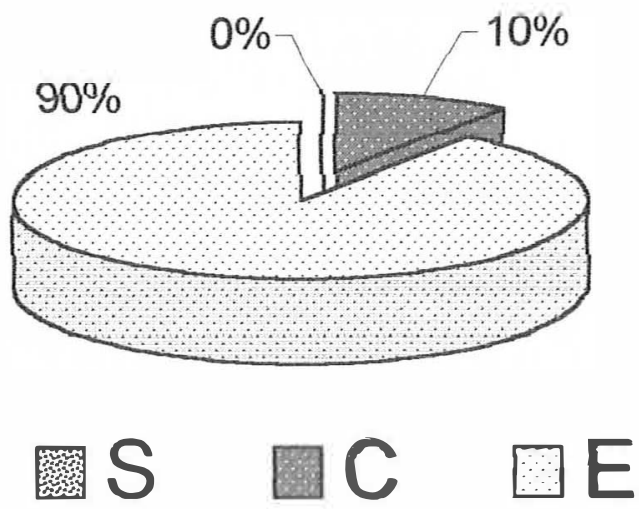

Figura 4: Qualidade comercial do lisianthus cultivado em diferentes substratos, sendo E - Plantas especiais, C - Plantas comuns, S - Plantas de segunda. 
O substrato casca de eucalipto : turfa convencional : areia também apresentou bons resultados, sendo $80 \%$ de seus vasos classificados como plantas especiais e $20 \%$ classificadas como plantas comuns.

Já o substrato casca de pinus : húmus de minhoca não apresentou plantas de valor comercial, sendo $90 \%$ de seus vasos classificados como plantas de segunda e $10 \%$ classificadas como plantas comuns.

Quando se avaliou o parâmetro características fitotécnicas (Tabela 05), observou-se que, plantas cultivadas nos substratos turfa cultivadora : vermiculita, testemunha e casca de eucalipto : turfa convencional : areia apresentaram, respectivamente, $97,83 \%, 95,00 \%$ e $99,67 \%$ de seus vasos floridos, com um grande número de flores $(6,80 ; 6,40$ e 6,00$)$ e botões $(30,00 ; 37,00$ e 44,00), sendo classificadas como plantas de alta qualidade. As flores não apresentavam deformações ou manchas. Os vasos possuíam três plantas vivas, sadias, de altura uniforme dentro do mesmo vaso $(25,60$; 30,40 e $32,00 \mathrm{~cm}$ ), com folhas sem manchas, de coloração intensa e bem desenvolvidas (peso fresco da parte aérea de 201,80; 204,20 e 207,20 g e peso seco de 34,00; 38,20 e 34,80 g).

Quando se avaliou o sistema radicular das plantas produzidas, pode-se observar que os substratos turfa cultivadora : vermiculita, testemunha e casca de eucalipto : turfa convencional : areia apresentaram, respectivamente, peso fresco de 60,$40 ; 28,60$ e $38,40 \mathrm{~g}$, peso seco de 17,$87 ; 11,38$ e $11,82 \mathrm{~g}$, e volume de 63,$20 ; 39,80$ e $52,80 \mathrm{~mL}$. O bom desenvolvimento do sistema radicular permitiu uma maior absorção de água e nutrientes e, como conseqüência, um maior desenvolvimento da parte aérea. 
Tabela 5: Resultados obtidos em características fitotécnicas, quando se avaliou o uso de diferente substratos no cultivo de lisianthus. ${ }^{x}$

\begin{tabular}{lcccc}
\hline Tratamento $^{Y}$ & TU $^{z}$ & CP & CE & TE \\
\hline NB & $30,0 \mathrm{~b}$ & $8,6 \mathrm{c}$ & $44,0 \mathrm{a}$ & $37,0 \mathrm{ab}$ \\
\%VF & $97,83 \mathrm{a}$ & $34,67 \mathrm{~b}$ & $95,00 \mathrm{a}$ & $99,67 \mathrm{a}$ \\
NFV & $6,8 \mathrm{a}$ & $0,2 \mathrm{~b}$ & $6,0 \mathrm{a}$ & $6,4 \mathrm{a}$ \\
AP $(\mathrm{cm})$ & $29,6 \mathrm{a}$ & $21,0 \mathrm{~b}$ & $32,0 \mathrm{a}$ & $30,4 \mathrm{a}$ \\
$\operatorname{PFPA}(\mathrm{g})$ & $201,8 \mathrm{a}$ & $42,0 \mathrm{~b}$ & $207,2 \mathrm{a}$ & $240,2 \mathrm{a}$ \\
$\operatorname{PSPA}(\mathrm{g})$ & $34,0 \mathrm{a}$ & $12,2 \mathrm{~b}$ & $34,8 \mathrm{a}$ & $38,2 \mathrm{a}$ \\
$\operatorname{PFSR}(\mathrm{g})$ & $60,4 \mathrm{a}$ & $12,8 \mathrm{~b}$ & $38,4 \mathrm{ab}$ & $28,6 \mathrm{~b}$ \\
$\operatorname{PSSR}(\mathrm{g})$ & $17,87 \mathrm{a}$ & $1,40 \mathrm{c}$ & $11,82 \mathrm{~b}$ & $11,38 \mathrm{~b}$ \\
$\operatorname{VSR}(\mathrm{mL})$ & $63,2 \mathrm{a}$ & $11,0 \mathrm{c}$ & $52,8 \mathrm{ab}$ & $39,8 \mathrm{~b}$ \\
\hline
\end{tabular}

${ }^{x}$ Teste de Tukey para as médias de densidade de substrato. Médias horizontais seguidas por letras distintas diferem, entre si, ao nivel de 5,00\% de significância.

${ }^{\mathrm{Y}}$ Número de botões (NB), porcentagem de vasos floridos (\%VF), número de flores por vaso (NFV), altura das plantas (AP), peso da matéria fresca da parte aérea (PFPA), peso da matéria seca da parte aérea (PSPA), peso da matéria fresca do sistema radicular (PFSR), peso da matéria seca do sistema radicular (PSRS), volume do sistema radicular (VSR).

${ }^{\mathrm{Z}}$ Substratos avaliados: Turfa cultivadora : vermiculita (TU), Casca de pínus : húmus de minhoca (CP), Casca de eucalipto : turfa convencional : areia (CE), Testemunha (TE). 

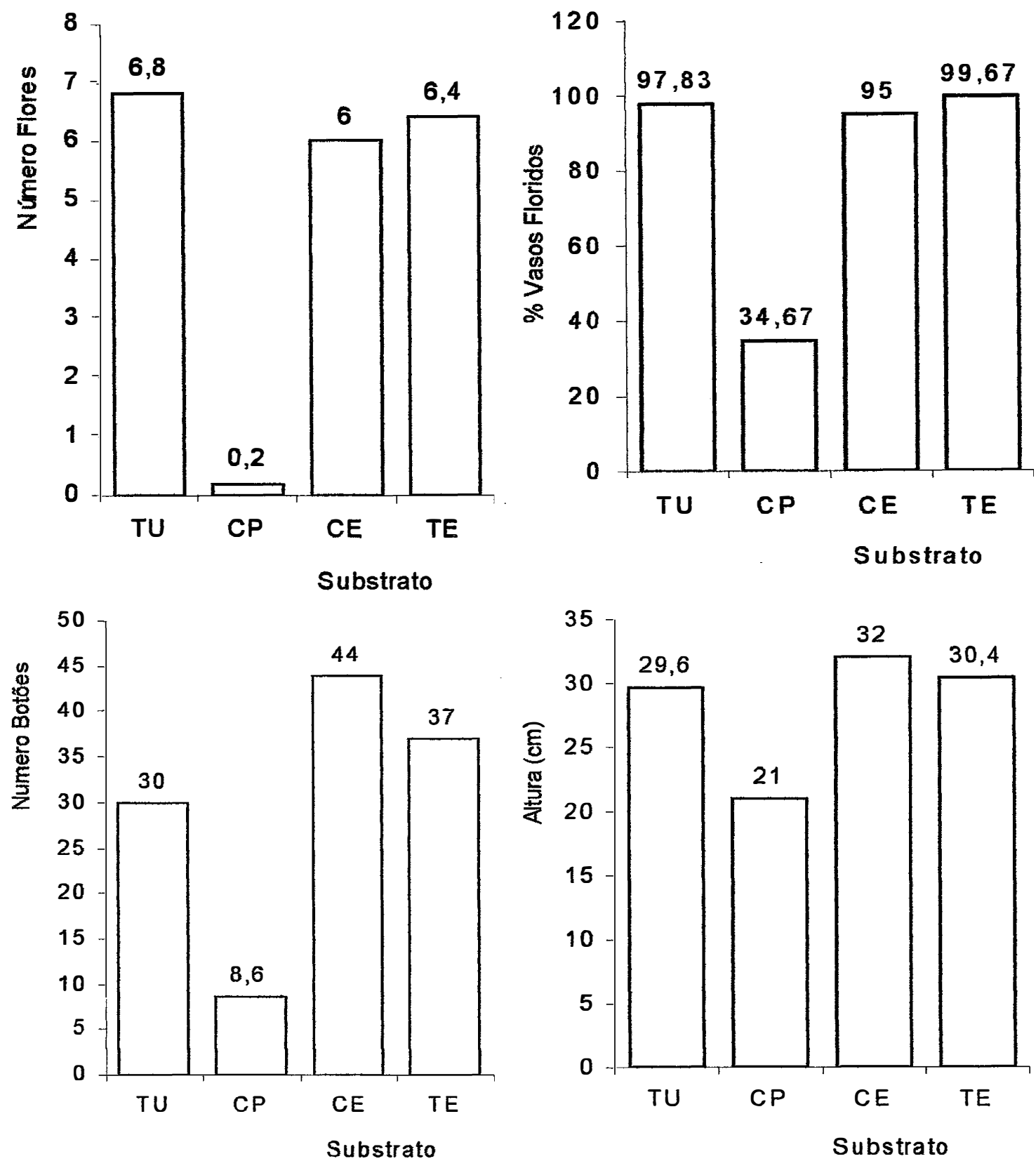

Figura 5: Características fitotécnicas avaliadas no cultivo do lisianthus em diferente substratos, sendo Turfa culteivadora : vermicuilita (TU), Casca de pínus : húmus de minhoca (CP), Casca de eucalipto ; turfa convencional : areia (CE), Testemunha (TE). 

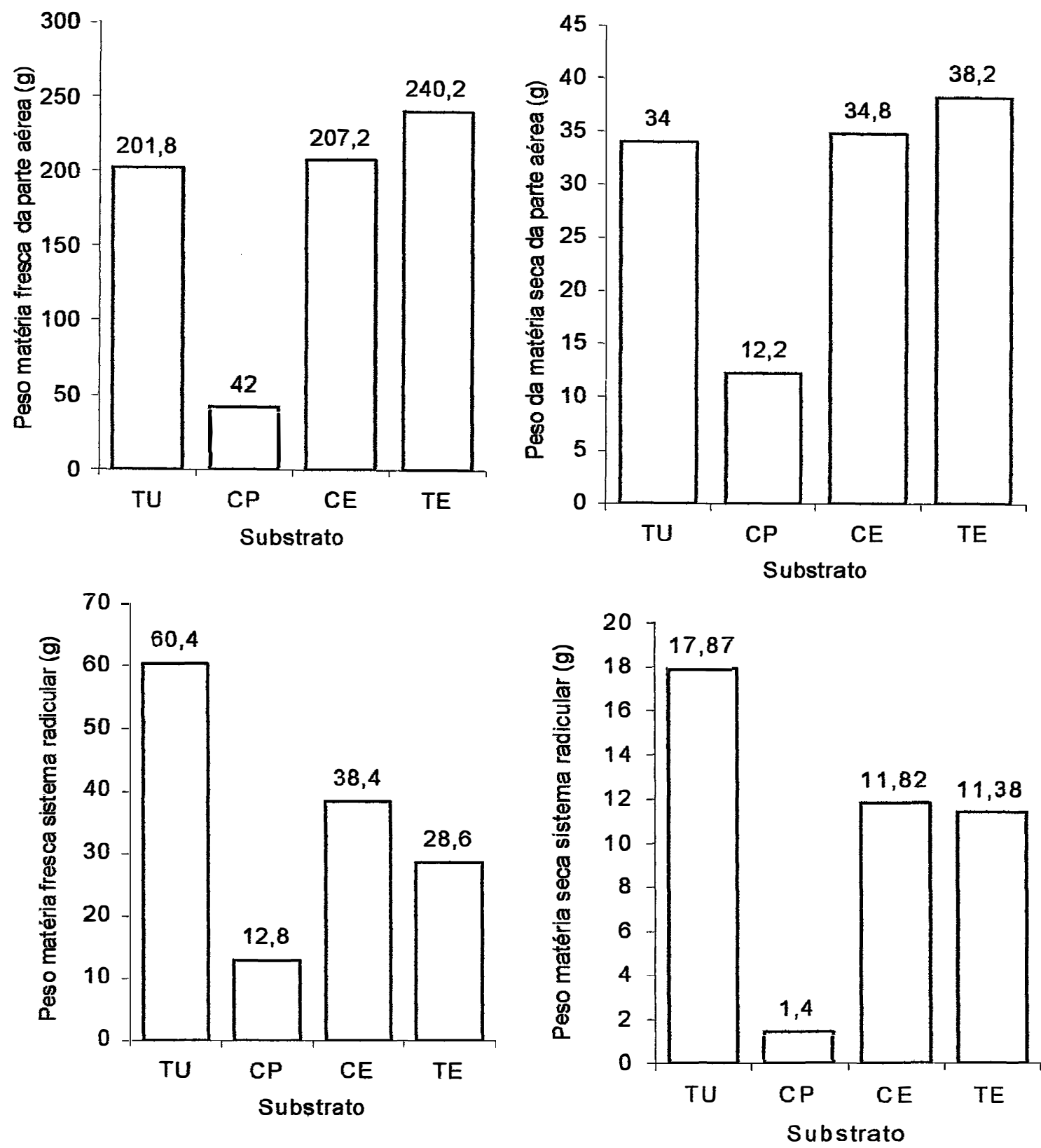

Figura 5: Características fitotécnicas avaliadas no cultivo do lisianthus em diferente substratos, sendo Turfa cultivadora : vermiculita (TU), Casca de pínus : húmus de minhoca (CP), Casca de eucalipto : turfa convencional : areia (CE), Testemunha (TE) (continuação). 


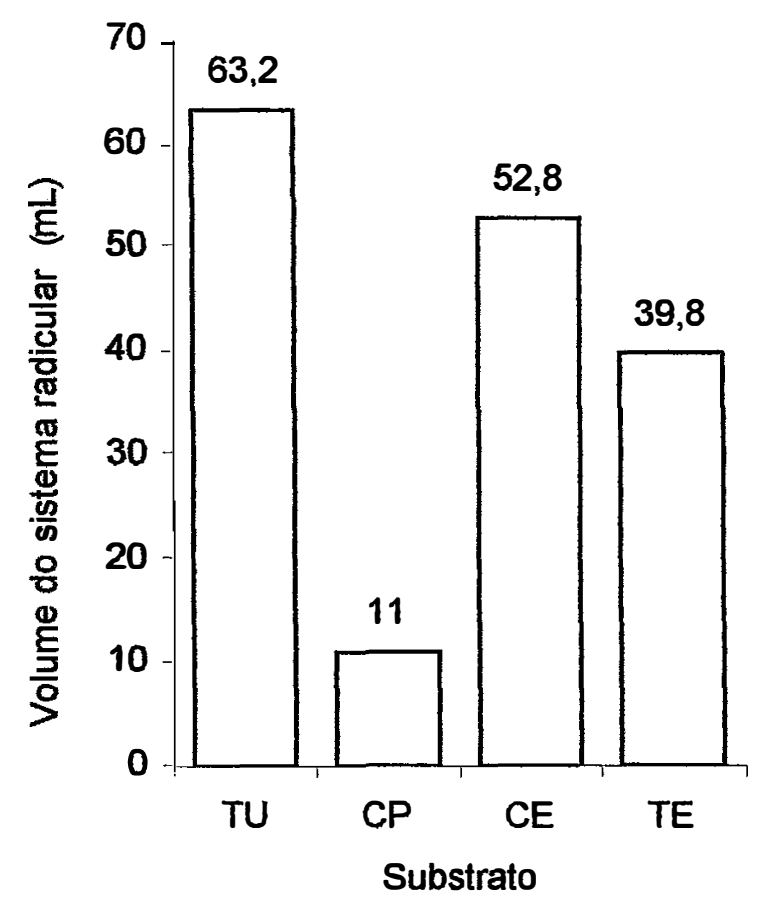

Figura 5: Características fitotécnicas avaliadas no cultivo do lisianthus em diferente substratos, sendo Turfa cultivadora : vermiculita (TU), Casca de pínus : húmus de minhoca (CP), Casca de eucalipto : turfa convencional : areia (CE), Testemunha (TE) (continuação).

O substrato casca de pínus : húmus de minhoca não se apresentou adequado ao cultivo de lisianthus. $O$ tratamento apresentou somente $34,67 \%$ dos seus vasos floridos, com média de 0,20 flores e 8,60 botões. Pode-se observar um grande número de vasos com plantas mortas, pequenas (21,00 cm de altura), pouco desenvolvidas (peso fresco da parte aérea de $42,00 \mathrm{~g}$ e peso seco $12,20 \mathrm{~g}$ ), com folhas pequenas e deformadas. 
Tais fatos estão relacionados ao mal desenvolvimento do sistema radicular (peso fresco de $12,80 \mathrm{~g}$, peso seco de $1,40 \mathrm{~g}$ e volume de $11,00 \mathrm{~mL}$ ), provando que, não somente as características físicas dos substratos são importantes para o bom desenvolvimento da cultura, mas também as características químicas inerentes aos materiais usados na composição do substrato, influenciam o crescimento da cultura.

Devido aos resultados apresentados, suspeita-se que o substrato casca de pínus : húmus de minhoca deve apresentar substâncias químicas que interferem no crescimento e desenvolvimento da cultura do lisianthus e que podem ser analisados em pesquisas posteriores, pois não era o objetivo deste experimento analisar características químicas dos materiais utilizados como componentes de substratos.

\section{CONCLUSÕES}

Um substrato adequado ao cultivo de lisianthus (Eustoma grandiflorum) deve apresentar porosidade de 72,60 a $75,10 \%$, espaço poroso de 12,81 a $19,53 \%$, água disponivel de 19,79 a $26,03 \%$ e água facilmente disponivel de 17,41 a $23,71 \%$.

Os substratos húmus de minhoca : vermiculita : perlita, casca de eucalipto : turfa convencional : areia e testemunha apresentaram-se adequados ao cultivo de lisianthus.

\section{REFERÊNCIAS BIBLIOGRÁFICAS}

\section{BALLESTER-OLMOS, J.F. Substratos para el cultivo de plantas} ornamentales. Valencia: Instituto Valenciano de Investigaciones Agrarias, 1992. 44p. (Hojas Divulgadoras, 11) 
BEARDSELL, D.V.; NICHOLS, D.G.; JONES, D.L. Physical properties of nursery potting-mixtures. Scientia Horticulturae, v.11, p.1-8, 1979.

BOERTJE, G.A. Physical laboratory analyses of potting composts. Acta Horticulturae, n.150, p.47-50, 1983.

BUNT, A.C. Some physical properties of pot-plant composts and their effect on plant growth. Bulky physical conditioners. Plant and Soil, n.4, p.322332, 1961.

BURÉS, S. ; MARTINEZ, F.X.; PEREZ, N. Monte Carlo computer simulation in horticulture: A model for container media characterization. Acta Horticulturae, n.294, p.207-214, 1991.

CASTRO, E.M.; DE ALVARENGA, A.A.; GOMIDE, M.B.; et. al. Efeito de substratos na produção de mudas de calabura (Muntingia calabura). Ciência e Agrotecnologia, v.20, n.3, p.336-370, 1996.

De BOODT, M.; VERDONCK, O. The physical properties of the substrates in floriculture. Acta Horticulturae, n.26, p.37-44, 1972.

GOH, K.M.; HAYNES, R.J. Evaluation of potting media for comercial nursery production of container grow plants: 1- Physical and chemical characteristics of soil and soiless media and their constituents. New Zealand Journal of Agricultural Research, v.20, p.363-370, 1977.

GONÇALVES, A.L. Características de substratos. In: SIMPÓSIO BRASILEIRO DE FLORICULTURA E PLANTAS ORNAMENTAIS, 
Maringá, 1992. Manual de Floricultura. Maringá: SBFPO, 1992. p.4452.

GRIESBACH, R.J. Correlation of $\mathrm{pH}$ and light intensity on flower color in potted Eustoma grandiflorum Grise. HortScience, v.27, n.7, p.817-818, 1992.

GÜNTHER, J. Analytics of substrates and problems by transmitting the results into horticultural practice. Acta Horticulturae, n.150, p.33-40, 1983.

HARBAUGH, B.K.; WOLTZ, S.S. Eustoma quality is adversely affected by low pH of root medium. HortScience, v.26, n.10, p.1279-1280, 1991.

HARTMANN, H.T.; FLOCKER, W.J.; KOFRANEK, A.M. Plant Science growth, development, and utilization of cultivated plants. New York: Prentice-hall, Inc, 1981. 637p.

OHKAWA, K.; KANO, A.; KANEMATSU, K.; KORENAGA, M. Reversal of heat-induced rosetting in Eustoma grandiflorum with low temperatures. Scientia Horticulturae, v.48, p.171-176, 1991.

PERGOLA, G.; FARINA, E. Giornata di studio sul lisianthus (Eustoma Grandiflorum (Raf.) Shinn.). Sanremo: Istituto Sperimentale per la Floricotura, 1989. 133p.

RAC, D. P. Disponibité en eau des substrats horticoles. Revue Suisse de Viticulture Arboriculture Horticultural. v.17, n.3, p.177-178, Mai/Juin. 1985. 
RIVIERE, L. M. Importance des caractéristiques physiques dans le choix des substrats pour les cultures hors sol. Revue Horticole. v.209, p.23-27, Sep 1980.

RUBINO, D.B. Inheritance of esterase, diaphorase, and glicose-6-phosphate isomerase in lisianthus. HortScience, v.28, n.6, p.661-663, 1993.

SINGH, B.P.; SAINJU, U.M. Soil physical and morphological properties and root growth. HortScience, v.33, n.6, p.966-971, 1998.

STARMAN, T.W. Lisianthus growth and flowering responses to uniconazole HortScience, v.26, n.2, p.150-152, 1991.

TERÉS; V.; ARRIETA, V.; ROZAS, M. A method for evaluation of air volumes in substrates. Acta Horticulturae, n.401, p.41-47, 1995.

VERDONCK, O. ; VLEESCHAUWER, D. ; De BOODT, M. The influence of the substrate to plant grow'h. Acta Horticulturae, n.126, p.251-258, 1981.

VERDONCK, 0 . New developments in the use of graded perlite in horticultural substrates. Acta Horticulturae, n.150, p.575-581, 1983.

VERDONCK, O.; GABRIËLS, R. Summary and discussion session 'standardization of analytical methods'. Acta Horticulturae, n.221, p.443444, 1988.

WHIPKER, B.E.; EDDY, R.T.; HAMMER, P.A. Chemical growth retardant application to lisianthus. HortScience, v.29, n.11, p.1368, 1994. 
WILSON, G.C.S. The physico-chemical and physical properties of horticultural substrates. Acta Horticulturae, n.150, p.19-32, 1983. 
5 AVALIAÇÃO DE DIFERENTES SUBSTRATOS NO CULTIVO DE VIOLETA AFRICANA (Saintpaulia ionantha WendI.) 


\section{AVALIAÇÃO DE DIFERENTES SUBSTRATOS NO CULTIVO DE VIOLETA AFRICANA (Saintpaulia ionantha Wendl.)}

Resumo: Dois experimentos com a cultura da violeta (Saintpaulia ionantha) foram conduzidos na propriedade dos produtores Rene e Etienne Groot, no município de Holambra, São Paulo. No primeiro experimento foram avaliadas as características físicas adequadas ao seu cultivo, observando-se que o substrato de densidade $0,75 \mathrm{~g} . \mathrm{cm}^{-3}$ apresentou os melhores resultados nos parâmetros avaliados. A violeta se desenvolveu bem em substrato com $75,10 \%$ de porosidade total, $19,53 \%$ de espaço ocupado por ar, $26,03 \%$ de água disponível e $23,71 \%$ de água facilmente disponível. Num segundo experimento analisou-se diferentes misturas de materiais que possuiam as características adequadas à cultura e observou-se que os substratos turfa convencional : casca de eucalipto : areia, húmus de minhoca : vermiculita : areia, casca de pinus : húmus de minhoca, turfa cultivadora : vermiculita e os substrato comerciais da Eucatex, à base de turfa, e Vida Verde - Substrato para Violeta, são indicados no cultivo de violeta.

Palavras-chave: violeta africana, Saintpaulia ionantha, substrato, análise física 


\section{EVALUATION OF DIFFERENT SUBSTRATES ON AFRICAN VIOLET (Saintpaulia ionantha Wendl.) GROWTH}

Summary: Two experiments on African violet (Saintpaulia ionantha) culture were conducted in the ornamental plant grower's property, in Holambra, Sao Paulo. The physical characteristics suitable for the cultivation of this plant were evaluated and it was observed that the substrate presenting $0.75 \mathrm{~g} \mathrm{~cm}^{-3}$ density showed the best results for the evaluated parameters. African violet developed well in the following conditions: $75.10 \%$ total porosity, $19.53 \%$ air space, $26.03 \%$ available water and $23.71 \%$ easily available water. Different mixtures of materials, which had physical characteristics suitable for the culture, were analyzed in a second experiment and conventional peat : eucalyptus bark: sand, earthworm humus : vermiculite : sand, pine bark : earthworm humus, cultivated peat : vermiculite, other commercial substrates ("Eucatex", made from peat, and "Vida Verde - substrate for African violet"), showed to be adequate for African violet cultivation.

Key words: african violet, Saintpaulia ionantha, substrate, physical analysis 


\section{INTRODUÇÃO}

No clima empresarial altamente competitivo e internacional da floricultura, produtores perceberam a importância de melhorar a qualidade de seus produtos para permanecerem competitivos (Prince et al., 1990). Nos últimos anos ocorreram grandes mudanças nas técnicas de produção de flores e plantas ornamentais, e cultivos que eram feitos em solos mudaram para cultivo em recipientes (Gabriëls,1995). O cultivo de plantas sem solo permite aumento de produção de biomassa, regularização do hábito de crescimento e florescimento, aumento da qualidade e maior facilidade de organizar e programar a produção (Lemaire, 1995 ).

A nível internacional, a indústria de substratos vem se tornando cada vez mais forte, devido ao crescente interesse pela produção vegetal em ambientes protegidos (Gabriëls \& Verdonck, 1991). Substratos artificiais são usados em cultivos em estufas (Evans, 1996), sendo uma das prioridades de produtores de mudas e plantas envasadas (Fitzpatrick et al., 1998).

A violeta africana (Saintpaulia ionantha Wendl.) é uma planta envasada muito cultivada no Brasil pela delicadeza e colorido de suas flores. Pertencente a família Gesneriaceae, é uma espécie florífera perene, da qual se originaram milhares de híbridos comerciais. É uma das mais populares plantas de interior. Nos últimos anos foram obtidas novas variedades com flores mais duradouras que a original, encontrada, em 1892, pelo Barão Walter von Saint Paul, nas montanhas de Usambara, Leste da África (Pasqual et al., 1996). No Brasil os híbridos comercializados são originários do Japão e Estados Unidos (Tombolato et al., 1993), com flores simples ou dobradas, de cores branca, rosa, roxo, azul ou bicolor, que florescem o ano todo e duram de 7 a 15 dias (Bianchini \& Pantano, 1974).

Violetas devem ser plantadas em substratos porosos, ricos em matéria, com boa drenagem (Bianchini \& Pantano, 1974). O substrato tem como 
função dar sustentação as plantas, apoiando o crescimento das raízes, fornecendo água e ar em quantidades adequadas (Singh \& Sainju, 1998).

Atualmente são usados diferentes substratos, dependendo das necessidades da espécie a ser cultivada. Existem substratos já preparados, com diferentes composições, que podem ser encontrados no comércio (Ballester-Olmos, 1992). Os substratos, adquiridos no comércio ou elaborados pelos próprios produtores, devem combinar condições físicas e químicas favoráveis, que permitam automação de programas de adubação e irrigação, padronização da produção, colheitas uniformes e redução de custos (Verdonck et al., 1981).

As condições que se buscam em substratos de boa qualidade são possuir propriedades físicas e químicas conhecidas e constantes; baixa densidade, porém firme e consistente; deve possuir adequadas capacidade de retenção de água, aeração e drenagem; elevada capacidade de troca de cátions; não deve alterar propriedades físicas e químicas quando submetido a esterilização ou armazenamento; deve ser livre de pragas, doenças e plantas daninhas; inodoro; não deve ser salino, nem conter substâncias tóxicas; não deve ser nem muito alcalino, nem muito ácido. Deve ser uniforme; de fácil manuseio; adequado ao cultivo de várias espécies; disponível em grandes quantidades e à baixo custo. É dificilmente encontrar um material que sozinho, atenda a todas essas exigências, para tanto são feitas misturas de materiais (Unver, 1991; Kämpf, 1993 e Strigheta et al., 1997).

Dependendo das características das matérias-primas podem-se fazer substratos com as quantias desejadas de ar e água (Verdonck et al., 1983). Vários componentes tem sido testados como substratos, avaliando-se a viabilidade de uso de materiais (Cull, 1981) que facilitem a utilização de sistemas automatizados de produção (Gabriëls, 1995). Günther (1983) ressalta que um controle rígido dos componentes e dos substratos comerciais 
deve ser evidente, mas, segundo Gonçalves (1992), no Brasil, infelizmente ainda não há uma legislação que regulamente tal comércio.

Para que haja um controle da qualidade dos substratos comercializados no Brasil é necessário, inicialmente, que se faça sua análise. Análises físicas feitas em laboratório são mais precisas do que as feitas visualmente. As análise físicas devem seguir uma metodologia unificada, oferecendo vantagens como os resultados poderem ser analisados e comparados à especificações padrões (Boertje, 1983).

A caracterização de um substrato começa na análise da sua relação arlágua. Como em solos, esta análise é feita pela curva de tensão de água (De Boodt \& Verdonck, 1972). As tensões usadas para substratos são mais baixas do que as usadas em solos, porque em recipientes as plantas são cultivadas em condições de umidade muito mais altas (Verdonck, 1983).

Da curva de tensão de água se obtém dados como (De Boodt \& Verdonck, 1972):

- porosidade total - corresponde a umidade volumétrica das amostras quando submetidas a uma tensão de $0 \mathrm{~cm}$.

. espaço de aeração - é a porcentagem de ar, em volume, após a drenagem do excesso de água do substrato. Corresponde a diferença entre os pontos de tensão 0 e $10 \mathrm{~cm}$.

. água disponivel - é a diferença entre o volume de água à $10 \mathrm{~cm}$ de tensão e o volume de água à $100 \mathrm{~cm}$ de tensão.

. água facilmente disponivel - é a quantidade de água retida entre 10 e $50 \mathrm{~cm}$ de tensão.

A caracterização física dos substratos dá informações sobre a distribuição de sólidos, água e ar, que podem ser usadas para estabelecer o manejo da irrigação (Terés et al., 1995). Propriedades físicas mudam durante o cultivo, devido ao crescimento do sistema radicular da planta, a degradação 
da estrutura, a reestruturação de partículas e a processos de mineralização (Burés et al., 1991).

Devido as condições restritas para o desenvolvimento de plantas em recipientes, diversos pesquisadores, no mundo todo, tem procurado estabelecer propriedades ideais de um substrato. Observando-se que os resultados obtidos no exterior não se adequavam as condições do Brasil, este trabalho teve como objetivos avaliar as necessidades especificas da violeta (Saintpaulia ionantha Wendl.), com relação a características físicas dos substratos, e elaborar substratos que apresentem as características físicas adequadas à cultura.

\section{MATERIAL E MÉTODOS}

O estudo com a cultura da violeta foi dividido em três fases distintas. Na primeira fase montou-se um experimento, em casa de vegetação, onde se avaliou características físicas adequadas ao seu cultivo. Numa segunda fase foram elaborados 136 diferentes substratos e suas características físicas foram determinadas. Numa terceira fase montou-se um novo experimento onde, dos 136 substratos analisados, foram selecionados quatro substratos, que apresentavam características físicas adequadas à cultura.

\section{Primeira fase - Primeiro experimento}

O experimento foi conduzido na propriedade dos Eng $\stackrel{\text { os }}{\text { Agrônomos }}$ Rene Groot e Etienne Groot, produtores de plantas ornamentais, no municipio de Holambra, estado de São Paulo.

O experimento foi montado no dia 30 de janeiro de 1998. O cultivo foi feito em casa de vegetação climatizada, com sistemas de aquecimento, 
ventilação, controle de luminosidade, irrigação, fertilização, medição de condutividade elétrica e $\mathrm{pH}$. Seguiu-se o manejo usualmente dado pelo produtor para a cultura.

O delineamento experimental adotado foi o inteiramente casualizado com cinco tratamentos, vinte plantas por parcela e cinco repetições, perfazendo um total de cem plantas por tratamento, e quinhentas plantas no total.

Os tratamentos constaram de misturas de casca de arroz carbonizada e areia, as quais foram lavadas e secas em estufa por 72 horas a $60^{\circ} \mathrm{C}$, até peso constante. A areia foi previamente peneirada em peneira $n^{0} 10$ da ABNT. Os tratamentos se diferenciaram na proporção dos componentes; de tal forma que se obtivessem substratos com densidades 0,$15 ; 0,35 ; 0,55 ; 0,75$ e $0,95 \mathrm{~g} \cdot \mathrm{cm}^{-3}$.

Foram utilizadas mudas da variedade comercial 'Inga', acondicionadas em bandejas plásticas, com 5 semanas e de 7 a 9 folhas. Plantou-se uma muda por vaso, estando esta centralizada no vaso, sendo o plantio idêntico ao feito pelo produtor. Usou-se vasos plásticos $n^{0} 11$, com capacidade de $500 \mathrm{~cm}^{3}$, já contendo os substratos em estudo.

A primeira irrigação foi feita após o plantio. Junto com a água de irrigação foi aplicado 1,0 grama de Manzate por litro de água, utilizando-se, ao todo, 10,0 litros de solução. Os vasos foram irrigados de 3 a 3,5 vezes por semana durante os meses de janeiro à maio.

Uma semana após o montagem do experimento fez-se uma adubação com o produto comercial Cristalon Fosfatado + Micronutrientes. Utilizou-se 10,0 litros da solução, com $8 \mathrm{~g}$ do produto por litro de água.

A adubação fornecida regularmente a cultura foi feita via fertirrigação, em dias alternados. Fez-se uma solução estoque de:

N-P-K : 1-2-3

$.250 \mathrm{~g}$ de sulfato de magnésio 
$.500 \mathrm{~g}$ de nitrato de potássio

$1500 \mathrm{~g}$ de nitrato de cálcio

. $36 \mathrm{~L}$ de água

Em cada $1000 \mathrm{~L}$ de água de irrigação foram acrescentados $4,0 \mathrm{~L}$ da solução estoque, que forneceram uma condutividade elétrica da água de $0,9 \mathrm{mS} . \mathrm{cm}^{-1}$.

No dia 24 de março foi realizada a desbrota, a retirada de flores precoces e o espaçamento dos vasos. Após a desbrota fez-se uma aplicação com Kasumin.

O experimento foi conduzido até o dia 06 de maio de 1998, quando as plantas chegaram no ponto de comercialização. Ao final do experimento foram avaliados os parâmetros qualidade comercial das plantas produzidas, características fitotécnicas e características físicas dos substratos.

A qualidade comercial de uma planta é uma característica importante a ser avaliada, pois indica seu preço no mercado consumidor. O produtor classifica suas plantas de acordo com os critérios de classificação da cooperativa de Holambra (Anexo E):

- Plantas A1 - A violeta deve estar bem distribuída na circunferência do vaso, apresentar as flores em forma de buquê, centralizadas e acima das folhas. $O$ vaso deve apresentar um aspecto arredondado. Cada vaso deve possuir um mínimo de 10 flores e 3 hastes, com folhas de aspecto brilhante, saudável, sem manchas ou queimaduras. Vasos classificados como A1 alcançam maiores preços por apresentar plantas de melhor qualidade. A média anual (1999/2000) do preço da caixa com 15 vasos, para o produtor, é de $\mathrm{R} \$ 13,00$ (US\$ 7,23).

. Plantas A2 - São vasos com plantas de tamanho menor que A1, com menos de 8 flores por vaso, de folhas pequenas, opacas ou quebradas. É aceitável de 4 a $5 \%$ dos vasos com plantas amareladas ou com folhas queimadas pela água ou pelo frio. Vasos classificados como A2 apresentam plantas de menor 
qualidade. A média de preço (1999/2000) da caixa com 15 vasos é de $\mathrm{R} \$ 8,00$ (US\$ 4,45).

. Plantas B - Apresenta plantas muito pequenas, murchas no centro do vaso, com 2 a 3 flores sem qualidade ou queimadas. Vasos com plantas tipo B são classificados pelo produtor como 'lixo ou refugo', podendo alcançam preço de $\mathrm{R} \$ 5,00$ (US $\$ 2,70$ ) pela caixa com 15 vasos.

As características fitotécnicas avaliadas na cultura da violeta foram:

. número de flores

. número de botões.

. número de hastes florais

. número de folhas

. área foliar

- porcentagem de plantas vivas

. peso da matéria fresca da parte aérea.

- peso da matéria fresca do sistema radicular.

- peso da matéria seca da parte aérea.

- peso da matéria seca do sistema radicular.

. volume do sistema radicular.

As características físicas dos substratos avaliadas foram :

. porosidade total.

. espaço de aeração.

. água disponível.

. água facilmente disponível.

\section{Segunda fase - Análises laboratoriais}

A segunda fase dos estudos com a cultura da violeta constou de duas etapas, a primeira foi a elaboração de diferentes substratos e a segunda a análise de suas características físicas. As duas etapas foram conduzidas nas 
instalações da Escola Superior de Agricultura "Luiz de Queiroz" ESALQ/USP, situada no município de Piracicaba, estado de São Paulo.

Na área experimental do Departamento de Produção Vegetal foram elaborados diferentes substratos, utilizando como componentes:

. areia

. casca de arroz carbonizada

. casca de pínus

. húmus de minhoca

. perlita

. turfa convencional

. turfa cultivadora

vermiculita

. torta de filtro

. casca de eucalipto

Os substratos constaram de misturas de dois a três materiais, em diferentes proporções. Foram elaborados, no total, 136 diferentes substratos, sendo que, quatro destes apresentaram características físicas adequadas à cultura (Anexo F).

A curva de tensão de cada substrato foi determinada, seguindo-se o método citado por De Boodt \& Verdonck (1972). As análises foram feitas no Laboratório de Análises Físicas de Solos do Departamento de Engenharia Rural.

Da curva de tensão de água se obteve dados como:

- porosidade total - corresponde a umidade volumétrica do substrato a $0 \mathrm{~cm}$ de tensão.

. espaço de aeração - corresponde a diferença entre os pontos 0 e $10 \mathrm{~cm}$ de tensão.

. água disponível - é a diferença entre 10 e $100 \mathrm{~cm}$ de tensão. 
. água facilmente disponível - é a quantidade de água retida entre 10 e $50 \mathrm{~cm}$ de tensão.

\section{Terceira fase - Segundo experimento}

O segundo experimento foi conduzido na propriedade dos Eng ${ }^{\text {os }}$ Agrônomos Rene Groot e Etienne Groot, produtores de plantas ornamentais, no município de Holambra, estado de São Paulo. O cultivo foi feito em casa de vegetação climatizada, com sistemas de aquecimento, ventilação, controle de luminosidade, irrigação, fertilização, medição de condutividade elétrica e $\mathrm{pH}$. Seguiu-se o manejo usualmente dado pelo produtor para a cultura.

$O$ delineamento experimental adotado foi o delineamento inteiramente casualizado com seis tratamentos, oito plantas por parcela e quatro repetições.

Para se definir os tratamentos foram utilizados dados obtidos em um experimento anterior, onde se avaliou as características físicas adequadas ao cultivo da violeta.

A partir dos resultados nas características fitotécnicas (Tabela 2), qualidade comercial (Tabela 1) e análise física dos substratos (Tabela 3), foram definidas misturas de materiais que atendessem as exigências da cultura. Buscou-se substratos que apresentassem as seguintes características físicas:

. porosidade total de $75,10 \%( \pm 2 \%)$

. espaço ocupado por ar de $19,53 \%( \pm 2 \%)$

. água disponível de $26,03 \%( \pm 2 \%)$

. água facilmente disponível de $23,71 \%( \pm 2 \%)$.

Foram encontrados quatro substratos, que apresentavam características físicas adequadas a cultura. Os tratamentos constaram dos quatro substratos formulados na segunda fase (Anexo F), um substrato 
comercial, da empresa Eucatex, indicado para o cultivo de violetas e uma testemunha. Os tratamentos constaram de:

. Turfa cultivadora : vermiculita (2:1)

. Casca de pínus : húmus de minhoca (1:3)

. Turfa convencional : casca de eucalipto : areia $(3: 1: 0,5)$

. Húmus de minhoca : vermiculita : areia $(3: 1: 0,2)$

. Substrato comercial da Eucatex à base de turfa

. Testemunha

Como testemunha foi utilizado o substrato comumente utilizado pelo produtor, que é o substrato comercial "Vida Verde - Substrato para Violeta".

Foram utilizadas mudas da variedade comercial 'Kalisa', adquiridas de produtores especializados. As mudas foram obtidas através de estacas de folhas e estavam acondicionadas em bandejas plásticas, com o substrato póde-xaxim, casca de pínus è vermiculita. Tinham 5 semanas de idade e de 7 a 9 folhas.

O expërimento foi montado no dia 08 de março de 1999. O manejo dado à cultura foi idêntico ao primeiro experimento.

A primeira irrigação foi feita após o plantio. Junto com a água de irrigação foi aplicado $1,0 \mathrm{~g}$ de Manzate por litro de água. Utilizou-se, ao todo, 10,0 L de solução. Verificou-se a necessidade de se repetir a aplicação de Manzate uma semana após o plantio, devido à alta incidência de fungos de solo dentro das estufas.

Os vasos foram irrigados de 3 a 3,5 vezes por semana durante os meses de março e abril, e 2 vezes por semana em maio e junho.

No dia 01 de maio foi realizada $a_{s}$ desbrota, a retirada de flores precoces e o espaçamento dos vasos. Após a desbrota fez-se uma aplicação com Kasumin. 

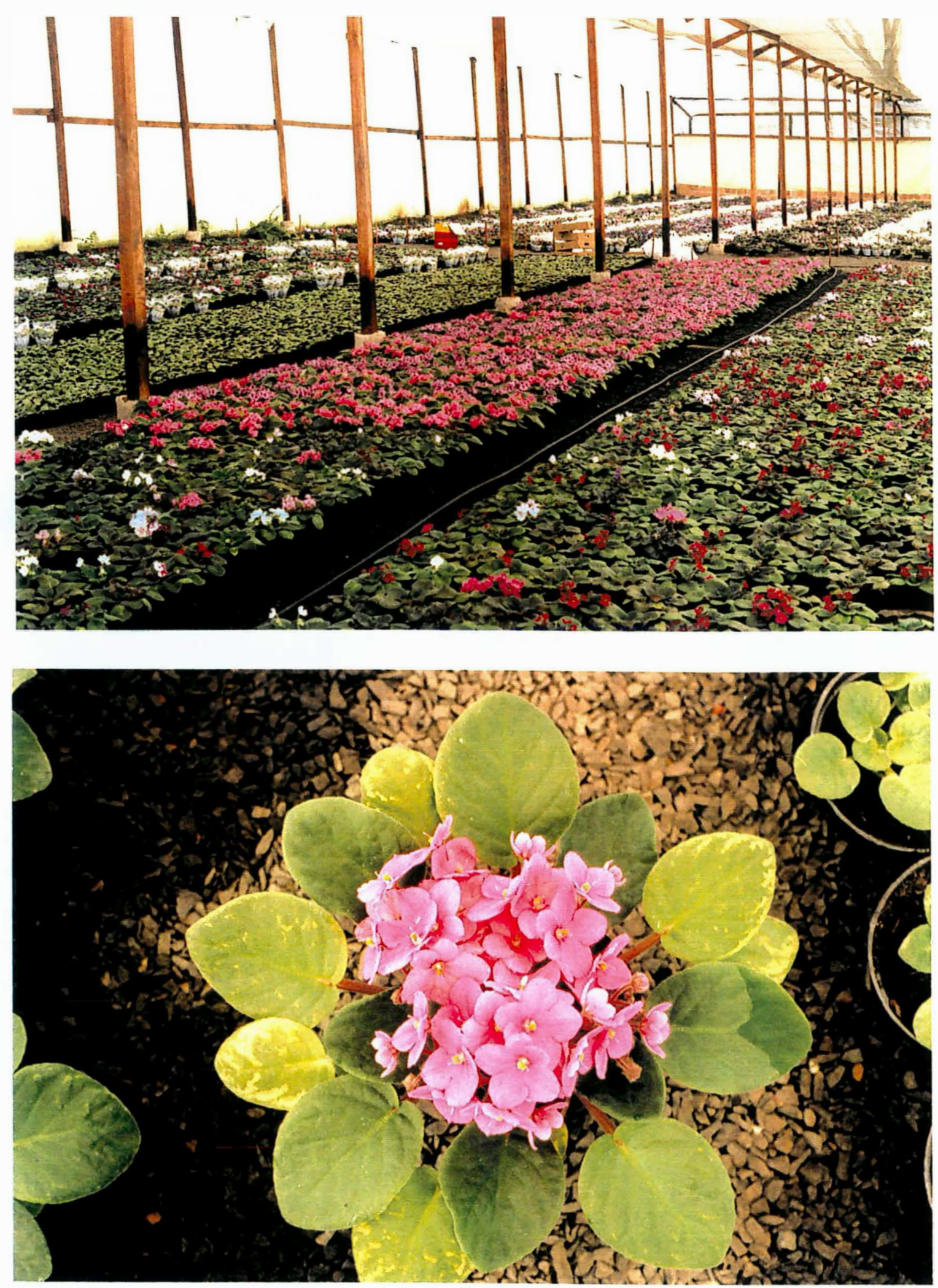

Figura 1. Cultura da violeta no ponto de colheita. 
O experimento foi conduzido até o dia 21 de junho de 1999, quando as plantas chegaram no ponto de comercialização. Ao final do experimento foram avaliados os parâmetros qualidade comercial e características fitotécnicas das plantas produzidas.

\section{RESULTADOS E DISCUSSÃO}

\section{Primeiro experimento}

Quando se avaliou diferentes densidades de substrato no cultivo de violeta, pode-se observar que a densidade $0,75 \mathrm{~g} . \mathrm{cm}^{-3}$ apresentou-se superior, dando os melhores resultados nos parâmetros avaliados. As plantas produzidas nesta densidade apresentaram alta qualidade, aspecto visual uniforme e um grande número de flores abertas, centralizadas no vaso.

Segundo a literatura consultada, densidade do substrato nos dá uma idéia antecipada de características físicas como porosidade total, água disponível e espaço de aeração (Boelter, 1969). Valores extremos de densidade são considerados inadequados (Bellé, 1990). Densidades muito altas indicam baixa porosidade, pois a densidade é inversamente proporcional a porosidade. Já baixas densidades fornecem pouca estabilidade às plantas (Beardsell, 1979).

No parâmetro qualidade comercial das plantas produzidas (Tabela 1), o tratamento $0,75 \mathrm{~g} . \mathrm{cm}^{-3}$ apresentou $94,8 \%$ de seus vasos classificados como plantas $\mathrm{A} 1$, ou seja, plantas de alta qualidade, apresentando um mínimo de 10 flores em forma de buquê, centralizadas no vaso e acima das folhas. As plantas apresentavam um aspecto arredondado, estando bem distribuídas na circunferência do vaso, com folhas de aspecto brilhante, saudável, sem manchas ou queimaduras. Possuía $5,2 \%$ de suas plantas classificadas como A2, apresentado, entre todos os tratamentos avaliados, as 
plantas de melhor qualidade, alcançando os melhores preços para comercialização.

Tabela 1: Qualidade comercial de violetas cultivadas em substratos de diferentes densidades. ${ }^{x}$

\begin{tabular}{cccc}
\hline Tratamento & Plantas A1 & Plantas A2 & Plantas B \\
\hline $0,15 \mathrm{~g} \cdot \mathrm{cm}^{-3}$ & $72,8 \%$ & $20,6 \%$ & $6,6 \%$ \\
$0,35 \mathrm{~g} \cdot \mathrm{cm}^{-3}$ & $94,4 \%$ & $5,6 \%$ & $0,0 \%$ \\
$0,55 \mathrm{~g} \cdot \mathrm{cm}^{-3}$ & $82,2 \%$ & $17,8 \%$ & $0,0 \%$ \\
$0,75 \mathrm{~g}^{-3} \mathrm{~cm}^{-3}$ & $94,8 \%$ & $5,2 \%$ & $0,0 \%$ \\
$0,95 \mathrm{~g} \cdot \mathrm{cm}^{-3}$ & $86,0 \%$ & $14,0 \%$ & $0,0 \%$ \\
\hline
\end{tabular}

${ }^{\mathrm{x}}$ Classificação das plantas quanto a qualidade comercial:

. Plantas Al - flores em forma de buquê, centralizadas e acima das folhas. Vasos com, no mínimo, 10 flores e 3 hastes, com folhas brilhantes, saudáveis, sem manchas ou queimaduras.

Plantas A2 - plantas com menos de 8 flores, de folhas pequenas, opacas ou quebradas.

. Plantas B - plantas muito pequenas, murchas no centro do vaso, com 2 a 3 flores sem qualidade ou queimadas. 

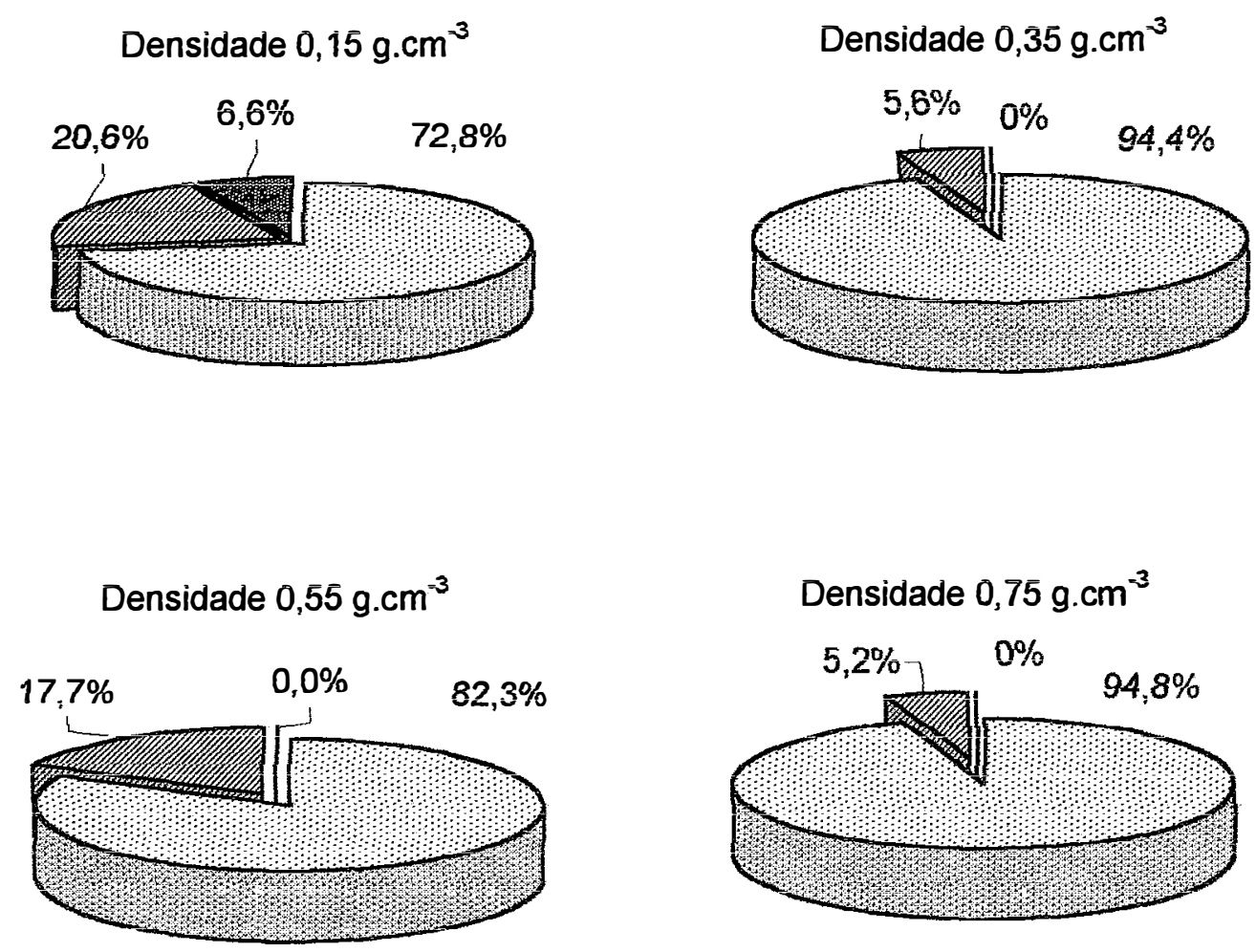

Densidade $0,95 \mathrm{~g} \cdot \mathrm{cm}^{-3}$

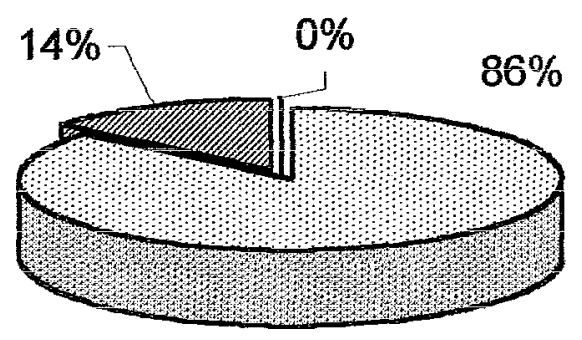

\section{T. Plantas Â1 \\ 圆 Plantas A2 \\ 圆Plantas B}

Figura 2: Qualidade comercial de violetas cultivadas em substratos de diferentes densidades. 
No parâmetro características fitotécnicas (Tabela 2), observou-se que o tratamento apresentou um grande número de flores e botões por vaso. Enquanto na classificação do produtor, plantas com mais de 8 flores abertas já tem qualidade para serem comercializadas, o tratamento $0,75 \mathrm{g.cm}^{-3}$ apresentou, em média, 23,62 flores e 31,82 botões por vaso. As flores apresentavam-se na forma de buquê, centralizadas no vaso e acima das folhas. A porcentagem de plantas vivas, de $93,00 \%$, está dentro de uma faixa aceitável de morte de plantas durante a condução das cultura, que normalmente é em torno de 10\%. Possuía 6,86 hastes florais, onde o mínimo esperado numa produção comercial são 3 hastes. Apresentou um menor número de folhas, 20,44 , quando comparado à outros tratamentos, mas com maior área foliar, $462,45 \mathrm{~cm}^{2}$, demonstrando que apesar do número menor de folhas, estas eram grandes. Também pode-se observar visualmente que as folhas estavam sadias, sem manchas ou deformações, bem distribuídas e abaixo das flores, dando uma conformação equilibrada e uniforme aos vasos produzidos. A parte aérea apresentou peso fresco de $63,64 \mathrm{~g}$ e peso seco de $9,03 \mathrm{~g}$.

Quando se avaliou o sistema radicular das plantas produzidas, pode-se observar que 0 tratamento $0,75 \mathrm{~g} . \mathrm{cm}^{-3}$ apresentou os melhores resultados. Em média, o peso fresco do sistema radicular foi de $5,71 \mathrm{~g}$, o peso seco de $0,29 \mathrm{~g}$ e o volume de $5,94 \mathrm{~mL}$. O melhor desenvolvimento do sistema radicular permitiu uma maior absorção de água e nutrientes e, conseqüentemente, um maior desenvolvimento da parte aérea. Um bom desenvolvimento do sistema radicular está relacionado ao substrato possuir as características físicas mais adequadas ao desenvolvimento da cultura da violeta. 
Tabela 2: Resultados obtidos em caracteristicas fitotécnicas, quando se avaliou diferentes densidades do substrato, no cultivo de violeta. ${ }^{x}$

\begin{tabular}{cccccc}
\hline Tratamento $^{y}$ & $\begin{array}{c}0,15 \\
\text { g.cm }\end{array}$ & $\begin{array}{c}0,35 \\
\text { g. } \mathrm{cm}^{-3}\end{array}$ & $\begin{array}{c}0,55 \\
\mathrm{~g} \cdot \mathrm{cm}^{-3}\end{array}$ & $\begin{array}{c}0,75 \\
\mathrm{~g} \cdot \mathrm{cm}^{-3}\end{array}$ & $\begin{array}{c}0,95 \\
\mathrm{~g} \cdot \mathrm{cm}^{-3}\end{array}$ \\
\hline NB & $21,76 \mathrm{~b}$ & $31,50 \mathrm{a}$ & $27,58 \mathrm{ab}$ & $31,82 \mathrm{a}$ & $29,59 \mathrm{a}$ \\
NFL & $15,30 \mathrm{~b}$ & $20,53 \mathrm{ab}$ & $19,09 \mathrm{ab}$ & $23,62 \mathrm{a}$ & $19,97 \mathrm{ab}$ \\
NH & $6,59 \mathrm{ab}$ & $6,41 \mathrm{ab}$ & $7,42 \mathrm{a}$ & $6,86 \mathrm{a}$ & $7,47 \mathrm{a}$ \\
NFO & $25,17 \mathrm{a}$ & $19,55 \mathrm{~b}$ & $25,89 \mathrm{a}$ & $20,44 \mathrm{~b}$ & $24,51 \mathrm{a}$ \\
AF (cm $\left.{ }^{2}\right)$ & $347,05 \mathrm{bc}$ & $421,84 \mathrm{abc}$ & $373,01 \mathrm{bc}$ & $462,45 \mathrm{a}$ & $436,52 \mathrm{ab}$ \\
\%PV & $99 \mathrm{a}$ & $80 \mathrm{~b}$ & $96 \mathrm{a}$ & $93 \mathrm{a}$ & $99 \mathrm{a}$ \\
PFPA (g) & $57,19 \mathrm{a}$ & $71,48 \mathrm{a}$ & $65,36 \mathrm{a}$ & $63,64 \mathrm{a}$ & $64,12 \mathrm{a}$ \\
PSPA (g) & $8,22 \mathrm{c}$ & $8,68 \mathrm{~b}$ & $8,61 \mathrm{~b}$ & $9,03 \mathrm{a}$ & $8,82 \mathrm{ab}$ \\
PFSR (g) & $4,08 \mathrm{~b}$ & $5,31 \mathrm{ab}$ & $4,33 \mathrm{ab}$ & $5,71 \mathrm{a}$ & $4,69 \mathrm{ab}$ \\
PSSR $(\mathrm{g})$ & $0,17 \mathrm{c}$ & $0,23 \mathrm{~b}$ & $0,18 \mathrm{bc}$ & $0,29 \mathrm{a}$ & $0,21 \mathrm{bc}$ \\
VSR $(\mathrm{mL})$ & $3,83 \mathrm{~b}$ & $5,17 \mathrm{ab}$ & $4,32 \mathrm{ab}$ & $5,94 \mathrm{a}$ & $4,17 \mathrm{ab}$ \\
\hline
\end{tabular}

${ }^{x}$ Teste de Tukey para as médias de densidade de substrato. Médias horizontais seguidas por letras distintas diferem, entre si, ao nível de 5,00\% de significância.

${ }^{y}$ Número de botões (NB), número de flores (NFL), número de hastes florais $(\mathrm{NH})$, número de folhas (NFO), área foliar (AF), porcentagem de plantas vivas (\%PV), peso da matéria fresca da parte aérea (PFPA), peso da matéria seca da parte aérea (PSPA), peso da matéria fresca do sistema radicular (PFSR), peso da matéria seca do sistema radicular (PSRS), volume do sistema radicular (VSR) 

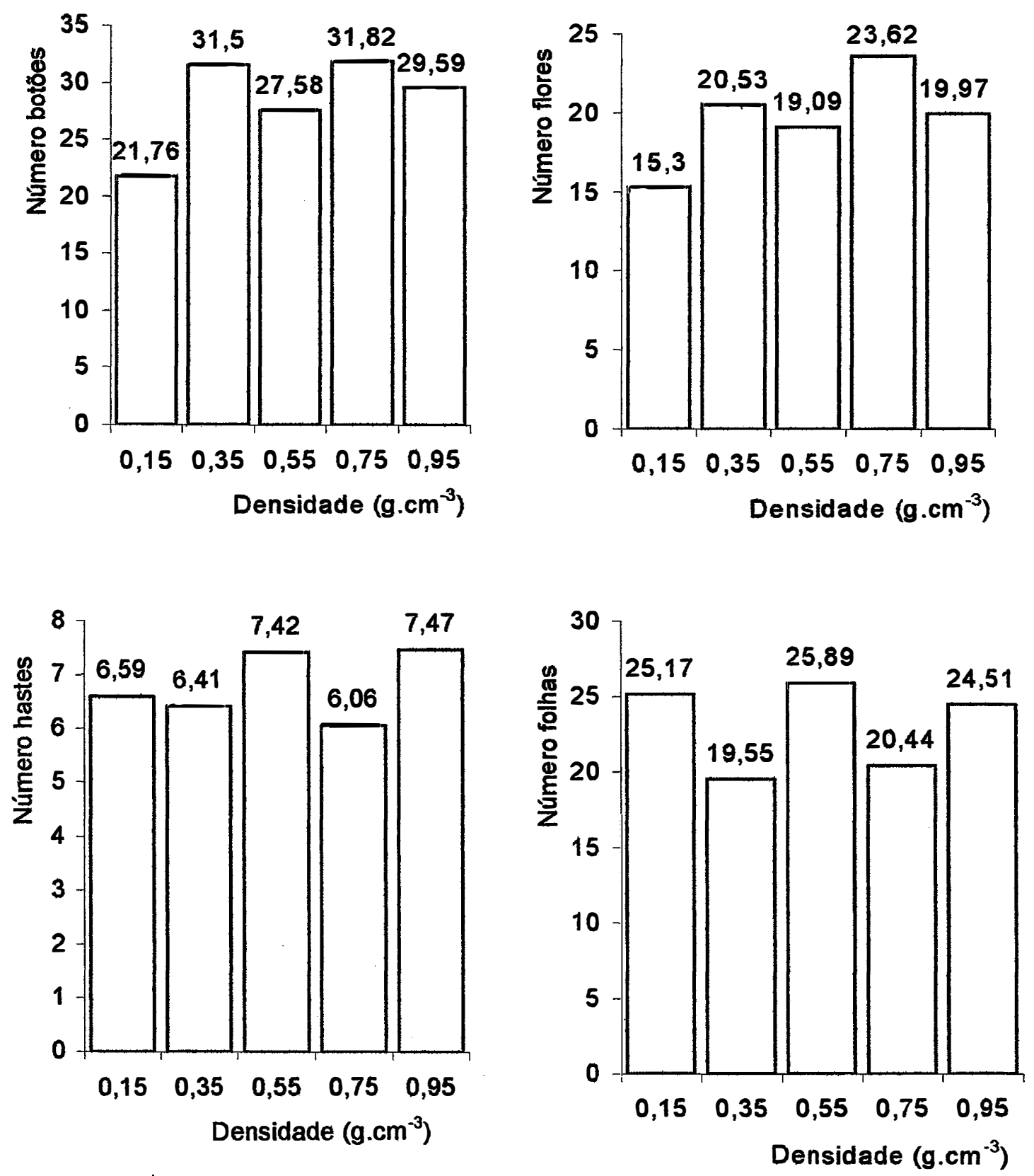

Figura 3: Resultados obtidos em caracteristicas fitotécnicas, quando se avaliou diferentes densidades do substrato, no cultivo de violeta. 

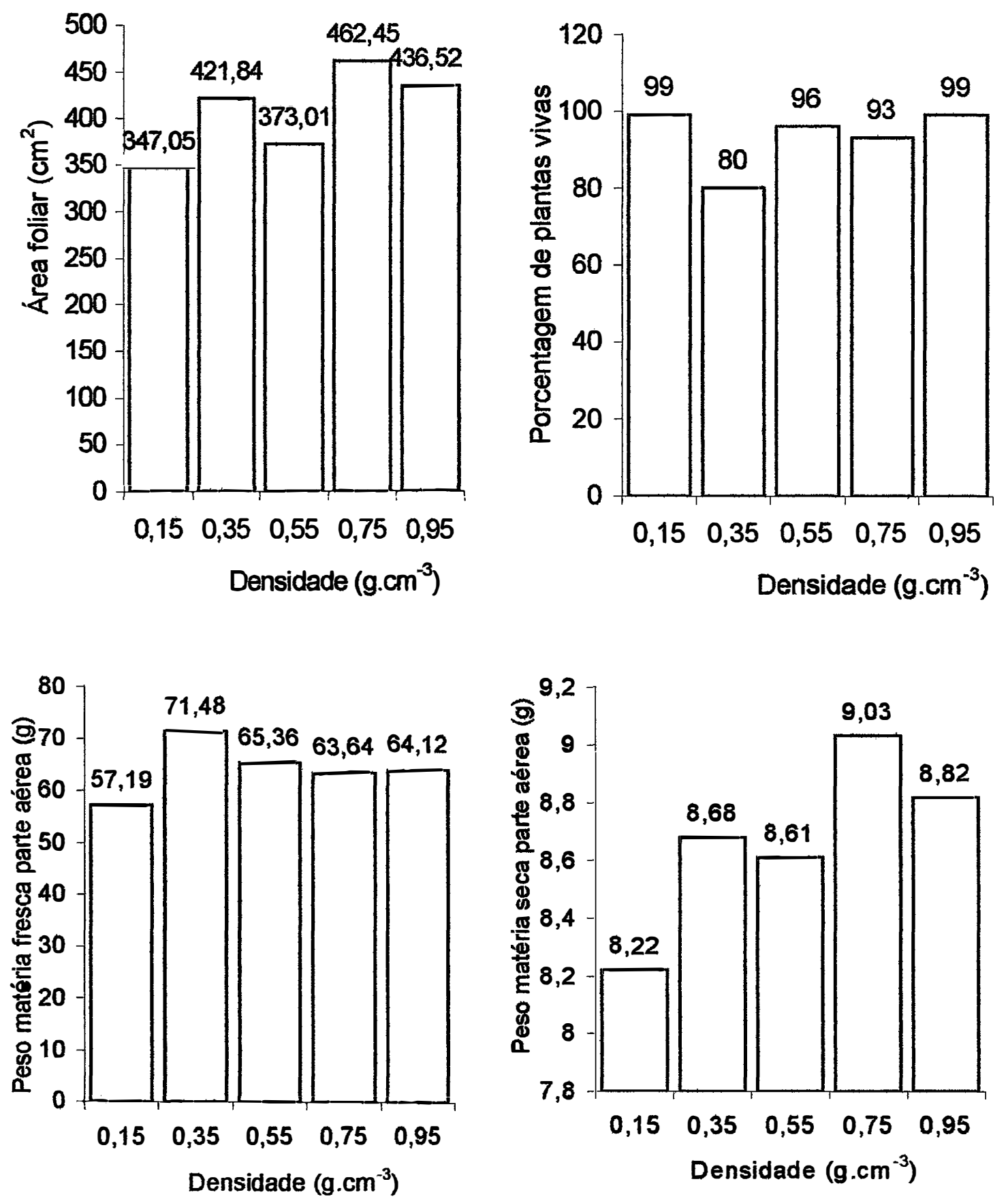

Figura 3: Rèsultados obtidos em características fitotécnicas, quando se avaliou diferentes densidades do substrato, no cultivo de violeta (continuação). 

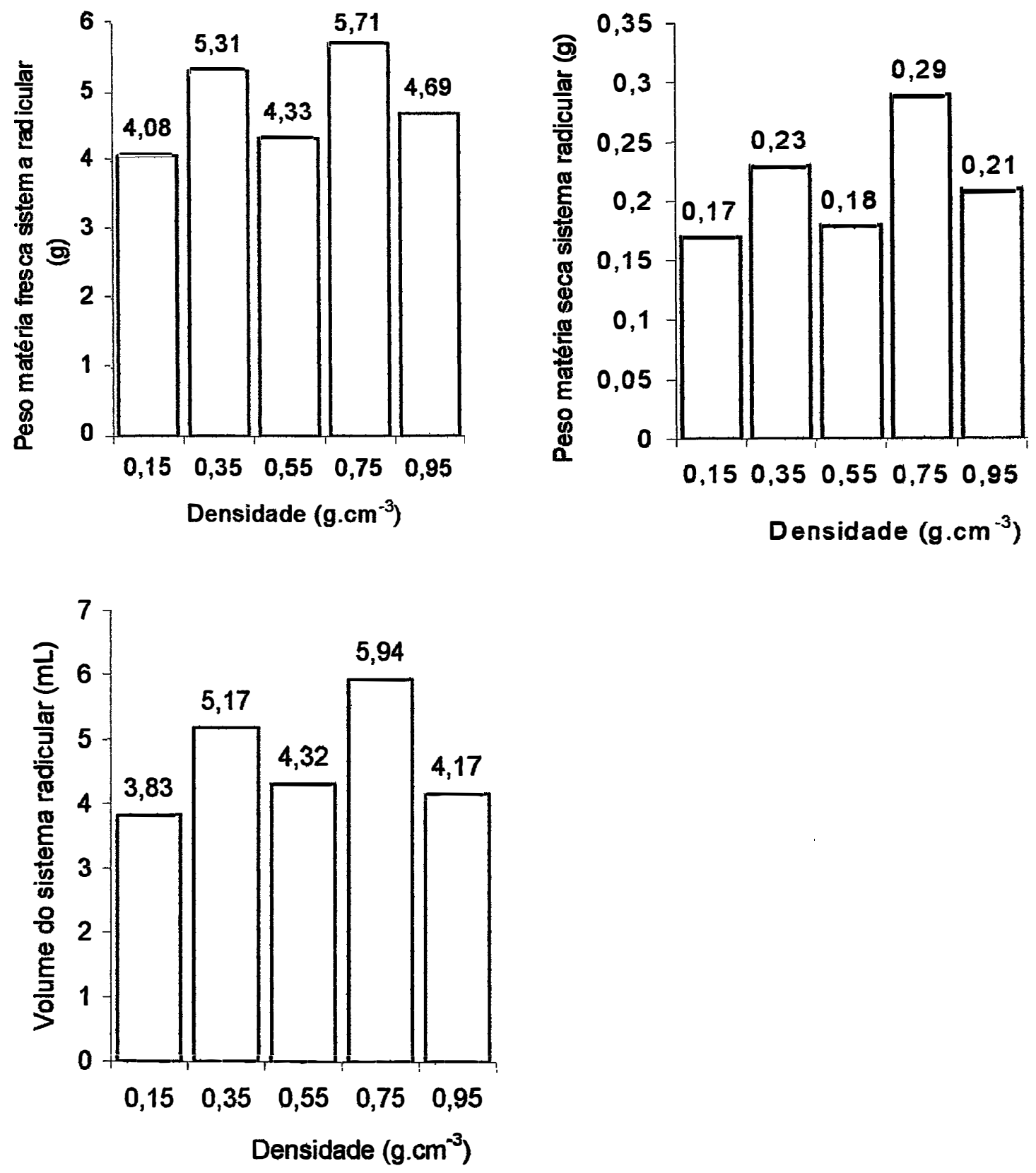

Figura 3: Resultados obtidos em características fitotécnicas, quando se avaliou diferentes densidades do substrato, no cultivo de violeta (continuação). 
Com relação as características físicas (Tabela 3), o substrato $0,75 \mathrm{~g} \mathrm{~cm}^{-3}$ apresentou porosidade total e espaço ocupado por ar de acordo com as recomendações dadas pelos autores consultados (De Boodt \& Verdonck, 1972; Goh \& Haynes, 1977; Riviere, 1980; Boertje, 1983; Rac, 1985 e Verdonck \& Gabriëls, 1988), enquanto que a água disponivel e água facilmente disponivel mostraram níveis abaixo dos indicados pelos autores.

Possui porosidade total de $75,10 \%$ (v/v), estando de acordo com a porosidade recomendada por Riviere (1980) para substratos, que é $75 \%$, e próxima a porosidade recomendada por De Boodt \& Verdonck (1972), Goh \& Haynes (1977), Boertje (1983), Rac (1985) e Verdonck \& Gabriëls (1988), que é de $85 \%$ em volume de poros.

O substrato possuía $19,53 \%$ de espaço ocupado por ar, estando próxima as recomendações dadas por Rac (1985), que relata que um substrato deve ter um volume ocupado por ar de 20 a 30\%. Gislerød (1982) cita que o teor de ar ideal, para formação de raízes de plantas cultivadas em recipientes, é de aproximadamente $20 \%$ e, em alguns casos, $45 \%$. Para De Boodt \& Verdonck (1972) e Bix (1973) o ideal é que seja próximo de 10 a $20 \%$. Ballester-Olmos (1992) cita que, para a maioria das espécie oscila entre os 10 e $30 \%$. Boa aeração é uma das características físicas importantes para o crescimento de plantas em recipientes (Beardsell et al., 1979). O crescimento das raízes é restringido por uma aeração deficiente (Singh \& Sainju, 1998).

A água disponível, 19,79\%, e água facilmente disponivel, 17,41\%, estão abaixo da recomendada pelos autores consultados, que citam que um substrato deve ter, no mínimo, $26 \%$ do volume ocupado por água, sendo $20 \%$ do volume ocupado com água facilmente disponível às plantas. 
Tabelá 3: Análise física dos substratos utilizados no cuitivo de violeta.

\begin{tabular}{lcccc}
\hline Tratamento & $\begin{array}{c}\text { Porosidade } \\
\text { total } \\
(\%)\end{array}$ & $\begin{array}{c}\text { Espaço de } \\
\text { aeração } \\
(\%)\end{array}$ & $\begin{array}{c}\text { Água } \\
\text { facilmente } \\
\text { disponível } \\
(\%)\end{array}$ & $\begin{array}{c}\text { Água } \\
\text { disponível } \\
(\%)\end{array}$ \\
\hline $0,15 \mathrm{~g} \cdot \mathrm{cm}^{-3}$ & 87,49 & 57,78 & 8,90 & 11,11 \\
$0,35 \mathrm{~g}^{-3} \mathrm{~cm}^{-3}$ & 83,34 & 40,56 & 10,38 & 13,13 \\
$0,55 \mathrm{~g} \cdot \mathrm{cm}^{-3}$ & 77,60 & 26,93 & 16,36 & 18,75 \\
$0,75 \mathrm{~g} \cdot \mathrm{cm}^{-3}$ & 75,10 & 19,53 & 17,41 & 19,79 \\
$0,95 \mathrm{~g} \cdot \mathrm{cm}^{-3}$ & 72,60 & 12,81 & 23,71 & 26,03 \\
\hline
\end{tabular}

0 tratamento $0,35 \mathrm{~g} \cdot \mathrm{cm}^{-3}$ apresentou alguns bons resultados. No parâmetro qualidade comercial das plantas produzidas (Tabela 1), observouse que $94,4 \%$ de seus vasos foram classificados como $A 1$ e $5,6 \%$ foram classificados como $A 2$, não se diferenciando muito do tratamento $0,75 \mathrm{~g} . \mathrm{cm}^{-3}$. No parâmetro características fitotécnicas (Tabela 2) apresentou bons resultados nas características número de flores $(20,53)$ e número de botões $(31,50)$, peso fresco do sistema radicular $(5,31 \mathrm{~g})$, peso seco do sistema radicular $(0,23 \mathrm{~g})$ e volume do sistema radicular de $(5,17 \mathrm{~mL})$. O grande problema da utilização deste substrato foi à alta perda de plantas (ao final do experimento a porcentagem de plantas vivas foi de somente $80,00 \%$ ), fato que onera os custos de produção, aumentando os prejuízos do produtor com a cultura.

O tratamento $0,95 \mathrm{~g} \cdot \mathrm{cm}^{-3}$ apresentou resultados intermediários em algumas características, como número de botões $(29,59)$, número de hastes 
florais $(7,47)$, número de folhas $(24,51)$, porcentagem de plantas vivas $(99 \%)$ e peso f́resco da parte aérea $(64,12 \mathrm{~g})$.

Os tratamentos $0,15 \mathrm{~g} \cdot \mathrm{cm}^{-3}$ e $0,55 \mathrm{~g} \cdot \mathrm{cm}^{-3}$ apresentaram resultados inferiores nas características fitotécnicas avaliadas. Com relação à suas características físicas apresentaram porosidade adequada, espaço de aeração elevado e baixas água disponível e água facilmente disponível.

Ao final do experimento observou-se que:

1. a densidade do substrato mais adequada ao cultivo de violeta foi $0,75 \mathrm{~g} \cdot \mathrm{cm}^{3}$.

2. a porosidade e espaço ocupado por ar devem estar dentro dos níveis indicados como ideais para substratos, com porosidade total de $75,10 \%$ e espaço de aeração de $19,53 \%$.

3. quando se avaliou características ligadas à capacidade do substrato em liberar água para as plantas, pode-se observar que a violeta se desenvolveu melhor em condições de baixa quantidade de água disponivel $(19,79 \%)$ e água facilmente disponivel $(17,41 \%)$, demonstrando que a cultura não se desenvolve bem em substratos com excesso de água. Tal fato sempre foi verificado, na prática, pelos produtores comerciais, mas até agora não havia sido mensurado.

4. a porosidade, o espaço ocupado por ar e a capacidade do substrato em liberar água para as plantas, são fatores limitantes no crescimento da cultura.

5. o bom desenvolvimento do sistema radicular está relacionado ao substrato possuir as características físicas ideais, permitindo uma boa absorção de água e nutrientes e, por conseqüência, um bom desenvolvimento da parte aérea.

6. não se pode generalizar recomendações dadas as características físicas dos substratos para todas as espécies de plantas, pois cada espécie tem suas próprias necessidades. 


\section{Segundo experimento}

Quando se avaliou o desempenho de seis diferentes substratos no cultivo da violeta, pode-se observar que todos apresentaram-se adequados ao seu cultivo.

Segundo Verdonck et al. (1981) a. qualidade de um substrato é determinada por suas características físicas e está na habilidade em fornecer água e ar adequadamente para as raízes das plantas e microorganismos do solo. Para ótimo crescimento das plantas um substrato tem que ter ar e água facilmente disponíveis (Verdonck et al., 1983). Os substratos analisados apresentavam características físicas adequadas ao crescimento da violeta, possuindo porosidade total de $73,10 \%$ a $77,10 \%$, espaço ocupado por ar de $17,53 \%$ a $21,53 \%$, água disponivel de $24,03 \%$ a $28,03 \%$ e água facilmente disponivel de $21,71 \%$ a $25,71 \%$.

No parâmetro qualidade comercial das plantas produzidas (Tabela 4) não houve grandes diferenças entre os tratamentos analisados. No geral, observou-se que, em média, $76 \%$ dos vasos avaliados conseguiram ter plantas de alta qualidade. Este fato se deve, provavelmente, a um problema ocorrido durante o manejo da cultura, quando o produtor pulverizou a cultura duas vezes com Manzate, no início do cultivo, devido a uma alta ocorrência de fungos de solo nas estufas de produção. A aplicação excessiva do produto fez com que a cultura tivesse um aumento no seu período vegetativo e uma superbrołação, produzindo um número de folhas maior que o habitual. Mesmo assim as plantas produzidas alcançaram um bom valor comercial, sendo que o substrato húmus de minhoca : vermiculita : areia foi o que apresentou os melhores resultados com $80 \%$ de suas plantas classificadas como A1 e 15\% como A2. Turfa convencional : casca de eucalipto : areia, casca de pinus : húmus de minhoca, turfa cultivadora : perlita, substrato Eucatex e testemunha apresentaram, respectivamente, $75,2 \%, 77,5 \%$, 
$75,2 \%, 78,3 \%$ e $72,1 \%$ de suas plantas classificadas como A1. Todos os tratamentos alcançaram bons preços para venda.

\section{Tabela 4: Qualidade comercial de violetas cultivadas em diferentes substratos. ${ }^{*}$}

\begin{tabular}{lccc}
\hline Tratamento & Plantas & Plantas & Plantas \\
& A1 & A2 & B \\
\hline Turfa convencional : casca de eucalipto : & $75,2 \%$ & $18,6 \%$ & $6,2 \%$ \\
areia & & & \\
Húmus de minhoca : vermiculita : areia & $80,0 \%$ & $15,0 \%$ & $5,0 \%$ \\
Casca de pinus : húmus de minhoca & $77,5 \%$ & $17,5 \%$ & $5,0 \%$ \\
Turfa cultivadora : vermiculita & $75,2 \%$ & $9,3 \%$ & $15,5 \%$ \\
Substrato comerciai da Eucatex & $78,3 \%$ & $15,5 \%$ & $6,2 \%$ \\
Testemunha & $72,1 \%$ & $21,7 \%$ & $6,2 \%$ \\
\hline
\end{tabular}

${ }^{\mathrm{x}}$ Classificação das plantas quanto a qualidade comercial:

Plantas Al - flores em forma de buquê, centralizadas e acima das folhas. Vasos com, no minimo, 10 flores e 3 hastes, com folhas brilhantes, saudáveis, sem manchas ou queimaduras.

Plantas A2 - plantas com menos de 8 flores, de folhas pequenas, opacas ou quebradas.

Plantas B - plantas muito pequenas, murchas no centro do vaso, com 2 a 3 flores sem qualidade ou queimadas. 
Turfa convencional : casca de eucalipto : areia

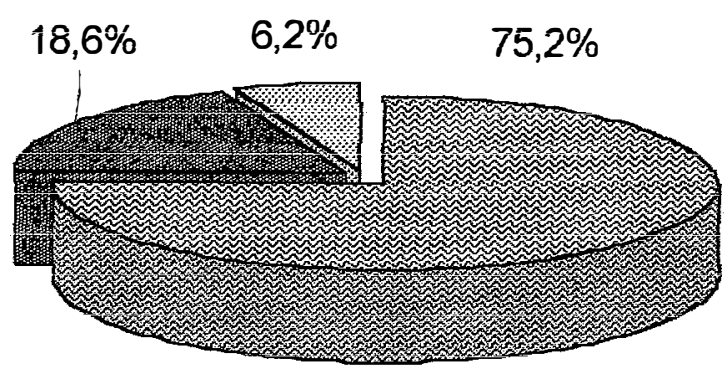

Substrato Eucatex

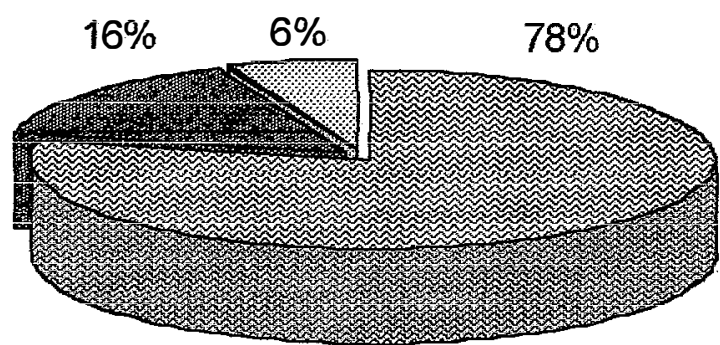

Turfa cultivadora vermiculita

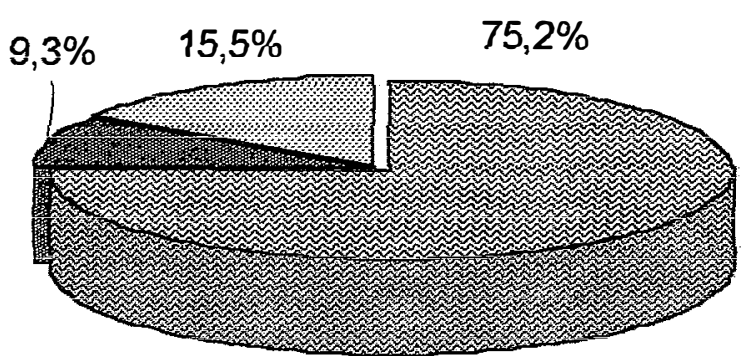

Testemunha

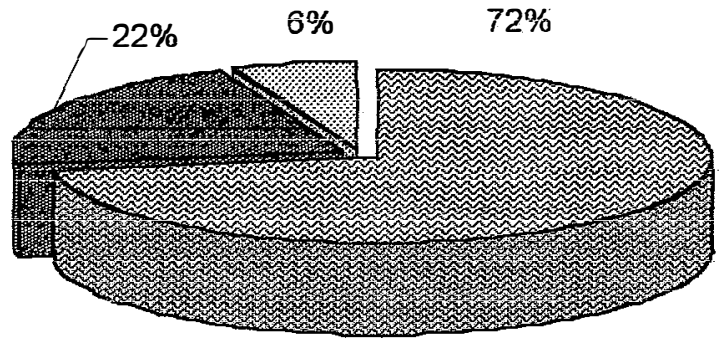

\section{图 Plantas A1 娄 Plantas A2 四Plantas B}

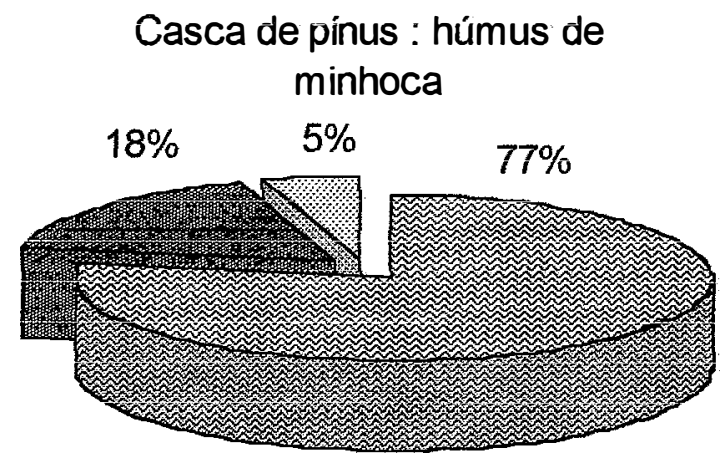

Húmus de minhoca : vermiculita : areia

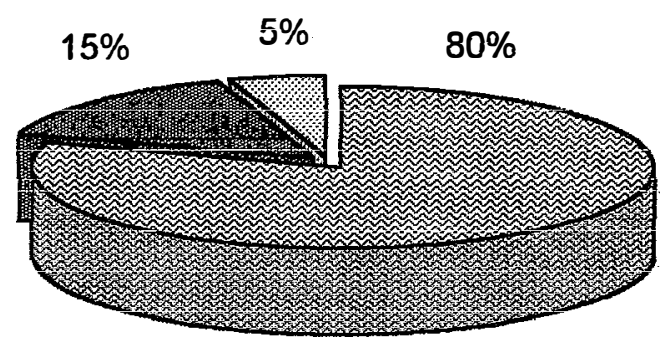

Figura 4: Qualidade comercial de vioieta cuitivada em diferentes substratos. 
No parâmetro características fitotécnicas (Tabela 5) observou-se que, estatisticamente, não houveram diferenças significativas. Isso se deve, provaveimente, a todos os substratos apresentarem as características físicas ideais ao crescimento da cuitura.

Tabeia 5: Resuitados obtidos em características fitotécnicas, quando se avaliou o uso de diferente substratos no cultivo de violeta. *

\begin{tabular}{|c|c|c|c|c|c|c|}
\hline Tratamento $^{\nabla}$ & $\mathrm{TC}^{2}$ & HV & $\mathrm{CP}$ & TV & $E U$ & TE \\
\hline NB & $35,2 \mathrm{a}$ & $39,4 a$ & $37,4 a$ & $36,0 \mathrm{a}$ & $38,4 a$ & $37,2 \mathrm{a}$ \\
\hline $\mathrm{NFL}$ & $12,4 \mathrm{a}$ & $15,8 \mathrm{a}$ & $17,2 \mathrm{a}$ & $12,2 \mathrm{a}$ & $14,4 \mathrm{a}$ & $12,8 \mathrm{a}$ \\
\hline $\mathrm{NH}$ & $7,0 \mathrm{a}$ & $7,4 a$ & $7,8 \mathrm{a}$ & $7,0 \mathrm{ab}$ & $6,6 a b$ & $7,2 a b$ \\
\hline NFO & $27,6 \mathrm{a}$ & $25,4 \mathrm{bc}$ & $21,8 \mathrm{c}$ & 28,0 aboc & $34,2 \mathrm{a}$ & $27,8 \mathrm{abc}$ \\
\hline $\mathrm{AF}\left(\mathrm{cm}^{2}\right)$ & $527,0 \mathrm{a}$ & $496,8 a b$ & $463,8 \mathrm{bcd}$ & $473,2 a b c$ & $512,6 a b$ & $432,8 \mathrm{~cd}$ \\
\hline$\% P V$ & $99 \%$ & $96 \%$ & $95 \%$ & $99 \%$ & $93 \%$ & $94 \%$ \\
\hline PFPA (g) & 76,8 a & $73,0 \mathrm{ab}$ & $71,6 \mathrm{abc}$ & $67,2 \mathrm{abc}$ & 75,6 a & $61 \mathrm{bc}$ \\
\hline PSPA $(g)$ & $8,6 \mathrm{a}$ & $9,0 \mathrm{a}$ & $8,8 \mathrm{a}$ & $8,6 \mathrm{a}$ & 9,2 a & $8,6 a$ \\
\hline PFSR (g) & $44,6 \mathrm{a}$ & $54,9 a$ & $35,2 b$ & $47,2 \mathrm{a}$ & $49,6 a$ & $39,9 a b$ \\
\hline PSSR (g) & $2,48 a$ & $3,05 a$ & $2,07 a$ & $3,00 \mathrm{a}$ & $2,67 a$ & $2,47 a$ \\
\hline VSR (mL) & $46 a$ & $54 a$ & $38 a b$ & $48 \mathrm{a}$ & $51 \mathrm{a}$ & $42 a b$ \\
\hline
\end{tabular}

"Teste de Tukey para as médias de densidade de substrato. Médias horizontais seguidas por letras distintas diferem, entre si, ao nível de 5,00\% de significância.

${ }^{y}$ Número de botões (NB), número de flores (NFL), número de hastes florais (NH), número de folhas $(\mathrm{NFO})$, área foliar $(\mathrm{AF})$, porcentagem de plantas vivas $(\% \mathrm{PV})$, peso da matéria fresca da parte aérea (PFPA), peso da matéria seca da parte aérea (PSPA), peso da matéria fresca do sistema radicular (PFSR), peso da matéria seca do sistema radicular (PSRS), volume do sistema radicular (VSR).

${ }^{\mathrm{z}}$ Turfa convencional : casca de eucalipto : areia (TC), Húmus de minhoca : vermiculita : areia (HV), Casca de pinus : húmus de minhoca (CP), Turfa cultivadora : vermiculita (TV), Substrato comercial da Eucatex (EU), Testemunha (TE). 

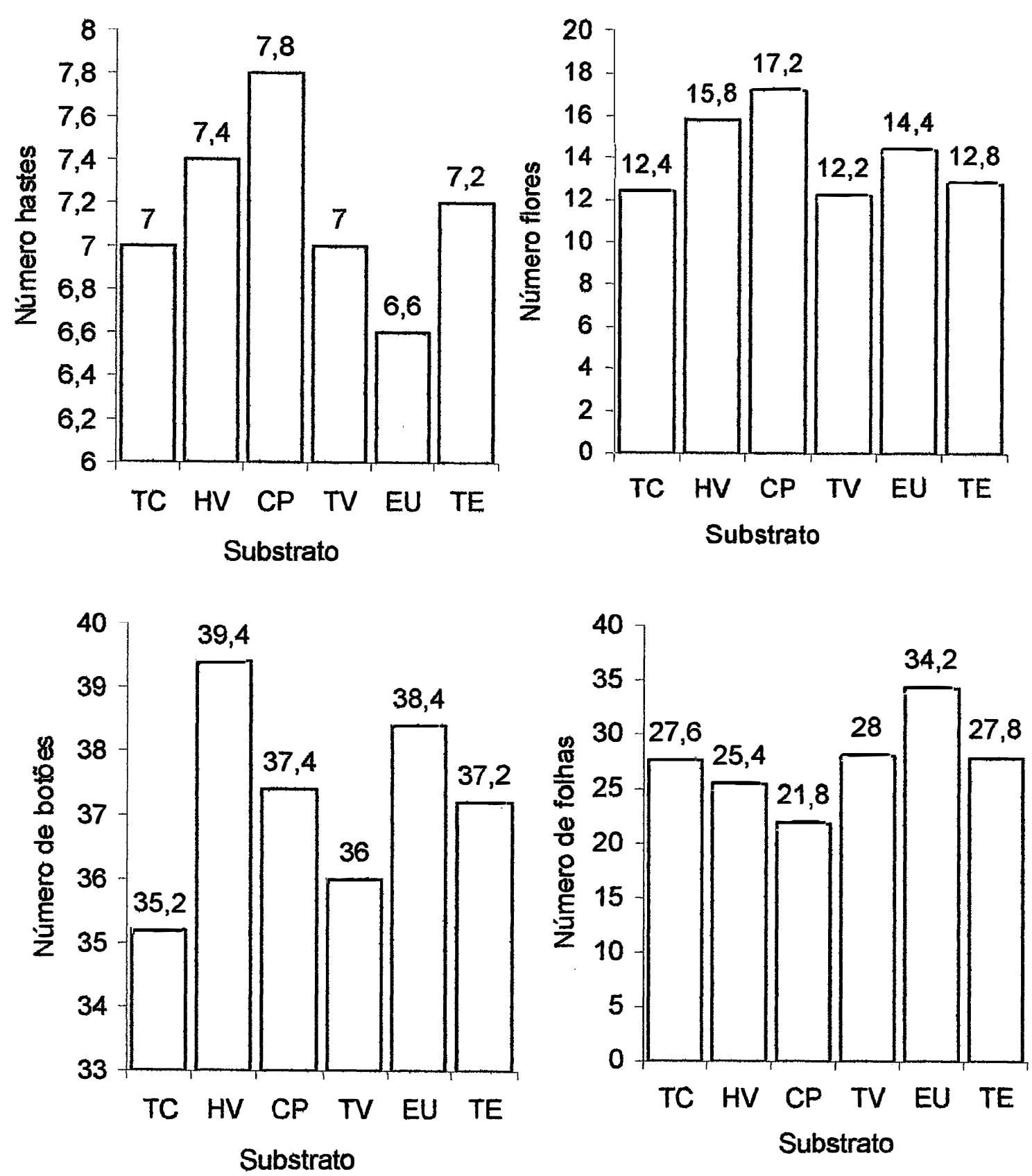

Figura 5: Características fitotécnicas avaliadas no cultivo da violeta em diferente substratos.

Turfa convencional : casca de eucalipto : areia (TC), Húmus de minhoca : vermiculita : areia (HV), Casca de pinus : húmus de minhoca (CP), Turfa cultivadora : vermiculita (TV), Substrato comercial da Eucatex (EU), Testemunha (TE). 

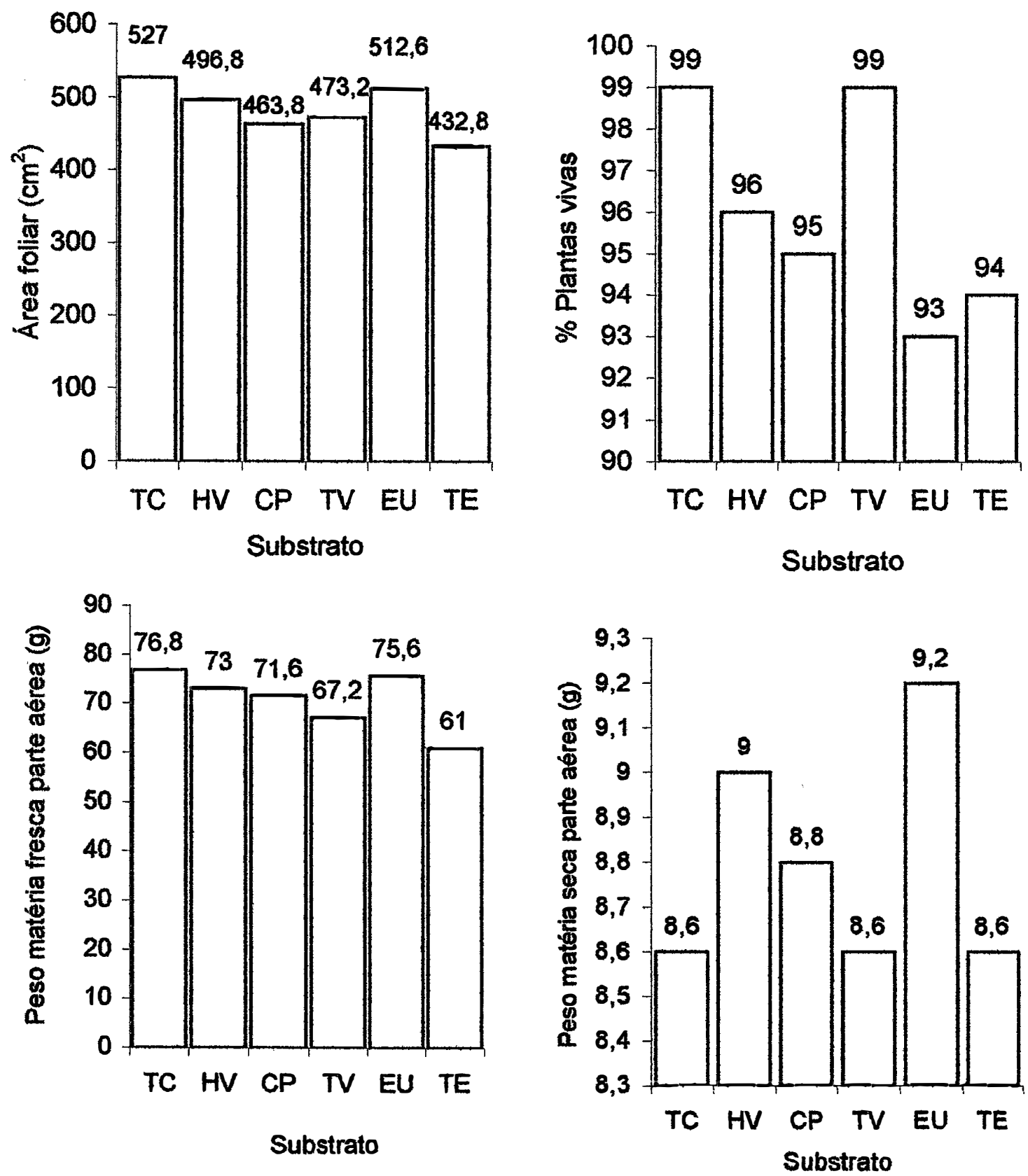

Figura 5: Características fitotécnicas avaliadas no cultivo da violeta em diferente substratos (continuação).

Turfa convencional : casca de eucalipto : areia (TC), Húmus de minhoca : vermiculita : areia (HV), Casca de pinus : húmus de minhoca (CP), Turfa cultivadora : vermiculita (TV), Substrato comercial da Eucatex (EU), Testemunha (TE). 

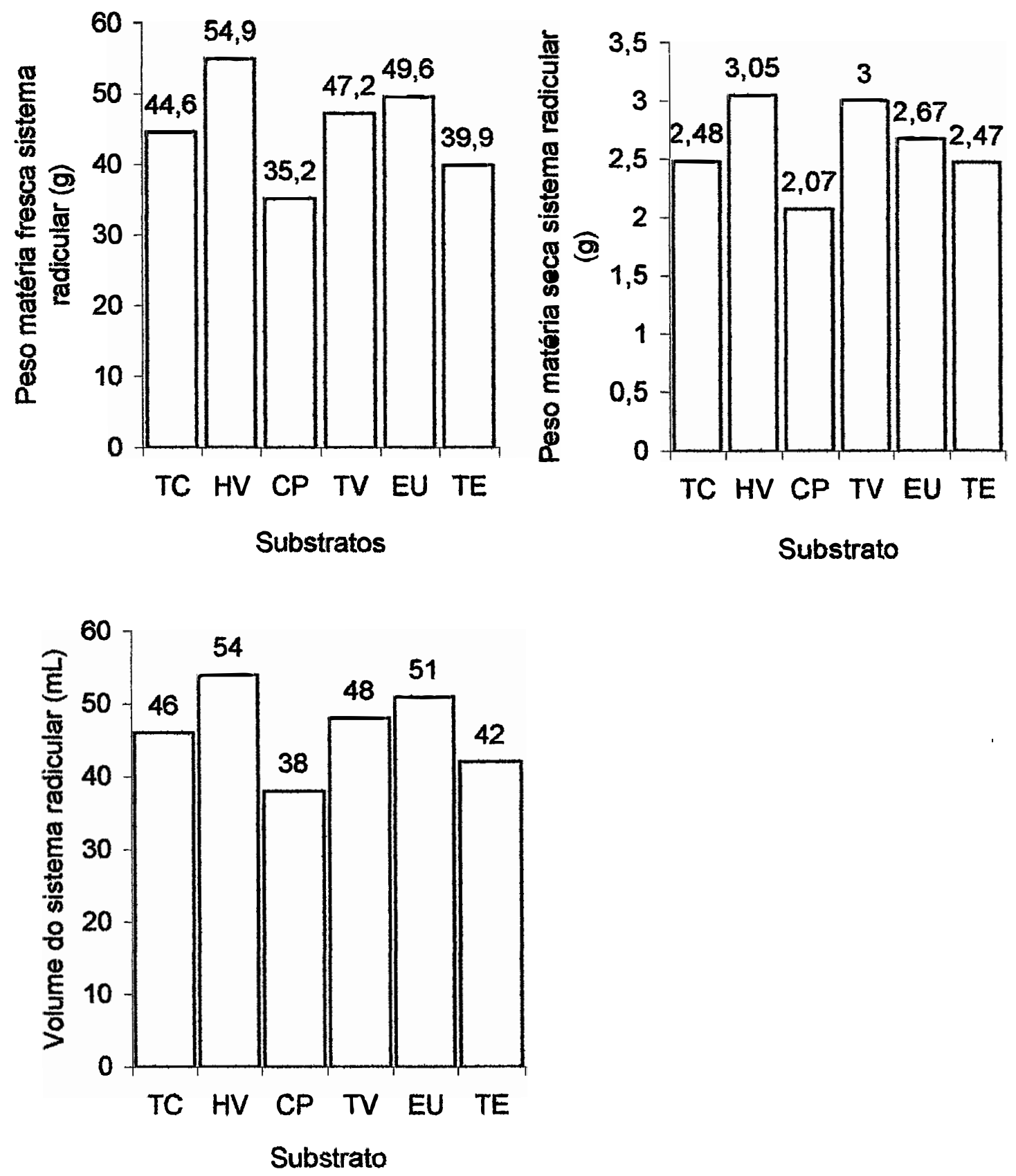

Figura 5: Características fitotécnicas avaliadas no cultivo da violeta em diferente substratos (continuação).

Turfa convencional : casca de eucalipto : areia (TC), Húmus de minhoca : vermiculita : areia (HV), Casca de pinus : húmus de minhoca (CP), Turfa cultivadora : vermiculita (TV), Substrato comercial da Eucatex (EU), Testemunha (TE). 
Todos os tratamentos apresentaram-se adequados para a comercialização, possuindo mais de 8 flores abertas flores, em forma de buquê, centralizadas no vaso, estando estas acima das folhas. A porcentagem de plantas vivas também está dentro da faixa aceitável.

Apesar de não haver diferenças estatísticas, o substrato casca de pinus : húmus de minhoca foi o que apresentou o maior número de flores abertas por vaso $(17,2)$ e o maior número de hastes florais $(7,8)$. O substrato turfa convencional : casca de eucalipto : areia apresentou a maior área foliar $\left(527,0 \mathrm{~cm}^{2}\right)$, e peso fresco da parte aérea $(76,8 \mathrm{~g})$. Húmus de minhoca : vermiculita : areia apresentou o maior número de botões $(39,4)$, peso fresco do sistema radicular $(54,9 \mathrm{~g})$, e volume do sistema radicular ( $54 \mathrm{~mL}$ ). Turfa cultivadora : vermiculita apresentou o maior peso seco do sistema radicular $(3,00 \mathrm{~g})$. O substrato comercial Eucatex apresentou o maior número de folhas $(34,2)$, e o maior peso seco da parte aérea ( $9,2 \mathrm{~g})$.

\section{CONCLUSÕES}

Um substrato adequado ao cultivo de violeta (Saintpaulia ionantha) deve apresentar características físicas próximas à $75,10 \%$ de porosidade, $19,53 \%$ de espaço ocupado por ar, $26,03 \%$ de água disponivel e $23,71 \%$ de água facilmente disponivel.

Violeta se desenvolve bem em condições de baixa quantidade de água disponivel, desde que o espaço ocupado por ar e a porosidade total sejam adequados.

Os substratos turfa convencional : casca de eucalipto : areia, húmus de minhoca : vermiculita : areia, casca de pinus : húmus de minhoca, turfa cultivadora : vermiculita, substrato comercial da Eucatex à base de turfa e testemunha, são indicados no cultivo de violeta. 


\section{REFERÊNCIAS BIBLIOGRÁFICAS}

BALLESTER-OLMOS, J.F. Substratos para el cultivo de plantas ornamentales. Valencia: Instituto Valenciano de Investigaciones Agrarias, 1992. 44p. (Hojas Divulgadoras, 11)

BEARDSELL, D.V.; NICHOLS, D.G.; JONES, D.L. Physical properties of nursery potting-mixtures. Scientia Horticulturae, v.11, p.1-8, 1979.

BELLE, S. Uso da turfa "Lagoa dos Patos" (Viamão/RS) como substrato hortícola. Porto Alegre, 1990. 143p. (Dissertação de Mestrado) Universidade Federal do Rio Grande do Sul.

BIANCHINI, F.; PANTANO, A.C. Tudo verde: guia das plantas e flores.

São Paulo: Ed. Melhoramentos, 1974. 135p.

BOELTER, D.H. Physical properties of peats as related to degree of decomposition. Soil Science Society of America Proceedings, n.33, p.606-609, 1969.

BOERTJE, G.A. Physical laboratory analyses of potting composts. Acta Horticulturae, n.150, p.47-50, 1983.

BURÉS, S. ; MARTINEZ, F.X.; PEREZ, N. Monte Carlo computer simulation in horticulture: A model for container media characterization. Acta Horticulturae, n.294, p.207-214, 1991.

CULL, D.C. Alternatives to peat as container media organic resources in the UK. Acta Horticulturae, n.126, p.69-81, 1981. 
De BOODT, M.; VERDONCK, O. The physical properties of the substrates in floriculture. Acta Horticulturae, n.26, p.37-44, 1972.

EVANS, M.R.; KONDURU, S.; STAMPS, R.H. Materials and methods source variation in physical and chemical properties of coconut coir dust. HortScience, v.31, n.6, p.965-967, 1996.

FITZPATRICK, G.E.; DUKE, E.R.; KLOCK-MOORE, K.A. Use of compost products for ornamental crop production: research and grower experiences. HortScience, v.33, n.6, p.941-944, 1998.

GABRIËLS, R.; VERDONCK, O. Physical and chemical characterization of plant substrates: towards a European standardization. Acta Horticulturae, n.294, p.271-259, 1991.

GABRIËLS, R. Standardization of growing media analysis and evaluation. Acta Horticulturae, n.401, p.555-557, 1995.

GOH, K.M.; HAYNES, R.J. Evaluation of potting media for comercial nursery production of container grow plants: 1- Physical and chemical characteristics of soil and soiless media and their constituents. New Zealand Journal of Agricultural Research, v.20, p.363-370, 1977.

GONÇALVES, A.L. Características de substratos. In: SIMPÓSIO BRASILEIRO DE FLORICULTURA E PLANTAS ORNAMENTAIS, Maringá, 1992. Manual de Floricultura. Maringá: SBFPO, 1992. p.4452. 
GÜNTHER, J. Analytics of substrates and problems by transmitting the results into horticultural practice. Acta Horticulturae, n.150, p.33-40, 1983.

KÄMPF, A.N. Substratos hortícolas: turfa e a casca de arroz. Lavoura Arrozeira, v.46, n.409, p.12-13, 1993.

LEMAIRE, F. Physical, chemical and biolological properties of growing medium. Acta Horticulturae, n.396, p.273-284, 1995.

PASQUAL, M.; MACIEL, A.L.R.; da SILVA, A.B. Enraizamento de brotações de violeta africana (Saintpaulia ionantha Wendl.): Efeitos da incubação em ácido indolbutírico. Ciência e Agrotecnologia, v.20, n.4, p.462-467, 1996.

PRINCE, T.L.; TAYAMA, H.K.; GRABNER JR., J.R. Floral supplier service levels to retail florist and mass market customers. HortScience, v.25, n.6, p.689-692, 1990.

RAC, D. P. Disponibité en eau des substrats horticoles. Revue Suisse de Viticulture Arboriculture Horticultural. v.17, n.3, p.177-178. Mai/Juin. 1985.

RIVIERE, L. M. Importance des caractéristiques physiques dans le choix des substrats pour les cultures hors sol. Revue Horticole. v.209, p.2327, Sep 1980.

SINGH, B.P.; SAINJU, U.M. Soil physical and morphological properties and root growth. HortScience, v.33, n.6, p.966-971, 1998. 
STRIGHETA, A.C. O.; RODRIGUES, L.A.; FONTES, L.E.F.; et. al. Caracterização física de substratos contendo composto de lixo urbano e casca de arroz carbonizada como condicionadores. Revista Brasileira de Ciência do Solo, n.21, p.155-159, 1997.

TERÉS; V.; ARRIETA, V.; ROZAS, M. A method for evaluation of air volumes in substrates. Acta Horticulturae, n.401, p.41-47, 1995.

TOMBOLATO, A.F.C.; TAKEBAYASHL S.S.G.; TAMADA, E.T.; FEITOSA, C.T. Cultivo comercial do violeta-africana. Campinas: IAC, 1993. 16p. (IAC. Boletim Técnico, 140)

UNVER, I. Water retention characteristics of some substrates used in Turkey. Acta Horticulturae, v.150, p.161-167, 1991.

VERDONCK, O. ; VLEESCHAUWER, D. ; De BOODT, M. The influence of the substrate to plant growth. Acta Horticulturae, n.126, p.251-258, 1981.

VERDONCK, 0 . New developments in the use of graded perlite in horticultural substrates. Acta Horticulturae, n.150, p.575-581, 1983.

VERDONCK, 0.; PENNINCK, R.; De BOODT, M. The physical properties of differet horticultural substrates. Acta Horticulturae, n.150, p.155-160, 1983.

VERDONCK, O.; GABRIËLS, R. Summary and discussion session 'standardization of analytical methods'. Acta Horticulturae, n.221, p.443444, 1988. 


\section{CONCLUSÕES GERAIS}

\section{A. Cultura da gloxínia}

. um substrato adequado ao cultivo de gloxínia (Sinningia speciosa) deve apresentar porosidade de $77,60 \%$, espaço ocupado por ar de $26,93 \%$, água disponivel de $18,75 \%$ e água facilmente disponivel de 16,36\%.

- gloxínias se desenvolve bem em condições de baixa quantidade de água disponivel, desde que o espaço ocupado por ar e a porosidade sejam adequados. $O$ excesso de água ou o excesso ou falta ar são fatores limitantes para a cultura.

. o substrato vermiculita : húmus de minhoca : perlita apresentou os melhores resultados, sendo o mais indicado para a cultura.

\section{B. Cultura do lisianthus}

. um substrato adequado ao cultivo de lisianthus (Eustoma grandiflorum) deve apresentar porosidade de 72,60 a $75,10 \%$, espaço poroso de 12,81 a $19,53 \%$, água disponível de 19,79 a $26,03 \%$ e água facilmente disponível de 17,41 a $23,71 \%$. 
. os substratos húmus de minhoca : vermiculita : perlita, casca de eucalipto : turfa convencional : areia e testemunha apresentaram-se adequados ao cultivo de lisianthus.

\section{Cultura da violeta}

. um substrato adequado ao cultivo de violeta (Saintpaulia ionantha) deve apresentar características físicas próximas à $75,10 \%$ de porosidade, $19,53 \%$ de espaço ocupado por ar, $26,03 \%$ de água disponível e $23,71 \%$ de água facilmente disponível.

. violetas se desenvolvem bem em condições de baixa quantidade de água disponível, desde que o espaço ocupado por ar e a porosidade total sejam adequados.

- os substratos turfa convencional : casca de eucalipto : areia, húmus de minhoca : vermiculita : areia, casca de pinus : húmus de minhoca, turfa cultivadora : vermiculita, substrato comercial da Eucatex à base de turfa e testemunha, são indicados no cultivo de violeta. 


\section{REFERÊNCIAS BIBLIOGRÁFICAS}

ANISKO, T.; NESMITH, D. S.; LINDSTROM, O.M. Time-domain reflectometry for measuring water content of organic growing media in containers. HortScience, v.29, n.12, p.1511-1513, 1994.

ANSTETT, A.; PASQUIER, P. Quesques reflexions sur les analyses de substrat. Acta Horticulturae, n.126, p.245-249, 1981.

BACKES, M.A.; KAMPF, A.N. Substrato a base de composto de lixo urbano para a produção de plantas ornamentais. Pesquisa agropecuária brasileira, v.26, n.5, p.753-758, maio 1991.

BALLESTER-OLMOS, J.F. Substratos para el cultivo de plantas ornamentales. Valencia: Instituto Valenciano de Investigaciones Agrarias, 1992. 44p. (Hojas Divulgadoras, 11)

BEARDSELL, D.V.; NICHOLS, D.G.; JONES, D.L. Physical properties of nursery potting-mixtures. Scientia Horticulturae, v.11, p.1-8, 1979.

BEHE, B.K.; PRINCE, T.A.; TAYAMA, H.K. Analysis of Consumer Purchases of floral Products in Supermarkets. HortScience, v.27, n.5, p.455-459, 1992. 
BEHE, B.K. Floral Marketing and Consumer Research. HortScience, v.28, n.1, p.11-14, 1993.

BELLE, S. Uso da turfa "Lagoa dos Patos" (Viamão/RS) como substrato hortícola. Porto Alegre, 1990. 143p. (Dissertação de Mestrado) Universidade Federal do Rio Grande do Sul.

BIANCHINI, F.; PANTANO, A.C. Tudo verde - guia das plantas e flores. São Paulo: Ed. Melhoramentos, 1974. 135p.

BIX, R.A. Some thoughts on the physical properties of substrates with special reference to aeration. Acta Horticulturae, n.31, p.149-160, 1973.

BITTENCOURT, J.F.N.; FERNANDES, P.D.; DE MATTOS, J.R. Efeitos da aplicação de fertilizantes comerciais, via foliar, em gloxínia (Sinningia speciosa, Hiern). Anais da Escola Superior de Agricultura "Luiz de Queiroz", v.34, p.121-126, 1977.

BOELTER, D.H. Physical properties of peats as related to degree of decomposition. Soil Science Society of America Proceedings, n.33, p.606-609, 1969.

BOERTJE, G.A. Physical laboratory analyses of potting composts. Acta Horticulturae, n.150, p.47-50, 1983.

BOYLE, T.H.; CRAKER, L.E.; SIMON, J.E. Growing medium and fertilization regime influence growth and essential oil content of rosemary. HortScience, v.26, n.1, p.33-34, 1991. 
BUGBEE, G. J. ; FRINK, C. R. Aeration of potting media and plant growth. Soil Science. v.141, n.6, 1986, p.438-441.

BUNT, A.C. Some physical properties of pot-plant composts and their effect on plant growth. Bulky physical conditioners. Plant and Soil, v.4, p.322332, 1961.

BUNT, A.C. Factors contributing to the delay in the flowering of pot chrysanthemums grown in peat-sand substrates. Acta Horticulturae, n.31, p.163-174, 1973.

BUNT, A.C. Physical properties of mixtures of peats and mineral of different particle size and bulk density for potting substrates. Acta Horticulturae, n.150, p.143-153, 1983.

BURÉS, S. ; MARTINEZ, F.X.; PEREZ, N. Monte Carlo computer simulation in horticulture: A model for container media characterization. Acta Horticulturae, n.294, p.207-214, 1991.

BURÉS, S.; FERRENBERG, A.M.; POKORNY, F. A.; et al. Computer simulation to understand physical properties of substrate. Acta Horticulturae, n.401, p.35-39, 1995.

CASTRO, E.M.; DE ALVARENGA, A.A.; GOMIDE, M.B.; GEISENHOFF, L.O. Efeito de substratos na produção de mudas de calabura (Muntingia calabura). Ciência e Agrotecnologia, v.20, n.3, p.336-370, 1996. 
CULL, D.C. Alternatives to peat as container media organic resources in the UK. Acta Horticulturae, n.126, p.69-81, 1981.

De BOODT, M.; VERDONCK, O. The physical properties of the substrates in floriculture. Acta Horticulturae, n.26, p.37-44, 1972.

De BOODT, M.; VERDONCK, O.; CAPPAERT, I. Method for measuring the waterrelease curve of organic substrates. Acta Horticulturae, n.37, p.2054-2063, 1973.

DEULOFEU, C.; AGUILA VILA, J. Fine bark as substrate for primula and petunia. Acta Horticulturae, n.150, p.283-288, 1983.

EVANS, M.R.; KONDURU, S.; STAMPS, R.H. Materials and methods source variation in physical and chemical properties of coconut coir dust. HortScience, v.31, n.6, p.965-967, 1996.

FITZPATRICK, G.E.; DUKE, E.R.; KLOCK-MOORE, K.A. Use of compost products for ornamental crop production: research and grower experiences. HortScience, v.33, n.6, p.941-944, 1998.

GABRIËLS, R. The effect of irrigation water quality on the growing medium. Acta Horticulturae, n.82, p.201-208, 1978.

GABRIËLS, R.; VERDONCK, O. Physical and chemical characterization of plant substrates: towards a European standardization. Acta Horticulturae, n.294, p.271-259, 1991. 
GABRIËLS, R. Standardization of growing media analysis and evaluation. Acta Horticulturae, n.401, p.555-557, 1995.

GISLERØD, H.R., Physical conditions of propagation media and their influence on the rooting of cuttings. Plant and Soil, v.69, p.445-456, 1982.

GOH, K.M.; HAYNES, R.J. Evaluation of potting media for comercial nursery production of container grow plants: 1- Physical and chemical characteristics of soil and soiless media and their constituents. New Zealand Journal of Agricultural Research, v.20, p.363-370, 1977.

GONÇALVES, A.L. Características de substratos. In: SIMPÓSIO BRASILEIRO DE FLORICULTURA E PLANTAS ORNAMENTAIS, Maringá, 1992. Manual de Floricultura. Maringá: SBFPO, 1992. p.4452 .

GONÇALVES, A.L. Substratos para produção de mudas de plantas ornamentais. In: MINAMI, K. Produção de mudas de alta qualidade em horticultura. São Paulo: Ed. T.A Queiroz, 1995. cap.14, p.107-115.

GRANQVIST, G. Recent experiences in the use of substrates for vegetable production under glass in Sweden. Acta Horticulturae, n.126, p.259262, 1981.

GRIESBACH, R.J. Correlation of $\mathrm{pH}$ and light intensity on flower color in potted Eustoma grandiflorum Grise. HortScience, v.27, n.7, p.817-818, 1992. 
GROLLI, P.R. Composto de lixo domiciliar como condicionador de substratos para plantas arbóreas. Porto Alegre, 1991. 125p. (Dissertação de Mestrado) - Universidade Federal do Rio Grande do Sul.

GÜNTHER, J. Analytics of substrates and problems by transmitting the results into horticultural practice. Acta Horticulturae, n.150, p.33-40, 1983.

HARBAUGH, B.K.; WOLTZ, S.S. Eustoma quality is adversely affected by low pH of root medium. HortScience, v.26, n.10, p.1279-1280, 1991.

HARBAUGH, B.K. Flowering of Eustoma grandiflorum (Raf.) Shinn. cultivars influenced by photoperiod and temperature. HortScience, v.30, n.7, p.1375-1377, 1995.

HARTMANN, H.T.; FLOCKER, W.J.; KOFRANEK, A.M. Plant Science growth, development, and utilization of cultivated plants. New York: Prentice-hall, Inc, 1981. 637p.

HUMMEL, R.L. Water relations of container-grown woody and herbaceous plants following antitranspirant sprays. HortScience, v.25, n.7, p.772$775,1990$.

JENKINS, J.R.; JARRELL, W.M. Predicting physical and chemical properties of container mixtures. HortScience, v.24, n.2, p.292-295, 1989.

KÄMPF, A.N. Substratos para floricultura. In: SIMPÓSIO BRASILEIRO DE FLORICULTURA E PLANTAS ORNAMENTAIS, Maringá, 1992. Manual de Floricultura. Maringá: SBFPO, 1992. p.36-43. 
KÄMPF, A.N. Substratos hortícolas: turfa e a casca de arroz. Lavoura Arrozeira, v.46, n.409, p.12-13, 1993.

LEMAIRE, F. Physical, chemical and biolological properties of growing medium. Acta Horticulturae, n.396, p.273-284, 1995.

LONGHI, A.A.; TOMBOLATO, A.F.C. Gloxínia. Comunicado Técnico - CATI. n.123, junho, 1995. $6 p$.

MATSUO, E. Analysis of Flower Appreciation and Its International Comparison Contribute to Progress of Flower Production and International Flower Trade. HortScience, v.25, n.12, p.1468-1470, 1990.

NIEDZIELA JR., C.E.; NELSON, P.V. A Rapid Method for Determining Physical Properties of Undisturbed Substrate. HortScience, v.27, n.12, p.1279-1280, 1992.

OHKAWA, K.; KANO, A.; KANEMATSU, K.; et al. Reversal of heat-induced rosetting in Eustoma grandiflorum with low temperatures. Scientia Horticulturae, v.48, p.171-176, 1991.

PASQUAL, M.; MACIEL, A.L.R.; da SILVA, A.B. Enraizamento de brotações de violeta africana (Saintpaulia ionantha Wendl.): Efeitos da incubação em ácido indolbutírico. Ciência e Agrotecnologia, v.20, n.4, p.462-467, 1996 
PERGOLA, G.; FARINA, E. Giornata di studio sul lisianthus (Eustoma grandiflorum (Raf.) Shinn.). Sanremo: Istituto Sperimentale per la Floricotura, 1989. 133p.

POKORNY, F.A.; HENNY, B.K. Construction of a milled pine bark and sand medium from component particles. I. Bulk density: a tool for predicting components. Journal of American Society of Horticultural Science. v.109, p.770-773, 1984.

PRASAD, M. Physical properties of media for container grown crops. 1. New Zealand peats and wood wastes. Scientia Horticulturae, v.10, p.317323, 1979.

PRINCE, T.L.; TAYAMA, H.K.; GRABNER JR., J.R. Floral supplier service levels to retail florist and mass market customers. HortScience, v.25, n.6, p.689-692, 1990.

RAC, D. P. Disponibité en eau des substrats horticoles. Revue Suisse de Viticulture Arboriculture Horticultural. v.17, n.3, p.177-178, Mai/Juin 1985.

RIVIERE, L. M. Importance des caractéristiques physiques dans le choix des substrats pour les cultures hors sol. Revue Horticole. v.209, p.2327, Sep 1980.

RUBINO, D.B. Inheritance of esterase, diaphorase, and glicose-6-phosphate isomerase in lisianthus. HortScience, v.28, n.6, p.661-663, 1993. 
SALVADOR, E.D. Efeito de diferentes substratos no crescimento e desenvolvimento de samambaia matogrossense (Polypodium aureum). Lavras, 1995. 67p. (Dissertação de Mestrado) - Universidade Federal de Lavras.

SANDERSON, K.C.; MCGUIRE, J. Growth regulator sprays during propagation increase African violet crowns and leaves. HortScience, v.23, n.6, p.1085, 1988.

SHEEHAN, T. J. ; TJIA, B. The effects of growing media on growth and flowering of gloxinia. Proceedings of Florida State Horticulturae Society, n.89, p.319-320, 1976.

SINGH, B.P.; SAINJU, U.M. Soil physical and morphological properties and root growth. HortScience, v.33, n.6, p.966-971, 1998.

STARMAN, T.W. Lisianthus growth and flowering responses to uniconazole HortScience, v.26, n.2, p.150-152, 1991.

STRIGHETA, A.C. O.; RODRIGUES, L.A.; FONTES, L.E.F.; COSTA C.A. Crescimento de crisântemo em substrato contendo composto de lixo urbano e casca de arroz carbonizada. Pesquisa agropecuária brasileira, v.3l, n.11, p.795-802, nov. 1996.

STRIGHETA, A.C. O.; RODRIGUES, L.A.; FONTES, L.E.F.; et. al. Caracterização física de substratos contendo composto de lixo urbano e casca de arroz carbonizada como condicionadores. Revista Brasileira de Ciência do Solo, n.21, p.155-159, 1997. 
TERÉS; V.; ARRIETA, V.; ROZAS, M. A method for evaluation of air volumes in substrates. Acta Horticulturae, n.401, p.41-47, 1995.

TOMBOLATO, A.F.C.; TAKEBAYASHL S.S.G.; TAMADA, E.T.; FEITOSA, C.T. Cultivo comercial do violeta-africana. Campinas: IAC, 1993. 16p. (IAC. Boletim Técnico, 140 )

UNVER, I. Water retention characteristics of some substrates used in Turkey. Acta Horticulturae, n.150, p.161-167, 1991.

VERDONCK, O. ; VLEESCHAUWER, D. ; De BOODT, M. The influence of the substrate to plant growth. Acta Horticulturae, n.126, p.251-258, 1981.

VERDONCK, 0 . Reviewing and evaluation of new materials used as substrates. Acta Horticulturae, n.150, p.467-473, $1983 a$.

VERDONCK, 0 . New developments in the use of graded perlite in horticultural substrates. Acta Horticulturae, n.150, p.575-581, 1983b.

VERDONCK, O. ; VLEESCHAUWER, D. ; PENNINCK, R. Barckcompost a new accepted growing medium for plants. Acta Horticulturae. n.133, p.221-227, 1983a.

VERDONCK, 0.; PENNINCK, R.; De BOODT, M. The physical properties of differet horticultural substrates. Acta Horticulturae, n.150, p.155-160, 1983b. 
VERDONCK, O.; GABRIËLS, R. Summary and discussion session 'standardization of analytical methods'. Acta Horticulturae, n.221, p.443444, 1988.

VERDONCK, O.; GABRIËLS, R.; VAN KEIRSBULCK, W. Reference standard materials for the determination of physical characteristics of growing media. Acta Horticulturae, n.401, p.559-560, 1995.

WALLER, P.L.; HARRISON A.M. Estimation of pore space and the calculation of air volume in horticultural substrates. Acta Horticulturae, n.294, p.29-39, 1991.

WHIPKER, B.E.; EDDY, R.T.; HAMMER, P.A. Chemical growth retardant application to lisianthus. HortScience, v.29, n.11, p.1368, 1994.

WILSON, G.C.S. The physico-chemical and physical properties of horticultural substrates. Acta Horticulturae, n.150, p.19-32, 1983. 
ANEXO A

\section{ADUBOS UTILIZADOS NO CULTIVO DE GLOXÍNIA}

Teor de nutrientes contidos no adubo NPK (06-06-08):

$6,0 \% \mathrm{~N}$ total

. 6,0\% $\mathrm{P}_{2} \mathrm{O}_{5}$ solúvel em citrato de amônio + água

$8,0 \% \mathrm{~K}_{2} \mathrm{O}$ solúvel

$.0,5 \% \mathrm{Mg}$

$.0,5 \% \mathrm{~S}$

$.0,03 \% B$

$.0,05 \% \mathrm{Zn}$

$.0,1 \% \mathrm{Fe}$

$.0,03 \% \mathrm{Mn}$

Teor de nutrientes contidos no adubo NPK (20-05-20):

$20,0 \% \mathrm{~N}$ total

. 5,0\% $\mathrm{P}_{2} \mathrm{O}_{5}$ solúvel em citrato de amônio + água

. $20,0 \% \mathrm{~K}_{2} \mathrm{O}$ solúvel

$.0,085 \% \mathrm{Mg}$

. $2,0 \% \mathrm{~S}$

. $0,03 \% \mathrm{~B}$

$.0,07 \% \mathrm{Zn}$ 
ANEXO B

FORMULAÇÃO 'MASTER 20-20-20'

$$
\begin{aligned}
& \mathrm{N} \text { total }-20 \% \\
& \mathrm{~N} \text { nítrico }-5,6 \% \\
& \mathrm{~N} \text { amoniacal }-3,9 \% \\
& \mathrm{~N} \text { uréia }-10,5 \% \\
& \mathrm{P}_{2} \mathrm{O}_{5}-20 \% \\
& \mathrm{~K}_{2} \mathrm{O}-20 \% \\
& \mathrm{~B}-0,05 \% \\
& \mathrm{Cu}-0,01 \% \\
& \mathrm{Mo}-0,005 \% \\
& \mathrm{Zn}-0,01 \%
\end{aligned}
$$


145

ANEXO C

FORMULAÇÃO MEGAFOL

. Aminoácidos - 35\%

. N total $-5,6 \%$

. N orgânico $-5,6 \%$

. Matéria orgânica - 32,3\%

. Carbono orgânico - 18,7\% 


\section{ANEXO D \\ CONTROLE QUÍMICO FEITO NA CULTURA DO LISIANTHUS.}

\begin{tabular}{|c|c|c|}
\hline Produto comercial & CONTROLE & DOSE \\
\hline Thiodan & Lagarta, trips, ácaro & $2,5 \mathrm{~mL} . \mathrm{L}^{-1}$ \\
\hline Acaristop & Ovicida, ácaro branco & $0,4 \mathrm{~mL} . \mathrm{L}^{-1}$ \\
\hline Captain & botritis, fusarium, antracnose & $1,0 \mathrm{~mL} . \mathrm{L}^{-1}$ \\
\hline CAB 2 & Ca + B & $3,0 \mathrm{~mL} \cdot \mathrm{L}^{-1}$ \\
\hline Azodrin & Ácaro & $0,5 \mathrm{~mL} \cdot \mathrm{L}^{-1}$ \\
\hline Rovral & Botritis & $1,0 \mathrm{~mL} \cdot \mathrm{L}^{-1}$ \\
\hline Vertimec & Lagarta, ácaro & $0,5 \mathrm{~mL} \cdot \mathrm{L}^{-1}$ \\
\hline CALBIT B & Ca + B & $3,0 \mathrm{~mL} \cdot \mathrm{L}^{-1}$ \\
\hline Açúcar & Trips & $3,0 \mathrm{~g} \cdot \mathrm{L}^{-1}$ \\
\hline Dicarzol & & $1,0 \mathrm{~g} \cdot \mathrm{L}^{-1}$ \\
\hline Dipterex & Lagarta & $3,0 \mathrm{~mL} \cdot \mathrm{L}^{-1}$ \\
\hline Confidor & Trips, ácaro & $0,30 \mathrm{~g} \cdot \mathrm{L}^{-1}$ \\
\hline
\end{tabular}




\section{ANEXO E \\ CRITÉRIOS DE CLASSIFICAÇÃO PARA VIOLETAS DO S.D.Q. \\ VEILING HOLAMBRA}

\begin{tabular}{|l|c|c|c|}
\hline & A1 & A2 & B \\
\hline Infecção de Botrytis & $0 \%$ & $3 \%$ & $6 \%$ \\
\hline Infecção de Phytophtora ou & $0 \%$ & $1 \%$ & $1 \%$ \\
\hline Infecção de Tripes (flores) & $0 \%$ & $5 \%$ & $10 \%$ \\
\hline Flores queimadas ou & $3 \%$ (leve) & $5 \%$ (leve) & $10 \%$ \\
manchadas & & & \\
\hline Folhas amareladas & $3 \%$ & $5 \%$ & $20 \%$ \\
\hline Plantas murchas & $0 \%$ & $1 \%$ & $3 \%$ \\
\hline Resíduos químicos & muito leve & leve & regular \\
\hline Número de botões ou flores & - & - & - \\
\hline Qualidade de raízes & boa & boa & regular \\
\hline Formação das plantas & ótima & boa & regular \\
\hline
\end{tabular}




\section{ANEXO F}

\section{ANÁLISE FÍSICA DE MISTURAS DE MATERIAIS}

\begin{tabular}{|c|c|c|c|c|}
\hline Tratamento ${ }^{1}$ & $\begin{array}{l}\text { Porosidade } \\
\text { total } \\
(\%)\end{array}$ & $\begin{array}{c}\text { Espaço de } \\
\text { aeração } \\
(\%)\end{array}$ & $\begin{array}{c}\text { Água } \\
\text { facilmente } \\
\text { disponível } \\
(\%)\end{array}$ & $\begin{array}{c}\text { Água } \\
\text { disponível } \\
(\%)\end{array}$ \\
\hline $\mathrm{CP}$ & 77,49 & 24,78 & 18,10 & 20,11 \\
\hline VE & 79,34 & 26,56 & 16,38 & 18,03 \\
\hline $\mathrm{HU}$ & 77,70 & 26,29 & 17,56 & 19,75 \\
\hline TU & 78,80 & 27,53 & 17,21 & 19,68 \\
\hline CE & 73,34 & 14,56 & 21,53 & 25,13 \\
\hline TV & 75,58 & 18,68 & 19,73 & 21,86 \\
\hline $\mathrm{CH}$ & 74,07 & 17,01 & 18,55 & 20,64 \\
\hline TC & 77,02 & 20,64 & 16,05 & 17,75 \\
\hline HV & 76,64 & 21,86 & 16,41 & 19,85 \\
\hline
\end{tabular}

${ }^{1}$ Casca pínus : húmus de minhoca + perlita (CP); vermiculita : húmus de minhoca : perlita (VE); turfa convencional : casca de eucalipto (HU); turfa cultivadora : casca de arroz carbonizada (TU); turfa cultivadora : vermiculita (TV); casca de pínus : húmus de minhoca $(\mathrm{CH})$; casca de eucalipto : turfa convencional : areia (CE); turfa convencional : casca de eucalipto : areia (TC); húmus de minhoca : vermiculita : areia (HV). 